\title{
Zur Kritik bürgerlicher Inflationstheorien
}

\author{
Olaf E. Dombrowsky
}

\section{Der Gegenstand dieses Beitrages}

Die permanente Inflation ist zu einer der dringlichsten Formen kapitalistischer Wirtschaftskrisen geworden. Da das Problem allgemeiner Preissteigerungen in der Geschichte wiederholt Aktualtität erlangte, liegt bereits eine ganze Reihe von Analysen darüber vor.

Diese Arbeit beabsichtigt, hier eine Orientierungshilfe zu geben und den Erklärungswert der gegenwärtig wichtigsten bürgerlichen Inflationstheorien auf Grundlage der Marx'schen Geldtheorie zu bestimmen. Wie ein Blick in die Literatur zeigt, bedarf bereits der Inflationsbegriff einer näheren Untersuchung. Zudem drängt sich die Frage nach der Motivation der bürgerlichen Wissenschaft auf, neben der bloß ideologischen Absicherung des kapitalistischen Systems eine realistische Inflationstheorie als Basis einer erfolgreichen Anti-Inflationspolitik zu entwickeln wenn doch gleichzeitig unterstellt wird, daß gerade die Kapital-Seite Nutznießer der Inflation ist.

An Hand eines kurzen dogmengeschichtlichen Rückblickes wird versucht, einen Eindruck davon zu vermitteln, wie auf der Grundlage irriger Vorstellungen über das Wesen des Geldes in den Krisenperioden des Geldsystems immer wieder neue, stets interessengebundene Inflationstheorien entwickelt wurden. Dabei zeigt es sich, daß die althergebrachten Ansätze eine außerordentliche Resistenz aufweisen und in verfeinerten Varianten immer wieder auftauchen. So kann z. B. der Streit um die richtige Interpretation der Quantitätsgleichung, ob ,von rechts nach links“ oder „von links nach rechts", auf eine lange Tradition verweisen. Jede Inflationsperiode der Neuzeit brachte ihre eigene Version der Quantitätstheorie hervor: Die Edelmetallzuströme aus Amerika die „vulgäre" Theorie Bodin's, die Napoleonischen Kriege die Theorie des Currency Principle, die Periode nach dem I. Weltkrieg die neoklassische Quantitätstheorie Fisher's und schließlich die gegenwärtige permanente Inflation den Monetarismus der Chicagoer Schule.

Vor diesem Hintergrund werden in den sich anschließenden Kapiteln die beiden Hauptstränge aktueller bürgerlicher Inflationstheorien, nämlich die keynesianisch bzw. monetaristisch ausgerichteten, auf ihr jeweiliges Geld-Verständnis und ihre logische Kosistenz hin analysiert. Ihre Realitätsnähe, das letztlich entscheidende Kriterium, wird an ihrem Erklärungswert insbesondere in Hinblick auf die Erscheinungsform der Stagflation zu messen sein.

Da die Theorien des ,demand-pull“ und des ,cost-push" auf dem Keynes'schen Geld-Verständnis beruhen, erscheint es notwendig, auch letzteres zu untersuchen, obwohl in Keynes' Werken unmittelbar keine Inflationstheorie enthalten ist. 
Dies kann auch kaum verwundern, zumal das ökonomische Problem seiner Zeit eben nicht allgemeine Preissteigerungen, sondern umgekehrt die große Depression und ein damit zusammenhängender allgemeiner Preisverfall war.

Wegen ihrer enormen tagespolitischen Bedeutung werden abschließend drei weitere Inflationserklärungen analysiert, die allerdings von jeder Geldtheorie losge. löst sind oder ihren theoretischen Ursprung zumindest vulgarisieren. Die Untersuchung kann sich hier kaum auf mehr als eine Konfrontation mit der Empirie erstrecken. Das Material wird dabei meist der BRD entstammen.

Die folgenden Darstellungen beschränken sich vornehmlich auf Geld- und Preisprobleme, zumal unmittelbar damit zusammenhängende Fragen, wie wirtschaftliches Wachstum, Produktivitätssteigerung oder Umverteilungseffekte, von der bürgerlichen Theorie selbst häufig übergangen werden.

Die Vielschichtigkeit des Untersuchungsgegenstandes sowie die gerade in letzter Zeit enorm anwachsende Literatur lassen es im Rahmen einer Übersicht zum einen nicht praktikabel erscheinen, die z. T. recht interessanten Detailuntersuchungen etwa über die Umlaufgeschwindigkeit des Geldes, über Angebot an und Nachfrage nach Geld oder über die Transmission autonomer monetärer Impulse auf den realen Bereich umfassend zu berücksichtigen (1).

Zum anderen kann das empirische Material hier nicht ausreichend exakt analysiert werden. Dabei geht es nicht nur um Fragen nach der Zusammensetzung von Warenkörben oder der Konstruktion von Preisreihen, sondern auch um eine differenziertere Untersuchung der Preisbewegungen nach Branchen und jeweiligen Marktkonstellationen. Ebenso erweist sich eine fundiertere Einschätzung der Wandlung gewisser Großunternehmen von Preis- zu Mengenanpassern sowie generell der Bedeutung administrierter Preise als dringend zu lösende Aufgabe.

\section{Einführung}

\subsection{Begriff}

In der tagespolitischen Diskussion bezeichnet man generell jede allgemeine Preissteigerung mit ,Inflation". Mit diesem Begriff werden in zunehmendem Maße Attribute verbunden, die nach $F$. Laege (2) etwa wie folgt klassifiziert werden können:

1. solche, die die (vermeintlich, O.E.D.) verursachenden Faktoren mit dem Ausdruck Inflation verknüpfen, z. B. Geldinflation, Kreditinflation, Kosteninflation, Nachfrageinflation etc.

2. solche, die den Begriff auf die Erscheinungsform des Prozesses ausrichten, z. B. offene, zurückgestaute, latente, schleichende, galoppierende Inflation etc.

1 Eine gute Darstellung der neueren Entwicklungen in der bürgerlichen Theorie bieten etwa H. G. Johnson's ,, Beiträge zur Geld theorie und Geld politik“, Berlin 1969

2 Siehe F. Läge ,Die säkulare Inflation“, Schriftenreihe zur Geld- und Finanzpolitik, Bd. 5, Frankfurt a. M. 1959 , S. 33 
3. solche, die den Terminus durch die Häufigkeit und Dauer charakterisieren, z. B. zyklische, chronische, säkulare, permanente Inflation etc.

Dabei ist es offenbar nicht selten das Ziel, das Wesen des Problems zu verschleiern und dem Begriff seine politische Brisanz zu nehmen. So schreibt H. Rieter: „Der Begriff ist (...) existent, man wird ihn weiter verwenden müssen, sollte ihn aber entschärfen (!) indem man sich bei seiner Definition allein von Zweckmäßigkeitserwägungen leiten läßt." (3)

Ebenso unmißverständlich äußerte sich Jöhr 1934: ,Neuerdings wird in Deutschland der Ausdruck, stabile Inflation'(!) gebraucht. Die Bezeichnung, verdeckte Inflation" ist zwar treffender, doch ist es begreiflich, daß der Ausdruck ,stabile Inflation" vorgezogen wird, da dieser weniger Mißtrauen einflößt (!) als jener" (4).

Es fehlt auch nicht an Versuchen, das Inflations-Problem aus der Verantwortlichkeit der Wirtschaftssubjekte heraus und in die Nähe von Naturkatastrophen zu rücken, etwa wenn die ,Zeit von einer ökonomischen ,Plage“ spricht (5) - oder die Inflation als ein zeitloses Problem hinzustellen, indem man z. B. auf Preissteigerungen in der antiken Stadt Aphrodisia hinweist (6).

Bei W. Röpke, der immerhin noch die Erk!ärungswürdigkeit der Tatsache ahnt, daß es in den sozialistischen Staaten die Erscheinung der permanenten Inflation nicht gibt, zeigt sich die Apologie besonders deutich. Er schreibt, daß „... nur noch in den kommunistischen Ländern (der) einigermaßen erfolgreiche Versuch unternommen wird, die ,offene ${ }^{6}$ Inflation in eine, zurückgestaute ${ }^{6} z$ verwandeln ... "(7). Für Länder mit kapitalistischer Wirtschaftsordnung dagegen gilt: „... der Inflationswelle unserer Zeit haftet zum ersten Male, eindeutig und nahezu ausschließlich, der Charakter einer Inflation an, die aus den Ideologien, Kräften und Würschen der modernen Massendemokratie selber hervorgegangen ist. Sie ist eine demokratisch (!)-soziale (!!) Inflation .. . (8).

Tatsächlich handelt es sich bei der heutigen Inflation, politisch gesehen, um einen Kampf um Anteile am BSP, um Klassenkampf auf ökonomischer Ebene. H. Giersch formuliert daher zurechí: „Im Grunde verschleiert diese schleichende Inflation nur den Verteilungskampf, in dem der alte Klassenkampf in der modernen Gesellschaft weiterlebt ${ }^{6}(9)$. Wie noch zu zeigen sein wird, verläuft die ,Front ${ }^{66}$ dabei keineswegs einfach zwischen der Arbeiterklasse und den Kapitalisten.

3 H. Rieter ,Die gegenwärtige Inflationstheorie und ihre Ansätze im Werk von Thomas Tooke“, Berlin 1971, S. 15

4 W. A. Jöhr ,Die Nachkriegsdeflation. Konjunkturtendenzen der Nachkriegszeit und die Aufgaben der schweizerischen Beschäftigungs- und Währungspolitik", St. Gallen 1945, S. 2

5 „Die Zeit" vom 5.1.73

6 "Frankfurter Rund schau" vom 19.1.73

7 W. Röpke "Jenseits von Angebot und Nachfrage", Reutsch, Erlenbach/Zürich/Stuttgart 1958, S. 271

8 Ebd., S. 272

9 H. Girsch , Rationale Wirtschaftspolitik in der pluralistischen Gesellschaft ${ }^{4}$, in: „Rationale Wirtschaftspolitik und Planung in der Wirtschaft von heute", Berlin 1967, S. 137 
Auch die wissenschaftliche Literatur verwendet den Terminus ,Inflation“ in unterschiedlicher Weise, nachdem er im Verlaufe des amerikanischen Sezessionskrieges in die Diskussion eingeführt worden war. Die damalige amerikanische Regierung finanzierte ihre Kriegsausgaben durch ,Betätigung der Druckerpresse, d. h. sie hatte, bei gleíchzeitigem Rückgang der Produktion, die kaufkräftige Nachfrage aufgebläht. Die Folge war eine allgemeine Preissteigerung.

Entsprechend seiner ursprünglichen Bedeutung will eine Reihe von marxistischen Autoren, wie z. B. Schumilin, den Terminus nur in diesem Sinne gelten lassen: „Wir bezeichnen als Inflation die Erhöhung der Papiergeldmenge im Lande über den Umlaufmittelbedarf hinaus“ (10). Preissteigerungen sind hier also lediglich ein Symptom der Inflation.

Mandel stimmt der Ansicht zu, daß die Existenz einer übermäßigen Papiergeldzirkulation immer nur post festum feststellbar ist. Er verneint jedoch W. Hofmann's Feststellung, daß es aus diesem Grund keinen Sinn habe, sich in der Begriffs-Definition auf die Geld-Sphäre zu beziehen. Für W. Hofmann ist Inflation immer dann gegeben, ,wenn das allgemeine Preisniveau eines Landes sich, aus welchen Gründen auch immer, langfristig von dem Preistrend entfernt, welchen die allgemeine Zunahme der Arbeitsproduktivität erwarten ließe ... Von Inflation soll jedoch, wie dies allgemein üblich ist, nur dann gesprochen werden, wenn der Vorgang von nicht-zyklischer, oder besser: von über-zyklischer Natur ist" (11).

Samuelson wiederum definiert ,Inflation" undifferenziert als ,eine Zeit allgemein steigender Güter- und Faktorpreise " (12). Andere bürgerliche Autoren wollen erst dann von Inflation sprechen, wenn die Preissteigerungsrate eine bestimmte Marke überschritten hat. So bemerkte der Sachverständigenrat: „Bis in die jüngste Zeit ist von vielen der Sprachgebrauch für falsch gehalten worden, der einen dauernden jährlichen Anstieg des Preisniveaus von 3 v. H. bis 4 v. H. schon (!) als Inflation kennzeichnete" (13).

Es ist offensichtlich, daß die Definition des Begriffs analytische Konsequenzen init sich bringt. Unter Verwendung der Hofmann'schen Definition wird jede langfristige Abweichung des Preisniveaus von der Entwicklung der Produktivität erfaßt. Preisstabilität im herkömmlichen Sinne erscheint dann tatsächlich als das, was sie ist: ein Grad der Abweichung der nominellen Preise von den Werten, bei dem das allgemeine Preisniveau zufällig weder steigt noch fällt.

Folgt man der Empfehlung von P. Samuelson, so bleibt die Frage ausgeklammert, warum sich in der Geschichte des frühen Kapitalismus Perioden fallenden, fixen und steigenden Preisniveaus wechselseitig ablösten, während in der Phase des Spätkapitalismus Produktivitätssteigerungen und Konjunkturschwankungen vornehmlich in unterschiedlichen Raten der Preissteigerung ihren Niederschlag finden. Es wird suggeriert, daß ein stabiles bzw. leicht steigendes Preisniveau der eigentlich

10 V. Schumilin ,Warum steigen die Preise? “, in: ,Marxismus Digest" Nr. 3/72, S. 23

11 W. Hofmann ,Die säkulare Inflation", Berlin 1962, S. 9

12 P. A. Samuelson „Volkswirtschaftslehre“, Bund-Verlag Köln 1973, Bd. I, S. 338

13 Sachverständigenrat ,Gleicher Rang für den Geldwert", Jahresgutachten 1972/73, S. 117 
angemessene Normalfall sei. Das Absinken des allgemeinen Preisniveaus wird dann zu einer unerwünschten, zumindest aber zu einer nicht positiv anzustrebenden Ausnahmeerscheinung.

Abgesehen davon, daß die Auswirkungen einer Deflation von denen der Inflation völlig divergieren (die Deflation begünstigt Geldbesitzer und Bezieher fixer Einkommen), wird sie wohl auch deshalb von manchen bürgerlichen Autoren als eine Art Schreckgespenst behandelt, dem man besser nicht begegnet, weil dieser Begriff ad hoc Assoziationen ökonomischer und politischer Krisenperioden hervorruft. Die Inflation hingegen wird insbesondere von Keynesianern als eine Art „Schmiermittel der Wirtschaft" (14) betrachtet. H. Rieter gibt in diesem Sinne zu bedenken „ob die Stabilisierung des Preisniveaus überhaupt einer Stabilisierung des Volkseinkommens vorzuziehen ist $t^{\text {" }}(15)$.

Eine wissenschaftliche Analyse von Preissteigerungen muß selbstverständlich deren Quellen exakt differenzieren; einige Autoren nennen bis zu 60 Ursachen (16). Dennoch scheint Schumilin's Fassung des Begriffs unnötig eng; es wäre sicher wenig sinnvoll, analog für jede Ursache einen besonderen Terminus zu verwencien, zumal das Problem der Preisniveau-Bewegungen im Bewußtsein der Allgemeinheit an die Begriffe ,Inflation' und ,Deflation' gebunden ist. Daher bietet sich der Hofmann'sche Inflations-Begriff als zweckmäßigster an. Es ist schwerlich einzusehen, wieso dadurch die Würdigung von ,Faktoren wie Konjunkturzustand, Monopoleinfluß usw." erschwert werden sollte, wie J. Pewsner offenbar glaubt (17).

Entsprechend seiner Definition begreift W. Hofmann die gegenwärtige Teuerungsphase als Bestandteil eines mit der Vorherrschaft der Monopole in den neunziger Jahren des vorigen Jahrhunderts einsetzenden Prozesses (18). Mandel dagegen vertritt die Ansicht: „Von säkularer Inflation kann frühestens seit dem Ersten Weltkrieg, genauer: seit der Überwindung der großen Wirtschaftskrise 1929-32 gesprochen werden“"(19). Die divergierenden Auffassungen über den Zeitpunkt des Einsetzens der permanenten Inflation sind offenbar durch die unterschiedlichen Fassungen des Inflationsbegriffs bedingt. Im Prinzip jedoch besteht - auch unter bürgerlichen Autoren (20) - Einigkeit über die These, daß sich zu Beginn dieses Jahrhunderts Änderungen im kapitalistischen Wirtschaftssystem vollzogen, die zu Modifikationen der Preisbildung gefuhrt haben.

14 P. A. Samuelson, a. a. O., S. 339

15 H. Rieter, a. a. O.

16 F. Läge, a. a. O., S. 33

17 J. Pewsner „Steigen der Preise - gesetzmäßige Erscheinung des staatsmonopolistischen Kapitalismus", in: ,Marxismus Digest" Nr. 3/72, S. 30

18 W. Hofmann, a. a. O., S. 15

19 E. Mandel „Der spätkapitalismus" Suhrkamp Verlag, Frankfurt a. M. 1972, S. 377

20 P. A. Samuelson, a. a. O., S. 337 


\subsection{Hyper- und schleichende Inflation und divergierende Interessenlagen verschie-}

dener Kapitalfraktionen

Ursprünglich gingen die Inflationstheoretiker von der Vorstellung aus, daß grundsätzlich jede Phase allgemeiner Preissteigerungen unmittelbar in einer Hyperinflation münden werde. Erst in den letzten Jahrzehnten, als es immer wieder gelang, die Inflationsraten, wenn auch nur temporär, zu senken, wurde diese Annahme in Frage gestellt. Ursache dieser überholten Hypothese war sicherlich die Tatsache, daß Inflationen stets im Zusammenhang mit außerordentlichen Umständen, wie Kriegen, Mißernten, Spekulationen etc., erlebt und gesehen wurden.

Aus technischen Gründen befindet sich Schaubild I auf Seite 164!

Spätestens nach dem Zweiten Weltkrieg jedoch trat ein bis dahin nicht bekannter Typ von Inflation offen in Erscheinung. ,Die Wirkung der ,permanenten Inflation wurde sichtbar, als der Rezession der Jahre 1953, 1957, 1960 in den USA wachsende Kleinhandelspreise (im Jahre 1953 gingen die Großhandelspreise nochmals leicht zurück) parallel liefen “ (21). Dieser Inflationstyp kann nicht mehr einfach mit den genannten außerordentlichen Ereignissen, sondern nur noch als ein der gegenwärtigen Stufe des Kapitalismus offenbar immanentes Moment erklärt werden.

Der neue Inflationstyp zeichnet sich gegenüber den ,herkömmlichen' Inflationen durch Unterschiede in den Ursachen, den Wirkungen und den Erscheinungsformen aus. Zu letzterem schreibt J. Valier: ,, l. Die schleichende Inflation zeigt sich in Preissteigerungen, die nicht allgemein sind und nicht kommulativ wirken, während die Inflation durch allgemeine und kummulativ wirkende Preissteigerungen gekennzeichnet ist. 2. Im Gegensatz zur Inflation zeichnet sich die schleichende Inflation durch langfristig anhaltende Preissteigerungen aus. Die schleichende Inflation bezeichnet eine Tendenz von Preissteigerungen auf lange Sicht" (22) (sämtliche Hervorhebungen J. Valier).

Entsprechend diesen unterschiedlichen Erscheinungsformen rufen Hyper- und schleichende Inflation wesentlich voneinander abweichende Wirkungen hervor. Auch die ökonomische Interessenlage der einzelnen Kapitalfraktionen gegenüber dem Inflationsprozeß ist keineswegs einheitlich. Denn neben einer Reihe „positiver $^{6 / 3}$ Begleiterscheinungen, wie Entschuldungseffekt und verbesserte Chancen der Profitrealisierung, bringt die schleichende Inflation auch negative Momente hervor. Der Entschuldungseffekt durch Geldentwertung ist unmittelbar einsichtig. Er ist jedoch bei der creeping Inflation nicht im gleichen Umfang wie bei einer Hyperinflation gegeben ist. „, Diese schleichende Geldentwertung", so klagt BDI-Volkswirt Baumann, ,ist nicht so schön wie eine galoppierende Inflation, bei der die Maschi-

E. Mandel, a. a. O., S. 383

22 J. Valier „Monopolistische Akkumulation und schleichende Inflation“ in: „Kapitalismus in den siebziger Jahren“, EVA Frankfurt a. M. 1971, S. 59 f. 
nen stehenbleiben und die Schulden weg sind" "(23).

Dagegen stellt sich wegen des steuerlichen Nominalwertprinzips ein Teil der - durch die Inflation allerdings auch aufgeblähten - Gewinne als Scheingewinne heraus. Denn allgemeine Preissteigerungen führen auch zu höheren Wiederbeschaffungspreisen für das fixe Kapital. Eine Anlage mit dem Anschaffungspreis von DM 100000 kostet beispielsweise bei ihrer Wiederbeschaffung nach 5 Jahren bereits DM 150 000. In der Zwischenzeit kann jedoch nur der ursprüngliche Kaufpreis von der Steuer abgesetzt werden. D. h., daß zur Wiederbeschaffung der Anlage neben den Rückstellungen in Höhe von DM 100000 weitere DM 50000 vom bereits versteuerten Gewinn entnommen werden müssen. Diese DM 50000 plus Steuern stellen sich daher als nur scheinbarer Gewinn, eben als Scheingewinn heraus.

Da nach $\S 58$, Abs. 2, Akte G, die Unternehmen gezwungen sind, mindestens $50 \%$ des Jahresgewinnes nach Steuern auszuschütten - so dies von den Aktionären gefordert wird - fürchten einige Manager um die Substanz bzw. Ertragskraft ,ihrer Unternehmen. „Die Formel Mark = Mark stimmt nicht mehr. Die Abschreibungen auf Anlagenwerte bleiben weit hinter dem Wiederbeschaffungspreis zurück; die Folge sind Scheingewinne, die zu Lasten der Substanz gehen" (24).

Das Problem der Scheingewinne stellt sich vor allem für Kapitalisten hoher organischer Zusammensetzung. Die Höhe der Scheingewinne ist nämlich abhängig vom absoluten Umfang des fixen Kapitals und von der Preissteigerungsrate bei seinen Bestandteilen, sie ist jedoch unabhängig von deren Umschlagsgeschwindigkeit. Denn wenn sich der Wiederbeschaffungspreis einer Anlage im Verlauf einer bestimmten Periode verdoppelt, so verteilen sich die zusätzlich benötigten Beträge bei Kapitalien hoher Umschlagsgeschwindigkeit auf mehrere Wiederbeschaffungen. In der Summe belaufen sie sich jedoch auf den gleichen Betrag; im angenommenen Fall auf $100 \%$ des ursprünglichen Preises.

Gegen solche Konsequenzen der Inflation versucht sich das Kapital allerdings auf verschiedenste Weise zu schützen. So sind gegenwärtig vor dem Bundesfinanzhof zwei Verfahren anhängig, die darauf abzielen, partielle Freistellung von Einkünften aus Kapitalvermögen bei der Veranlagung zur Einkommensteuer zu erlangen (25).

Vermutlich wird dieser Vorstoß im Hinblick auf die Auswirkungen eines positiven Bescheids auf andere Steuern, vor allem auf die Lohnsteuer, wenig erfolgreich sein.

Eine weitere Möglichkeit, Scheingewinne zu umgehen, besteht im übrigen in der degressiven, der vorauseilenden Abschreibung, die, staatlich sanktioniert, heute in großem Umfang angewendet wird.

Mit dem gleichen Ziel empfiehlt E. Gutenberg den Unternehmern, den Fremdkapitalanteil über das konventionelle Maß hinaus zu steigern: .. Unter dem 
Einfluß inflatorischer Tendenzen lohnt sich ... Kreditfinanzierung, und zwar solange es nicht ęrforderlich ist, die Vereinbarung über Rückzahlung des Kapitals und Entrichtung der Zinsen durch Gleitklauseln der Geldentwertung anzupassen ${ }^{\text {s6 }}$ (26).

Anders als in Perioden kurzfristiger Hyperinflation ist es den Arbeitern während der Zeit einer permanenten, also langandauernden Inflation potentiell möglich, durch Lohnkämpfe immer wieder einen Ausgleich für den Geldwertschwund zu erzwingen. Der allmähliche Anstieg des Lebensstandards - gemessen am Verbrauch von Konsumgütern - beweist entgegen einer weitverbreiteten Ansicht, daß es den Arbeitern in der BRD, langfristig betrachtet, bisher noch immer gelungen ist, Lohnerhöhungen über die Inflationsrate hinaus durchzusetzen. Dies sagt freilich nichts über den Grad der Ausbeutung aus, zumal im gleichen Zeitraum auch Produktivität und Intensität der Arbeit zugenommen haben. Ein Symptom für den Verlust der Geldillusion in der Arbeiterklasse ist darin zu sehen, daß sie in den letzten Jahren nötigenfalls auch sogenannte, wilde" Streiks durchführte, um innerhalb laufender Tarifperioden entstandene Kaufkraftverluste auszugleichen. Die Gewerkschaften gehen dazu über, kürzere Laufzeiten für Tarifverträge zu vereinbaren, um entsprechend kurzfristiger in der Lage zu sein, auf Preissteigerungen zu reagieren.

Die permanente Erhöhung des allgemeinen Preisniveaus behindert die Akkumulation von Kapital in liquider Form, da die Zirkulationsmittel die Wertaufbewahrungsfunktion nur noch unzureichend erfüllen. Sie müssen tendenziell durch Sachwerte ersetzt werden. Die „Flucht in Sachwerte" beschleunigt ihrerseits wiederum die Inflation. So ist die umfangreiche private Bautätigkeit der letzten Jahre z. T. eine Folge der Inflation und steigert wiederum die Nachfrage, wodurch sie dem Preisanstieg weitere Impulse verleiht.

Permanente Preissteigerungen gefährden, falls sie größer sind als bei den Konkurrenzländern, langfristig die Exportfähigkeit eines Landes. Für J. Robinson ist dies der kritische Punkt an allgemeinen Preissteigerungen überhaupt (27). Entsprechend läßt die Regierung der BRD immer wieder verlautbaren, daß es ihr Bemühen sei, am ,Ende des Inflationszuges“" zu fahren.

Gerade in der BRD sind viele wichtige Branchen auf den Export eines erheblichen Teiles ihrer Produktion angewiesen und daher in besonderem Maße der Weltkonkurrenz ausgesetzt - wobei diese auf nationale Inflationsraten bekanntlich wenig Rücksicht nimmt. Da hohe Preissteigerungen beim Input aber in dem Maße, in welchem sie nicht durch Produktivitätssteigerungen aufgefangen werden können, sich auch als Kostensteigerungen niederschlagen, gefährden sie die Exportfähigkeit

E. Gutenberg „Grundlagen der Betriebswirtschaftslehre“ Springer-Verlag, Berlin 1970, Bd. III, S. 214

27 „Der stärkste Einwand gegen die Inflation besteht nicht in dem Hinweis, sie sei grausam, ermüdend und demoralisierenden im eigenen Land, sondern beruht darauf, daß sie sich im internationalen Wettbewerb verheerend auswirkt. Ein Land in ohnehin schon schwacher Position wird zur Verzweiflung getrieben, wenn (bei fix gegebenen Wechselkursen) seine Kosten rascher steigen als jene der Konkurrenten. Genau aus diesem Grund ist die Dämpfung des Preisauftriebs ein Hauptziel der Politik geworden."

J. Robinson „Die fatale politische Ökonomie“ EVA Frankfurt a. M. 1968, S. 12 
der betreffenden Branchen. Es ist daher folgender Fall denkbar: Hohe Preissteigerungen etwa bei den Lebensmitteln und den Mieten führen zur Durchsetzung starker Lohnerhöhungen auch in der Auto-Industrie. Dort aber können sie u. U. weder per Produktivitätssteigerung aufgefangen noch auf Grund einer bestimmten momentanen Verfassung des Weltmarktes - zumindest nicht ohne mengenmäßigen Absatzverlust - einfach im Preis abgewälzt werden. Das Ergebnis wäre ein Export- und Absatzrückgang und/oder eine Gewinneinbuße bei der Auto-Industrie als Folge von Preissteigerungen in ganz anderen Branchen. Der Möglichkeit nach ist hier also ein Interessenkonflikt zwischen exportorientierten und nicht-exportorientierten Branchen angelegt.

Das Beispiel der Bauwirtschaft veranschaulicht, wie die schleichende Inflation notwendige Strukturwandlungen in der Wirtschaft behindert. Viele der sogenannten Grenzbetriebe können ihre Existenz nur auf Grund des inflationären Preisauftriebs behaupten. Relativ geringfügige Verschlechterungen, wie die Aussetzung des Abschreibungsparagraphen $7 \mathrm{~b}$, lösen daher prompt Insolvenzen aus.

Von der Entwertung des Geldes sind auf Seiten des Kapitals vor allem auch Versicherungen, Sparkassen, Banken und andere Kreditinstitute betroffen, weil die Inflation sowohl die Bereitschaft des breiten Publikums zum Kontensparen gefährdet (28), als auch die Gefahr heraufbeschwört, daß langfristig gewährte Kredite mit fixen Zinssätzen sich zu Verlustgeschäften entwickeln, nämlich dann, wenn sich das Einlagenkapital auf Grund der steigenden Inflation verteuert. Eine Absicherung der realen Kaufkraft durch Index-Bindung ist nur begrenzt möglich und bedarf zudem der Genehmigung durch die Bundesbank - was bisher selten praktiziert wurde.

Wie die jüngsten Erfahrungen erneut zeigen, sind Wechselkurse unter den Bedingungen von unterschiedlichen nationalen Produktivitätssteigerungen und unterschiedlichen Inflationsraten in den einzelnen kapitalistischen Staaten nicht stabil $\mathrm{zu}$ halten. D. h. aber, daß die permanente Inflation permanente Störungen im Währungssystem der kapitalistischen Staaten mitverursacht, die Wettbewerbsbedingungen relativ rasch verändert und den internationalen Handel behindert.

Schließlich aber wird eine permanente und sich allmählich beschleunigende Inflation zur Bedrohung des kapitalistischen Systems. So erkannte der Sachverständigenrat in seinem Gutachten 72/73: „Stopp der Mieten, Stopp der Bodenpreise, Kontrolle der Preise bei den Großen, dies sind populäre Parolen. Hier liegen Gefahren für die marktwirtschaftliche Ordnung; denn dirigistische Entscheidungen könnten an die Stelle des Marktprozesses treten, obwohl der Markt und die sich hier

28 Denn während z. B. im Jahre 1971 die Summe der Zinsen und Zinseszinsen für Sparguthaben in der BRD etwa 11 Mrd. DM ausmachten, blief sich der Kaufkraftverlust dieser Guthaben im gleichen Zeitraum auf etwa 12 Mrd. DM. Die Summe der Spareinlagen nahm im März 1973 in der BRD erstmals seit Jahren ab, nämlich um 250 Mill. DM. Eine weitere Folge der negativen Realverzinsung ist offensichtlich die Verlagerung des Sparens auf zinsträchtigere Sparformen. So gibt die Dresdener Bank an, daß ,1971 per Saldo 500 Mill. DM zu Lasten von Sparkonten in Wertpapiere umdisponiert" (29) wurden. Zitiert nach: ,Der Volkswirt" Nr. 38/72 
bildenden Preise nach wie vor die beste Form sind, knappe Güter und Resourcen zuzuteilen - oder wo er doch die beste Form wieder sein könnte, wenn nicht länger eine inflationäre Entwicklung Nachfrage und Angebot verzerrten" (30).

Noch aber verzerrt die inflatorische Entwicklung Nachfrage und Angebot. Da auch niemand eine ernsthafte Prognose für die Beendigung dieses Zustandes abzugeben vermag, ist es kaum verwunderlich, daß die Anzahl derer wächst, ,die angesichts der fortgesetzten Mißerfolge bei dem Versuch, den Geldwert zu wahren, gegenüber der Frage der Erhaltung unseres Wirtschaftssystems gleichmütig geworden $\operatorname{sind}^{\text {" }}$ (31). Damit wird die Inflation neben dem Wirtschaftswachstum zu einem der wichtigsten ökonomischen Probleme der System-Konkurrenz: „Das Bewußtsein wächst, daß eine solche Dauerinflation Zeichen der Niederlage unseres Wirtschaftssystems wäre" (32).

\section{Dogmengeschichtlicher Ruickblick}

\subsection{Ausplünderung Amerikas und vulgäre Quantitätstheorie}

Nach der „Entdeckung“ Amerikas und mit der Heranbildung des spanischen Kolonialreiches zu Anfang des 16. Jahrhunderts begann eine ungeheuere Plünderung der Gold- und Silberschätze vor allem aus Peru und Mexiko. Etwa ab 1530 setzte dann in ganz Europa eine lange Periode enormer Preissteigerungen ein. Die Teuerung betrug im Zeitraum zwischen 1501-1510 und 1591-1600 nach Schätzungen von E. J. Hamilton etwa $303 \%$ (33). Neben Lohnarbeitern und Handwerkern waren hierdurch vor allem die Großgrundbesitzer betroffen, die von meist nominell fixierten Grundrenten lebten. Sie versuchten, den Zustrom der Edelmetalle zu stoppen, da es ihrer Auffassung nach, wie J. Bodin formulierte, ,.... der Überfluß des Goldes und Silbers (war - O.E. D.) welcher das Geld unwert und alle Dinge teuer macht $^{\text {" }}$ (34). J. Bodin griff also beide Erscheinungen unmittelbar auf und brachte sie in den Zusammenhang, der prima facie auf der Hand lag: Die rasche Ausweitung der Geld- (Edelmetall-) Menge wurde von einer ebenso raschen Entwertung des Geldes begleitet. Folglich stehen Geldmenge und Geldwert in einem reziproken Verhältnis zueinander; oder anders ausgedrückt, der Wert des Geldes wird durch seine Quantität bestimmt.

Leider untersuchte J. Bodin nicht die sich hier aufdrängende Frage, aus welchem Grund die Edelmetalle in diesem riesigen Ausmaß nach Europa geschafft

30 Sachverständigenrat, a. a. O., S. 117, Ziffer 343

31 Ders。 Jahresgutachten $1973 / 74$, S. 115 , Ziffer 310

32 Ebd., S. 115, Ziffer 310

33 H. Mottek ,Wirtschaftsgeschichte Deutschlands“, VEB Deutscher Verlag der Wissenschaft, Berlin 1973, Bd. I, S. 251

34 J. Bodin, hier zitiert nach: Kruse "Geschichte der volkswirtschaftlichen Theorien", Duncker und Humblot, Berlin 1959, S. 22 
wurden. Wie W. Petty und später A. Smith zu zeigen vermochten, war die Ursache hierfür die Wertminderung der Edelmetalle auf Grund kostengünstigerer Methoden ihrer Gewinnung bzw. Aneignung in den Kolonien: ,Allein diese Verminderung ihres Wertes ist nicht dem Wachstum des wirklichen Wohlstandes in Europa, des jährlichen Produkts seines Bodens und seiner Arbeit zuzuschreiben, sondern der zufälligen Entdeckung von Bergwerken, die ergiebiger waren, als alle bis dahin bekannten $^{6}(35)$.

Mottek nennt zwei weitere wichtige Faktoren, welche in diesem Sinne wirkten: Erstens die Beschäftigung von billigen Negersklaven und eingeborenen Zwangsarbeitern und zweitens die Umwälzung der Produktionstechnik in der Silbererzeugung durch ein sog. Amalgamierungsverfahren. (Übrigens mußten als direkte Folge hiervon zahlreiche weniger ergiebige europäische Minen schließen.) Den Absorptionsprozeß der Edelmetalle beschrieb A. Smith wie folgt: „Einige Zeit nach der ersten Entdeckung Amerikas wurde das Silber weiterhin zu seinem früheren oder nicht viel unter seinem früheren Preis verkauft. Die Bergwerksprofite waren eine zeitlang sehrgroß und weit über ihrem natürlichen Satze. Indes fanden die, welche die Metalle nach Europa brachten, bald, daß die ganze jährliche Einfuhr nicht zu diesem hohen Preise abgesetzt werden konnte. Silber wurde stufenweise gegen eine immer geringere Quantität von Gütern eingetauscht. Sein Preis sank tiefer, bis er auf seinen natürlichen Preis, d. h. auf den Betrag fiel, der gerade hinreichend war, um, entsprechend ihren natürlichen Sätzen, den Arbeitslohn, die Kapitalprofite und die Grundrente zu bezahlen, die bezahlt werden mußte, um es vom Bergwerk auf den Markt zu bringen" (36).

Es ist also keineswegs so, wie J. Bodin glaubte, daß die Erhöhung der Edelmetall-Menge unmittelbar zu den Preissteigerungen geführt hatte. Die rasche Erhöhung der Geldmenge war vielmehr erst möglich geworden, nachdem die Produktionskosten und damit die Werte der Edelmetalle rapide gesunken waren - und sie wurde dann auch notwendig, weil die relativen Werte und damit die Preise der anderen Waren stiegen. Die Zirkulation konnte nun ein größeres Geldvolumen aufnehmen. Marx schreibt daher: „Der Preis der Waren wechselt erst umgekehrt wie der Wert des Geldes, und dann wechselt die Masse der Zirkulationsmittel direkt wie der Preis der Waren“" (37).

Die Vorstellungen Bodin's werden heute als ,,vulgäre" oder ,naive " Quantitätstheorie des Geldes bezeichnet, weil sie, im Gegensatz zu späteren Varianten dieser Theorie, einen direkten Zusammenhang zwischen der Quantität des Geldes und seinem Wert annehmen, ohne dabei etwa den Einfluß der Umlaufgeschwindigkeit des Geldes.zu reflektieren. Dieses Moment wurde zuerst von J. Locke in die Diskussion eingeführt. Aus der Tatsache, daß die Preise dem Anstieg des Geldvolumens nicht in vollem Umfang und auch nur zeitverzögert folgten, schloß D. Hume,

35 A. Smith ,Eine Untersuchung über Natur und Wesen des Volkswohlstandes“, FischerVerlag, Jena 1923 , Bd. I, S. 323

36 Ebd., S. $270 \mathrm{f}$.

37 K. Marx, MEW 23, S. 131 
daß nicht die in einem Land absolut vorhandene, sondern nur die tatsächlich in der Zirkulation befindliche Masse an Gold und Silber das Preisniveau determiniere.

In Anbetracht moderner Varianten der Quantitätstheorie ist es gewiß gerechtfertigt, wenn P. Samuelson schreibt, daß ,die naive Quantitätstheorie, die einen direkten Zusammenhang zwischen $\mathrm{P}$ und $\mathrm{M}$ behauptet, ziemlich unvollkommen ist"; er fällt aber, wie ersichtlich, noch hinter den Erkenntnisstand von A. Smith zurück, wenn er weiter schreibt, daß sie ,dennoch die Ursachen von Hyperinflationen und gewissen langfristigen Preistendenzen zu erklären (vermag - O. E. D.), wie etwa diejenige, die in Spanien und Europa auftraten, nachdem die Schätze der Neuen Welt entdeckt worden waren" (38).

Mit der vulgären Quantitätstheorie wurde immerhin der Versuch unternommen, den Wert des Geldes durch objektive Bedingungen zu erklären. Deshalb stellt sie einen Fortschritt gegenüber der bis dahin vorherrschenden Konventionstheorie dar, welche vorgab, daß der Geldwert nur aus dem Willen und durch den Befehl des Herrschers abzuleiten sei. Mit dieser These war versucht worden, die betrügerischen Münzverschlechterungen des Mittelalters zu rechtfertigen, obwohl sie zu erheblichen Preissteigerungen geführt und den Handel beeinträchtigt hatten. (Graham'sches Gesetz!).

\subsection{Ursprüngliche Akkumulation und Metallismus}

Die Phase des Niedergangs des europäischen Feudalismus ist u. a. gekennzeichnet durch die ,ursprüngliche Akkumulation des Kapitals, durch Entstehung verschiedenster Manufakturen, Handelsunternehmungen und vor allem durch die Herausbildung von Nationalstaaten und -wirtschaften. Die Handelspolitik dieser jungen Staaten war darauf gerichtet, die eigene Wirtschaftsmacht maximal zu entwickeln und möglichst eine ,positive' Handelsbilanz zu erzielen, was durch Förderungsmaßnahmen für den Export und Drosselung des Imports angestrebt wurde. Der Besitz von Edelmetallen galt als Symbol für wirtschaftliche Macht und Reichtum.

Als Ideologen des Handelskapitals setzten Metallisten wie Mun und North Geld mit Kapital gleich und identifizierten es mit den Edelmetallen - folglich auch den Wert des Geldes mit seinem Metallwert. Sie erhoben folgerichtig die Forderung, nur vollwertige Münzen zirkulieren zu lassen. Jede Emission von Wertzeichen wurde ausdrücklich abgelehnt. Die wegen der Expansion der Warenproduktion notwendig werdende Ausweitung der Masse an Zirkulationsmitteln wollte man durch die Exportüberschüsse, welche in Edelmetallen zu begleichen waren, erwirtschaften. Objektiv förderte der Metallismus damit sowohl die Akkumulation von Kapital (die hier Akkumulation von realen Werten, Edelmetallen, darstellte) als auch die Entfaltung der Ware-Geld-Beziehung, da er den Tausch von wirklichen Äquivalenten anstrebte und den Geldwert zu stabilisieren suchte.

Der Metallismus übersah allerdings den richtigen Ansatz der Konventionstheo-

P. A. Samuelson, a. a. O., Bd. I, S. 353 
rie, daß das Gold in seiner Funktion als Zirkulations- und Zahlungsmittel von anderen, nicht vollwertigen Stoffen ersetzbar ist. Obwohl Marx diesen Sachverhalt klar herausgearbeitet hatte, behauptet A. Schumpeter, der Metallismus sei „von niemanden unbedingter als von Marx" (39) anerkannt worden. Richtig ist, daß Marx davon ausging, daß die Wertmaßfunktion nur von einer Ware ausgeuibt werden kann, die selbst Wert ist. Als Zirkulations- und Zahlungsmittel kann Gold jedoch durch andere Wertzeichen ersetzt werden, weil es in dieser Funktion selbst nur Repräsentant von Wert ist. Wie weit Marxisten vom Metallismus, der im bürgerlichen Lager noch heute Verfechter wie den Franzosen J. Rueff hat, entfernt sind, möge zusätzlich folgendes Lenin-Zitaţ illustrieren: ,Wenn wir dereinst im Weltmaßstab gesiegt haben, dann werden wir, glaube ich, in den Straßen einiger der größten Städte der Welt öffentliche Bedürfnisanstalten aus Gold bauen" (40).

\subsection{Napoleonische Kriege und ,currency principle“}

Der Krieg gegen Napoleon (1793-1815) hatte England etwa 830 Mill. \& gekostet. Dieser Finanzbedarf war u. a. durch vermehrte Ausgabe von Banknoten gedeckt worden. Da außerdem die Zahlungen an die Truppen auf dem Kontinent sowie bestimmte Verbindlichkeiten gegenüber verbündeten Staaten in Gold beglichen werden mußten, sank der Goldbestand der Bank von England beständig und entsprach im Jahre 1814 nur noch weniger als $10 \%$ des Notenumlaufs (41).

Bereits 1797 mußte im Verlauf eines run's auf die Bank die Einlösung von Papiergeld gegen Edelmetalle eingestellt werden. Das Englische Pfund wurde entwertet, insbesondere ab 1809. Daraufhin beauftragte das Unterhaus einen Ausschuß, das sog. ,Bullion Committee", die Ursachen der Preissteigerungen zu ermitteln. In dem bekannten ,Bullion-Report" von 1810 gelangte das Committee zu der Auffassung, daß die Ausgabe ungedeckter Noten die Inflationsursache sei.

Verfechter des ,currency principle' führten einen heftigen Disput mit den Anhängern der sog. Banking-Theorie (Currency-Banking-Controverse), welche der Ansicht waren, daß nicht die erhöhte Papiergeldmenge, sondern die kriegsbedingt ungünstige Entwicklung der Handels- und Zahlungsbilanz der Inflationsherd sei.

Neben Lord Overstone und Mc Culloch gilt D. Ricardo als einer der wichtigsten Vertreter der currency-school. Bei ihm findet sich eine zweifache Bestimmung des Wertes der Edelmetalle. Zunächst schreibt er: ,Wie alle anderen Waren haben Gold und Silber nur Wert entsprechend der Menge Arbeit, die für ihre Produktion und um sie auf den Markt zu bringen, erforderlich ist" (42).

39 J. A. Schumpeter "Geschichte der ökonomischen Analyse", Vanderhoeck \& Ruprecht, Göttingen 1965, S. 369 f。

40 W. I. Lenin "Ausgewählte Werke" Bd. 3, S. 740

41 Siehe R. Gaettens ,Inflationen“, Richard Pflaum-Verlag, München 1955, S. 210

42 D. Ricardo "Grundsätze der Politischen Ökonomie“", Akademie-Verlag, Berlin 1959, S. 344 
Der Wert der Edelmetalle (des Geldes) ist hier eindeutig und unabhängig von der Warenzirkulation bestimmt, nämlich durch die gesellschaftlich notwendige Arbeitszeit. Das bedeutet, daß bei gegebenem Wert der zu zirkulierenden Warenmasse und bei gegebener Ökonomie der Zahlungen auch die Quantität des benötigten Geldes bestimmt ist.

Dieses Prinzip gilt auch für das Papiergeld als bestes, weil billigstes Zirkulationsmittel: „Obwohl es keinen inneren Wert besitzt, so ist infolge der Begrenzung seiner Menge sein Tauschwert doch ebenso groß wie der gleiche Nennwert (Denomination) in Münzen oder in Barren dieses Münzmetalls. Ebenfalls gemäß dem gleichen Prinzip, nämlich der Beschränkung ihrer Menge, wird eine entwertete Münze zu dem Werte zirkulieren, den sie hätte, wenn sie gesetzlich vorgeschriebenes Gewicht und Feingehalt besäße, nicht aber zu dem Werte der Metallmenge, die sie tatsächlich enthält" (43).

Papiergeld wird hier noch als Repräsentant einer bestimmten Menge Goldes aufgefaßt. Bis hierher wird also der Forderung von Marx entsprochen, daß ,Jede wissenschaftliche Untersuchung über das Verhältnis von Anzahl der Zirkulationsmittel und Preisbewegung der Waren (.) den Wert des Geldmaterials als gegeben voraussetzen" muß (44). Doch dann unternimmt Ricardo einen zweiten ganz anders gearteten Versuch der Geldwert-Bestimmung: Selbst wenn das Papiergeld gegen Gold und Silber konvertibel, so sagt er nun, kann es passieren, daß die aggregierten Umlaufmittel im Wert steigen oder fallen. Nämlich dann, wenn bei gleicher Quantität des Geldaggregates die Summe der Warenwerte steigt/fällt oder bei gleicher Quantität der Warenwerte das Geldaggregat schrumpft/zunimmt.

Der Wert der Edelmetalle müßte demnach entsprechend den quantitativen Verhältnissen von Gold- und Warenmenge über/unter den durch die Arbeit bestimmten Wert steigen/fallen können. Diesen Widerspruch kann Ricardo nicht auflösen. Er kann auch keinen Beweis für seine zweite Wertbestimmung anbieten, sondern versichert nur: „Daß die Waren im Preis steigen oder fallen würden, im Verhältnis zur Vermehrung oder Verminderung des Geldes, setze ich als eine unbestreitbare Tatsache voraus" (45) (Hervorhebung Marx).

Nach Ricardo wird, wohl gemerkt, nicht nur das Papiergeld gegenüber den Edelmetallen, sondern werden auch diese selbst im Falle des Überflusses entwertet. Ricardo übersieht hier das wichtige Moment, daß Gold jederzeit ins Ausland oder als Schatz aus der Zirkulation abfließen kann. Er begreift die Edelmetalle allein als Zirkulationsmittel, als Wertzeichen. Um den Geldwert zu stabilisieren, kommt es ihm logischerweise darauf an, das Geldangebot knapp zu halten, also zu steuern. Auf der Suche nach dem geeignetesten Steuerungsinstrument findet er dann: „Die Erfahrung zeigt jedoch, daß weder ein Staat noch eine Bank jemals die uneingeschränkte Macht zur Ausgabe von Papiergeld hatten, ohne diẹse Macht zu mißbrau. chen. Daher sollte die Ausgabe von Papiergeld in allen Staaten irgendeiner Beschrän- 
kung oder Kontrolle unterliegen. Nichts erscheint für diesen Zweck so geeignet zu sein wie die Verpflichtung für die Emmittiten von Papiergeld, ihre Noten entweder in Goldmünzen oder -barren einzulösen ${ }^{6}(46)$.

Ricardo hatte durchaus recht, wenn er forderte, daß nur so viel Papiergeld zirkulieren sollte, wie Metallgeld umlaufen könnte. Diese Größe ist jeđoch logisch nicht abhängig davon, wieviel Gold in einem gegebenen Augenblick im Keller irgendeiner Bank akkumuliert worden ist. Die benötigte Geldmenge ist abhängig von dem momentanen Umfang der Warenzirkulation. Die vorhandene Goldmenge dagegen ist abhängig von den natürlichen Gold-Vorkommen und der Arbeitszeit, die zu deren Ausbeutung aufgebracht worden ist.

Ricardo's Vorschlag zur Geldmengen-Steuerung wurde 1844 in Sir R. Peel's Bankakt erstmals realisiert. Das Gesetz beinhaltete etwa folgendes: „Für jede fünf Pfund in Gold (.), die aus dem Bankschatz abfließen, geht eine Fünfpfundnote zurück an das Ausgabe-Department und wird vernichtet; für jede dem Schatz zugehenden fünf Sovereigns kommt eine neue Fünfpfundnote in Umlauf" (47).

Die Papiergeldzirkulation war in idealer Weise nach der Gold-Zirkulation ausgerichtet worden. Doch die Kritiker dieser Konzeption, wie Th. Tooke und Fullarton, welche der Auffassung waren, die Banken müßten von derlei Beschränkungen frei bleiben, zumal der Bankenapparat sich durch Schöpfung bzw. Vernichtung von Buchgeld ohnehin den aktuellen Forderungen der Wirtschaft anpasse, sollten Recht behalten. Das Gesetz führte zum Fiasko. Marx schreibt darüber: „Der Bankakt von 1844 provozierte also sämtliche Handelswelt direkt dazu, bei hereinbrechender Krise sich einen Reserveschatz von Banknoten beizeiten anzulegen, also die Krise zu beschleunigen und zu verschärfen ...

Zweimal, am 25. Okt. 1847 und am 12. Nov. 1857, war die Krisis auf diese Höhe gestiegen; da befreite die Regierung die Bank von der Beschränkung ihrer Notenausgabe, indem sie den Akt von 1844 suspendierte, und dies reichte beidemal hin, die Krise zu brechen" (48).

\subsection{Reaktion und Chartalismus}

Als ideologische Reaktion auf die sozialen Bewegungen Mitte des 19. Jahrhunderts entstand in Deutschland die ,Historische Schule", die sich ideologisch sowohl gegen die klassische bürgerliche als auch gegen die Marx'sche Theorie richtete. Ihre Vertreter gaben vor, daß es die eigentliche Aufgabe der Nationalökonomie sei, die Geschichte des Wirtschaftslebens der einzelnen Völker und Epochen zu katalogisieren und zu beschreiben. Sie begriffen es ausdrücklich nicht als ihre Aufgabe, ökonomische Gesetzmäßigkeiten offenzulegen. Ihre Theorie-Feindlichkeit ging so weit, daß K. Wicksell schreiben konnte: „Eine Wissenschaft, die kein einziges feststehendes

46 Ders, a. a. O., S. 349

47 K. Marx, MEW 25, S. 570

48 Ebd., S. $570 \mathrm{f}$. 
Resultat, keinen allgemein anerkannten Lehrsatz aufzuweisen hat, muß konsequentermaßen darauf verzichten, in den Maßnahmen der Regierungen und Parlamente eine leitende Rolle zu spielen" (49).

Während der einen Richtung bürgerlichen Denkens, den Metallisten, das Wesen des Geldes als identisch mit den natürlichen Eigenschaften der Geldware erscheint, verfällt die Historische Schule in das genau entgegengesetzte Extrem: Das Geld wird dargestellt als reines Produkt des Denkens, als Ausfluß einer Idee. F. Knapp, einer der führenden Vertreter der Historischen Schule, schreibt: „Das Geld ist ein Geschöpf der Rechtsordnung. Es ist im Lauf der Geschichte in den verschiedensten Formen aufgetreten. Eine Theorie des Geldes kann daher nur rechtsgeschichtlich sein" $(50)$. Der Geldwert ist demnach kein ökonomisches, sondern ein juristisches Problem! Weiter heißt es bei Knapp: „Die Frage nach dem Werte des Geldes ist sekundär, was allein von Bedeutung ist, das ist seine Geltung (.) die ihm der Staat verschafft" (51). Aus der Tatsache, daß Scheidemünzen und Papiergeld letztlich des staatlichen Zwangskurses bedürfen, leitet er hier, in Anlehnung an die nominalistische Konventionstheorie und im Gegensatz zum Metallismus, die These $a b$, daß der staatliche Charakter des Geldes primär sei. Als Beweis führte er an, daß vor den staatlichen Eingriffen in das Zirkulationswesen die Geldware stets nur zu ihrem tatsächlichen Stoffwert gehandelt wurde. Erst mit Hilfe der Staatsintervention sei es möglich geworden, zur, wie er es nannte, „chartalen“" Zahlung, zur Zahlung mit bloßen Wertzeichen überzugehen. Aus welchem Stoff das Geld bestehe, sei seitdem völlig gleichgültig, und das Geldsystem bedürfe des Goldes nicht mehr. Was F. Knapp hier, anders als die Metallisten, durchaus richtig gesehen hat, ist, daß eine Vielzahl von Stoffen die Funktion des Zirkulationsmittels übernehmen könnte, die Edelmetalle als Zirkulationsmittel sehr wohl ersetzbar sind.

F. Knapp verstand aber nicht, daß die Funktionen des Geldes nur die Erscheinungsformen seines Wesens sind und die Zirkulationsmittel-Funktion eben nur eine von mehreren ist. Andere als diese und begrenzt auch die Schatz-Funktion vermag Papiergeld nicht zu übernehmen. Der Staat kann in normalen Zeiten die Zirkulationsmittel-Funktion des Papiergeldes qualitativ sichern, doch eine quantitative $\mathrm{Ga}$ rantie kann er nicht geben. Der Wert des Geldes bestimmt sich nicht durch die Geltung, die ihm der Staat verschafft, sondern durch objektive Bedingungen. In Krisenzeiten, etwa während einer Hyperinflation, zeigt es sich daher, daß das $\mathrm{Pa}$ piergeld selbst als Zirkulationsmittel versagen kann. Da Papiergeld gegebenenfalls rasch an Tauschwert verliert und es $u$. U. sogar zweifelhaft erscheint, daß das für eine Ware erhaltene Geld wieder gegen Waren rücktauschbar ist, kann es dann auch als Zirkulations- bzw. Zahlungsmittel abgelehnt werden. Papiergeld aber hat Gebrauchswert nur in der Zirkulation. In diesem Sinne hat M. Friedman daher einmal völlig zurecht die in Japan massenhaft gehorteten US-Dollar ,,green printed paper ${ }^{66}$ genannt.
49 K. Wicksell , Über Wert, Kapital und Rente nach den neueren nationalökonomischen Theorien", Scientia-Verlag, 1969, S. 3
50 F. Knapp, hier zitiert nach Ch. Rist „Geschichte der Geld- und Kredittheorien von John Law bis heute", Francke-Verlag Bern, 1947, S. 322
Ebd., S. 322 


\section{Bürgerliche Geldwerttheorien der Gegenwart}

\subsection{Der Keynes'sche Ansatz}

\subsubsection{Geld und Zins}

Die Funktionen und Eigenschaften des Geldes problematisiert Keynes in seinem Hauptwerk erst im Zusammenhang mit der Abhandlung des Geldzinses. Er glaubte, entdeckt zu haben, ,daß der Zinsfuß-auf Geld eine eigenartige Rolle in der Begrenzung des Niveaus der Beschäftigung spielt, da er einen Standard festsetzt, den die Grenzleistungsfähigkeit eines Kapitalwertes erreichen muß, wenn er neu erzeugt werden soll"“ (52) (Hervorhebung K.).

Keynes leitet den Zinsfuß nicht als Bestandteil des Gesamtmehrwertes ab, sondern begreift ihn als eine autonom bestimmbare Größe, die eine ,in hohem Grade psychologische Erscheinung" sei. Deshalb wird der Zins bei ihm nicht durch den Profit begrenzt, sondern umgekehrt, der Geldzinsfuß erscheint als Minimalgröße des Profits.

Nachdem Keynes dann die These aufstellt, daß jede Ware ihren eigenen Zinsfuß habe, - er spricht von unterschiedlichen Sätzen etwa beim „Häuser-“ und „Stahlwerkzinsfuß" (53) - analysiert er, warum nun gerade der Zinsfuß des Geldes eine bestimmende Größe im Wirtschaftsprozeß darstelle.

Im Gegensatz zur Neo-Klassik, die das Geld allein als Zirkulationsmittel begriffen hatte, versteht Keynes das Geld auch als Vermögensobjekt. Daher stellt er es in eine Reihe mit den Produktionsmitteln, denen er folgende drei Merkmale zuschreibt:

1. „Einige Vermögensbestände erzeugen eine Erträgnis oder eine Produktion..."(54) - Was in realitas allerdings unmöglich ist. Gemeint ist hier der Umstand, daß sie Gebrauchswert haben und ihr Besitz die Aneignung von Mehrwert ermöglicht.

2. Die meisten Vermögensbestände verlieren laufend an Wert durch natürlichen Schwund. Dessen Geld-Äquivalent wird als Durchhaltekosten bezeichnet. Bei den modernen Geldmaterialien sind diese Kosten allerdings, wie Keynes bemerkt, sehr gering und erstrecken sich vornehmlich auf Verwahrungskosten.

3. „Endlich mag die Verfügungsmacht über einen Vermögensbestand während eines Zeitabschnittes eine potentielle Annehmlichkeit oder Sicherheit bieten, die für verschiedene Arten von Vermögen ungleich ist. ... Es gibt hierfür sozusagen kein greifbares Ergebnis am Ende des Zeitabschnittes in der Form von Produktion, und

52 J. M. Keynes „Allgemeine Theorie der Beschäftigung, des Zinsen und des Geldes“, Duncker u. Humblot, Berlin 1936, S. 186

53 Ebd., S. 186

54 Ebd., S. 188 
doch ist es etwas, für das die Leute bereit sind, etwas zu bezahlen ${ }^{6}(55)$.

Was Keynes hier so dubios umschreibt, ist die Eigenschaft der Waren, als Träger von Wert auch Tauschwert zu sein, d. h. als Äquivalent für andere Waren dienen zu können. Diese Eigenschaft trifft für das Geld als allgemeines Äquivalent im höchsten Grade zu.

Keynes definiert đie Liquditätsprämie als den Betrag, den die Wirtschaftssubjekte angeblich bereit sind, zu zahlen, für die ,Annehmlichkeit", liquide Mittel zu halten. - Gemeint ist hiermit die potentielle Verzinsung der liquiden Mittel, genauer: der Spekulationskasse.

D. h., daß der Zins die Belohnung für die Aufgabe von Liquidität ist. Für Keynes ergibt sich danach der Eigenzinsfuß der Waren mit $q-x+1$. Aus mehreren Gründen ist die Liquiditätsprämie des Geldes im Vergleich mit dem Eigenzinsfuß anderer Waren relativ hoch und stabil:

1. Die Nachfrage nach Geld ist stets sehr hoch,

a) weil seine Durchhaltekosten extrem gering sind,

b) weil es die höchste Form der Liquidität darstellt,

c) weil sein Wert weniger schwankt als der anderer Waren, wodurch u. a. die Wertaufbewahrungsfunktion am besten verwirklicht ist.

Hier kündigt sich offenbar ein Zirkelschluß an: Der Geldwert ist relativ stabil, weil - bei begrenztem Angebot - die Nachfrage stets hoch ist; und diese ist wiederum hoch, weil der Geldwert relativ stabil ist!

2. Das Angebot an Geld ist verhältnismäßig starr. Denn, obwohl es Beschäftigung und Produktion nach oben zu begrenzen vermag, kann es nicht einfach durch Umlenkung von bestimmten Ressourcen vermehrt werden, ,sofern es sich um die Macht der privaten Unternehmungslust, im Gegensatz zur Macht der Währungsbehörde handelt" (56). Keynes vermutet, daß, ,wenn Geld wie eine Ernte angebaut oder wie ein Kraftwagen fabriziert werden könnte, wirtschaftliche Notlagen vermieden oder gemildert werden könnten, weil bei einer Neigung des Preises anderer Vermögensbestände, in Größen von Geld zu fallen, mehr Arbeit auf die Erzeugung von Geld abgelenkt würde" (57). Ökonomische Krisen werden somit auch als Geldkrisen hingestellt. Marx wies jedoch nach, daß die relative Geldknappheit innerhalb eines Konjunkturzyklusses erst in dem Augenblick entsteht, in dem die Warenzirkulation wegen zu geringer Endnachfrage, d. h. mit anderen Worten wegen des relativen Überangebotes an Waren auf Grund von Kapital-Überakkumulation ins Stocken gerät.

3. Die Elastizität seiner Ersetzbarkeit ist nahezu Null. Denn während bei steigendem Wert (Preis) anderer Waren eine Tendenz entsteht, sie durch andere, billigere Waren zu ersetzen, bleibt das Geld weiterhin begehrt, weil es in einem solchen Falle gegen eine entsprechend größere Warenmenge rückgetauscht werden kann.

57 Ebd., S. 193 
Beim Geld ist q gleich Null, c nahezu Null und 1 sehr groß. Ein weiterer Grund für die relative Höhe und Dominanz des Geldzinses ist angeblich der Umstand, ,daß Löhne, in Größen von Geld, verhältnismäßig zähe sind“, weshalb ,,der Wert der Produktion in Größen von Geld gemessen, beständiger sein wird ${ }^{66}(58)$. - Und warum werden die Löhne in Einheiten von Geld festgelegt und gezahlt? Weil ,die Löhne in der Ware mit der geringsten Elastizität der Erzeugung und dem geringsten Ủberschuß der Durchhaltekosten über die Liquiditätsprämie am zähesten sein wer$\operatorname{den}^{66}(59)$. - Offenbar ein zweiter Zirkelschluß .

Keynes kommt bezüglich der Krisen zu dem „Ergebnis, daß das Merkmal, das nach überlieferter Annahme Gold besonders zweckmäßig für den Gebrauch als Wertstandard machen soll, nämlich die Unelastizität seines Angebotes, sich gerade als das Merkmal erweist, das der Kern des Übels ist ${ }^{66}$ (60).

Hier geraten ihm offensichtlich die Funktionen des Geldes durcheinander. Denn als Maß der Werte, als Preismaßstab sowie als Schatz bleibt das Gold auf Grund seiner natürlichen Eigenschaften trotz relativ geringen Vorkommens weiterhin geeignet. Als Zirkulationsmittel aber - und nur diese Funktion hat Keynes hier tatsächlich im Sinn - kann und muß es allerdings durch andere Materialien ersetzt werden, da die Goldproduktion nicht einmal mit dem rasanten Wachstum allein des internationalen Handels Schritt halten kann.

Die falsche Überlieferung, daß nur ein knappes Gut Geldfunktionen erfüllen könne, ist trotzdem in der bürgerlichen Wissenschaft weiterhin lebendig. Man erinnere sich daran, daß J. Rueff noch heute die Rückkehr zum Gold-Standard fordert! Wenn Keynes jedoch meint, daß die Unelastizität der Geldproduktion, sprich die Knappheit an Zirkulationsmitteln, die letzte Ursache gewisser Krisen sei, dann erschiene es allerdings sinnvoll, die Zentralbanken gegebenenfalls mehr "Grünkäse" produzieren, d. h. die Papiergeldmenge ausweiten zu lassen; es gäbe in der Tat keinen vernünftigen Grund dafür, den Produktionsumfang der Gcsamtwirtschaft durch den Umfang der Produktion an Zirkulationsmittel zu begrenzen.

\subsubsection{Liquiditätsfalle}

Keynes unterteilt das Geldvolumen in die Mengen $\mathbf{M}_{1}$ und $\mathbf{M}_{2}$. Dabei ist „, $\mathbf{M}_{1}$ der Geldbetrag, welcher auf Grund des Umsatz- und Vorsichtsmotive und $\mathrm{M}_{2}$ der Betrag, der wegen des Spekulationsmotivs gehalten wird ${ }^{66}$ (61). Diese Aufspaltung bedeutet für $\mathrm{H}$. G. Johnson ,abgesehen davon, daß sie mathematisch unelegant wirkt, eine mechanistische Behandlung der Transaktionskasse, die Keynes selbst bei der Quantitätstheorie kritisiert hatte" (62).

Ebd., S. 199

59 Ebd., S. 199

60 Ebd, S. 197

61 Ebd., S. 167

62 H. G. Johnson, a. a. O., S. 36 
$M_{1}$ ist, so Keynes, vornehmlich vom Volkseinkommen $Y$ abhängig, während $\mathrm{M}_{2}$ hauptsächlich durch den Zins $r$ bestimmt ist. „Die Verteilung des Zuwachses von Bargeld zwischen $M_{1}$ und $M_{2}$ in der neuen Gleichgewichtslage wird davon abhängen, wie die Investitionen auf eine Senkung des Zinsfußes und das Einkommen auf eine Vermehrung in der Investition reagieren. Da $Y$ teilweise von $r$

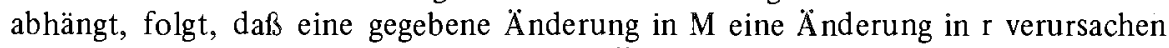
muß, die genügt, daß die sich ergebenden Ånderungen in $\mathrm{M}_{1}$ und $\mathrm{M}_{2}$ sich zusammen auf die gegebene $\ddot{A}$ nderung in M belaufen werden" (63). Verschiedene Anhänger Keynes' haben es später unternommen, die Trennung von $\mathrm{M}_{1}$ und $\mathrm{M}_{2}$ aufzuheben und die gesamte Geldmenge als zinselastisch und abhängig vom realen Prozeß zu behandeln.

Auf der Zinsreagibilität von $\mathrm{M}_{2}$ beruht nach Keynes die Chance staatlicher Geldpolitik. Eine autonome Ausweitung der Geldmenge, bzw. die relative Erhöhung des Angebotes an Leihkapital, führt zu einer Zinssenkung, was bei gegebenem Hang zum Verbrauch und gegebener Grenzleistungsfähigkeit des Kapitals die Ausdehnung der Produktion lukrativ erscheinen lassen kann. Die Nachfrage nach Investitionsgütern und Arbeitskräften steigt, das NSP wächst. Allerdings seien auch Situationen möglich, in denen von einer Zunahme der Geldmenge nur unerhebliche Einflüsse auf das Zinsniveau ausgehen, - nämlich dann, wenn auf Grund von Unsicherheiten über die Zukunftserwartung mehr Geld an die Sicherheitskasse gebunden wird. Umgekehrt müsse davon ausgegangen werden, daß die Wirtschaftssubjekte bei Unterschreitung eines bestimmten Minimalzinssatzes unbeschränkt Geld horten (Liquiditätsfalle). Es sei vorstellbar, daß „die Vorliebe für Liquidität im Publikum mehr als die Geldmenge zunimmt, und während man von einer Abnahme des Zinsfußes, unter sonst gleichen Bedingungen, eine vermehrte Menge der Investition erwarten kann, wird dies nicht eintreten, wenn die Tabelle der Grenzleistungsfähigkeit des Kapitals rascher als der Zinsfuß fällt; und während man von einer Zunahme in der Menge der Investition, unter sonst gleichen Bedingungen, eine Vermehrung der Beschäftigung erwarten kann, wird dies nicht eintreten, wenn der Hang zum Verbrauch abnimmt" (64).

Indem Keynes die Möglichkeit der Abnahme des „Hangs zum Verbrauch“ konstatiert - wozu er sich durch die aktuelle Krise gezwungen sieht - stellt er sich bewußt in Gegensatz zur Neoklassik. Denn sein Begriff der ,,Vorliebe für Liquidität" ist, wie er selbst anmerkt, annähernd mit dem Begriff der Hortung identisch. Weil die Neoklassik aber das Geld ausschließlich als Zirkulationsmittel faßte und obendrein bzw. gerade deshalb dessen Umlaufgeschwindigkeit $\mathrm{V}$ als konstant annahm, konnte in ihrer Theorie dieses Phänomen nicht existieren. 


\subsubsection{Determinanten des Preisniveaus}

Keynes kritisiert an „den Ökonomen", daß sie die relativen Preise durch das Verhältnis von Angebot und Nachfrage, das allgemeine Preisniveau aber durch die Relation von Waren- und Geldmenge erklären. Für sich nimmt er nun in Anspruch, als erster eine einheitliche Preistheorie - und zwar in Anlehnung an seine Theorie des Wertes - zu entwickeln.

Er unterstellt, daß sich die Entschädigungssätze für die Erzeugungsfaktoren relativ gleichmäßig verändern und zieht daraus den Schluß, „daß das allgemeine Niveau der Preise (...) teilweise von der Lohneinheit und teilweise von der Menge der Beschäftigung abhängt. Die Wirkung von Änderungen in der Geldmenge auf das Niveau der Preise kann folglich als eine Zusammensetzung der Wirkung auf die Lohneinheit und der Wirkung auf die Beschäftigung betrachtet werden" (65).

Für die Keynes'sche Preistheorie wesentlich erscheint die weitere Annahme, daß das Lohnniveau bei Unterauslastung des Arbeitsmarktes außerordentlich starr sei. Daraus resultiert nämlich die Kritik an der neoklassischen Theorie, daß im Zustand der Unterbeschäftigung eine autonome Ausweitung der Geldmenge keineswegs das Preis- sondern vielmehr das Beschäftigungsniveau erhöhen werde. Erst wenn der Zustand der Vollbeschäftigung erreicht ist, würden Lohn- und Preisniveau im Verhältnis der Geldmengen-Ausdehnung steigen.

Verschiedene Einflußfaktoren bewirken jedoch, daß selbst bei Vollbeschäftigung das Verhältnis von Steigerung der Geldmenge und Steigerung der Preise nicht parallel verläuft. So begreift Keynes, anders als die Neoklassiker vor ihm, daß ,natürlich kein Grund (besteht) anzunehmen, daß V beständig sei. Sein Wert wird von dem Aufbau der Banken und der Industrie abhängen, von gesellschaftlichen Gewohnheiten, von der Verteilung des Einkommens zwischen verschiedenen Klassen und von den tatsächlichen Kosten des Haltens von müßigem Bargeld“" (66).

\subsubsection{Begründung der Staatsintervention}

Bereits anläßlich der Ottawa-Konferenz von 1933 hatte Keynes das Bedürfnis des Kapitals, Produktion, Preise und damit die Profite durch zusätzlich staatliche Nachfrage zu erhöhen, in dankenswerter Weise recht unumwunden artikuliert: „Das erklärte Ziel der Regierung, ebenso wie der Vèrtreter des Empire, die sich in Ottawa versammelt haben, ist es, die Preise zu erhöhen. Wie können wir das tun? ' Keynes verwirft die (bis dahin häufig verfolgte) Praxis, die Preise durch Kürzung des Angebots zu steigern; dies schädige letztlich auch die Gewinne der Anbieter und führe nicht aus der Massenarbeitslosigkeit heraus. Dagegen empfiehlt Keynes den folgenden Weg: ,1) Für die Warengesamtheit gibt es die Möglichkeit einer Erhöhung der

Ebd., S. 169 
Preise nur, wenn die Ausgaben der Käufer rascher vermehrt werden, als das gleichzeitige Angebot auf den Märkten steigt" “(67).

Keynes arbeitet dann heraus, daß eine bedeutsame Steigerung der Gesamtnachrfrage in einem Land faktisch nur uiber eine Ausdehnung des Kreditvolumens oder über eine "Verbesserung ${ }^{66}$ der $\mathbb{Z}$ ahlungsbilanz zu erreichen sei. Er urteilt dann: „5) Allerdings besteht zwischen diesen beiden Verfahrensweisen ein großer Unterschied: Nur die erste steht allen Ländern zugleich zu Gebote... Es gibt nur noch ein wirksames Mittel, die Preise in der Weltwirtschaft zu erhöhen, und das ist eine weltweite Vergrößerung der kreditfinanzierten Ausgaben. ... Das Bau- und Verkehrswesen, die öffentlichen Versorgungsbetriebe sind schon immer in erheblichem Umfang Mitträger der laufenden Kreditausgaben gewesen. - So fällt die Initiative den öffenilichen Organen $\mathrm{zu}^{66}(68)$ (Hervorhebungen W. H.).

Keynes begründete in der Theorie somit das, was sich in der Wirtschaftspraxis unter dem Schlagwort „New Deal" ohnehin bereits abzeichnete, die direkte Staatsintervention zugunsten der großen Konzerne - vorwiegend auf dem Wege erhöhter staatlicher Nachfrage, die über Kredite finanziert wird. Die Strategie läuft darauf hinaus, nicht etwa die Endnachfrage durch Reallohn-Erhöhungen per Preisdeflation, sondern die Profite vermittels der Erhöhung der Staatsaufträge und damit der Beschäftigung zu erhöhen.

\subsubsection{Stabiles Preisniveau und, ,gestempeltes Geld ${ }^{* 6}$}

Während Keynes in der Weltwirtschaftskrise das Preisniveau anheben und das nominelle Lohnniveau möglichst stabil halten will, präferiert er angeblich langfristig, ohne dies allerdings abzugrenzen, genau das Gegenteil: „Auf lange Sicht stehen wir andererseits immer noch vor der Wahl zwischen einer Politik, die Preise mit dem Fortschritt der Technik und der Ausriistung langsam fallen zu lassen und die Löhne beständig zu halten, und einer Politik, die Löhne langsam steigen zu lassen und die Preise beständig zu halten. Im ganzen ziehe ich die zweite Möglichkeit vor ${ }^{66}(69)$.

Dem widersprechen allerdings seine Ausführungen über das sog. ,gestempelte Geld". Nachdem er nämlich zu der Auffassung gelangt war, daß die geringen Durchhaltekosten des Geldes für die hohe Liquiditätsvorliebe und damit letztlich auch für die Krisen mitverantwortlich sind, stellte er Überlegungen an, die Durchhaltekosten für Geld künstlich zu schaffen bzw. zu erhöhen. Er schreibt: ,Jene Reformatoren, die in der Erzeugung künstlicher Durchhaltekosten des Geldes ein Heilmittel gesucht haben, zum Beispiel durch das Erfordernis periodischer Abstempelungen der gesetzlichen Zahlungsmittel zu vorgeschriebenen Gebühren, sind somit auf der rich-

67 Ders, „The Mearis to Prosperity“, London 1933, hier zitiert nach W. Hofmann, a. a. O., S. 24

68 Ders. a. a. O., S. 25

69 Ders, ,Allgemeine Theorie" ${ }^{66}$ S. 229 
tigen Spur gewesen; und der praktische Wert ihrer Vorschläge verdient, erwogen zu werden" (70). Zwar wird eingestanden, daß Gesell's Ideen, von denen hier die Rede ist, ,in der vorgeschlagenen Form nicht durchführbar" (71) sind, einfach schon deshalb nicht, weil im Falle ihrer Durchsetzung das Geld als Zirkulationsmittel tendenziell durch andere Waren ersetzt werden würde. Dennoch stellt Keynes Über* legungen über den eventuellen Preis solcher Marken an. Seiner Meinung nach ,sollte er ungefähr gleich dem Überschuß das Geldzinsfußes (von den Marken abgesehen) über diejenige Grenzleistungsfähigkeit des Kapitals sein, die einer Rate der Neuinvestition entspricht, die mit Vollbeschäftigung vereinbar ist. Die von Gesell tatsächlich vorgeschlagene Gebühr war $1 \% \%$ in der Woche, gleich 5,2\%o im Jahr. Dies würde unter bestehenden Verhältnissen zu hoch sein, aber die richtige Zahl, die von Zeit zu Zeit geändert werden müßte, könnte nur durch Versuch und Irrtum erreicht werden $^{66}(72)$. Die Einführung irgendeiner Art von, gestempeltem Geld "6 aber wäre genau das Gegenteil eines stabilen Preisniveaus auf lange Sicht, nämlich die dann sogar noch institutionalisierte, beliebig und exakt steuerbare Geldentwertung.

\subsubsection{Demand-pull}

Für eine Situation, in der sowohl Produktionskapazitäten, als auch Arbeitskräfte unausgelastet sind, gilt nach Keynes, daß ,eine Zunahme der Geldmenge überhaupt keine Wirkung auf die Preise haben wird, solange es irgendwelche Arbeitslosigkeit gibt, und daß die Beschäftigung im genauen Verhältnis zu jeder Zunahme in der wirksamen Nachfrage zunehmen wird, die durch die Zunahme in der Geldmenge herbeigefuihrt wurde ..." (73).

Bei Vollbeschäftigung wird jede weitere Ausdehnung der monetären Nachfrage die Produktion nicht mehr steigern, da ja alle Produktionsfaktoren ausgelastet sind. Ubersteigt aber in einer Volkswirtschaft die Gesamtnachfrage das Warenangebot bei voll oder zumindest nahezu voll ausgelasteten Kapazitäten, so entsteht nach keynesianischer Ansicht ein "demand-pul1"6. Die Übernachfrage führt angeblich so lange zu Preissteigerungen, bis die monetäre Nachfrage mit dem monetären Angebot wieder im Gleichgewicht ist. Der Nachfrageüberhang könne dadurch entstehen, daß das inländische Warenangebot sich verringert, entweder durch Exportüberschüsse - die ihrerseits wieder zusätzliches Geld hereinbringen, das zusätzliche Nachfrage bedeuten kann (Multiplikator-Effekt!) - oder durch inländischen Produktionsriickgang bzw. durch künstliche Verknappung zwecks Spekulation.

Es sei möglich, daß Übernachfrage zunächst nur in einigen Branchen herrscht und sich von dort inflatorische Impulse über die ganze Wirtschaft ausbreiten. Solche

$\begin{array}{ll}70 & \text { Ebd., S. } 196 \\ 71 & \text { Ebd., S. 301 } \\ 72 & \text { Ebd., S. 302 } \\ 73 & \text { Ebd., S. 250 }\end{array}$


„sektoralen Spannungen " könnten sich entweder aus Verschiebungen bzw. Divergenzen von Angebots- und Nachfragestrukturen oder aus plötzlichen Angebots-Verknappungen (vor allem bei Rohstoffen und landwirtschaftlichen Produkten) ergeben. Der Nachfrage-Sog entsteht aber vor allem auch dadurch, daß die Gesamtnachfrage schneller wächst als das Warenangebot. Die Gesamtnachfrage in einer Volkswirtschaft wird dabei aufgefaßt als die aggregierte Nachfrage von vier Sektoren: Dem Ausland, dem Staat, den Unternehmern und den Konsumenten.

Den Fall überhöhter Investitionsgüter-Nachfrage beschreibt P. A. Samuelson folgendermaßen:

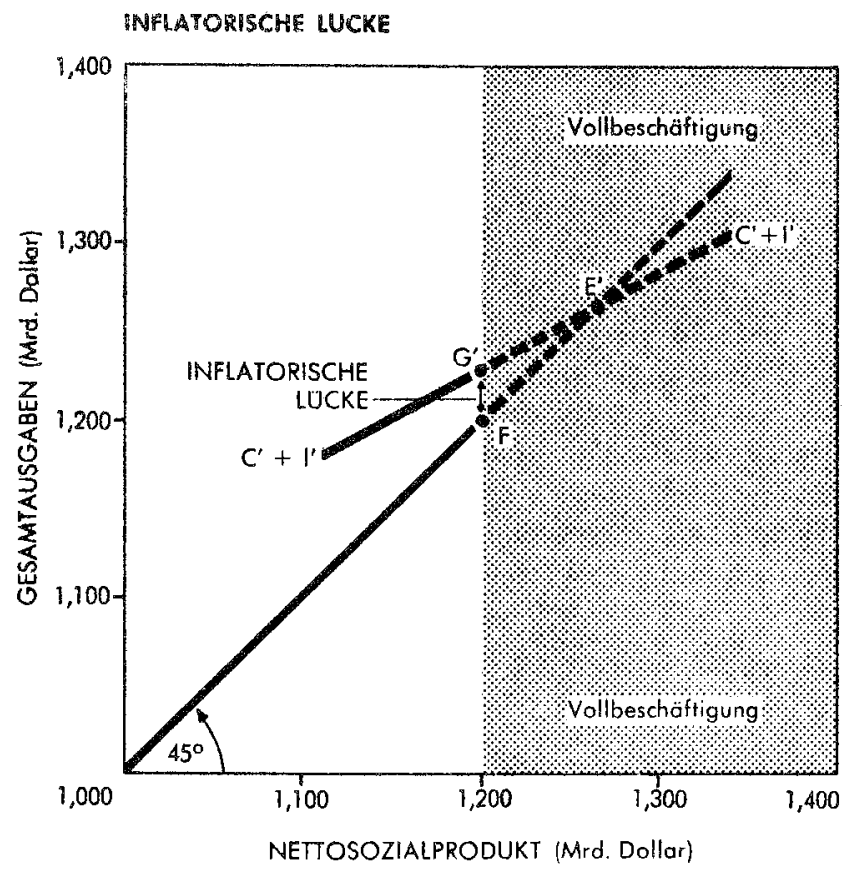

„Wenn die Vollbeschäftigungsersparnisse niedriger ausfallen als die geplanten Investitionen, so spricht man von einer inflatorischen Lücke. Ihre Höhe ergibt sich aus dem Abstand zwischen der C+L-Funktion und der 450-Linie beim Vollbeschäftigungs-Volkseinkommen (oder was dasselbe ist, aus dem Überschuß der bei Vollbeschäftigung geplanten II über SS)“ (74).

Da jeder der vier genannten Bereiche gleichzeitig an der Gesamtnachfrage beteiligt ist, kann angeblich im konkreten Fall logisch kein Sektor allein für eine bestimmte Übernachfrage-Situation verantwortlich gemacht werden. Im keynesiani- 
schen Verständnis kommt hier dem Staat jedoch eine besondere Verantwortung zu (75). Gelegentliche Nachfrageüberschüsse bei Vollbeschäftigung der Kapazitäten muissen von ihm durch eine restriktive Haushalts- und Finanzpolitik (Steuern) abgebaut werden.

Als Indiz dafür, daß eine Übernachfrage herrscht, wird häufig eine Ausweitung des Gewinnanteils am jährlichen BSP angesehen, weil die Übernachfrage zu einer Stärkung der Marktposition der Warenanbieter führt und den Wettbewerbsdruck mildert (seller's inflation).

Der Nachfrage-Sog wird auch häufig umschrieben als der Versuch gesellschaftlicher Gruppen, sich vom ,großen Kuchen“ einen übermäßigen Teil abzuschneiden, d. h. man begreift ihn als Verteilungskampf, der allerdings erst nach dem Akt der Produktion angesiedelt wird. Tabelle I zeigt die Aufteilung des BSP in der BRD für die Jahre von 1950 bis erstes Halbjahr 1973. Analysiert man sie im Hinblick auf die vier aggregierten Nachfrager, dann zeigt sich folgendes Bild: Dem Markt der BRD wurde mit den geringfügigen Ausnahmen der Jahre 1950 und 1965 durch die relative Übernachfrage des Auslandes permanent eine beträchtliche Warenmenge gewissermaßen vorenthalten. Der ,positive Außenbeitrag ${ }^{66}$ betrug in jeweiligen Preise bis zu 3,9\% (1957) des BSP! Es ist anzunehmen, daß die permanenten Exportüberschüsse einen gewissen Teil der Preissteigerungen in der BRD hervorgerufen haben.

Wie aus Tabelle I weiter ersichtlich, ist in der BRD der Anteil des Staatsverbrauchs am BSP bei jeweiligen Preisen fast ausschließlich auf Kosten des privaten Verbrauchs langfristig gestiegen.

Die These, wonach Nachfrageschübe aus überhöhten Lohnforderungen und -zahlungen resultieren würden, wird an anderer Stelle untersucht werden. Hier sei lediglich darauf hingewiesen, daß aus Tabelle I folgendes hervorgeht: In jeweiligen Preisen gerechnet, hat der Anteil des privaten Verbrauchs am BSP bisher nicht wieder den Stand von 1950 erreicht - und nach den Zahlen mit dem Basisjahr 1962 ist dies nur in einigen Ausnahmen der Fall gewesen.

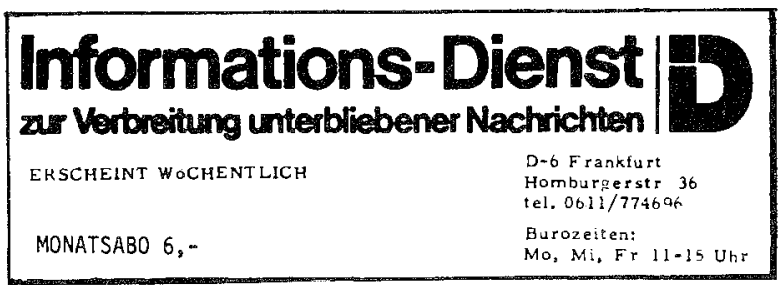

Diese Verantwortung für die Konjunktursteuerung wird im übrigen häufig als Argument für eine reaktionäre Sozialpolitik mißbraucht. So wurde der Bundesregierung im Frühjahr 1973 von der Bundesbank vorgehalten, sie habe durch ,Erstattung der Krankenversicherungskosten an Rentner, Rückzahlung des Konjunkturzuschlages, vorgezogene Rentenanpassung (und) zu stark expandierende öffentliche Ausgaben" die Inflation mitverschuldet. Hier zitiert nach: ,Der Volkswirt“ Nr。19/73 


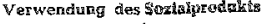

b) Anteilin \&H

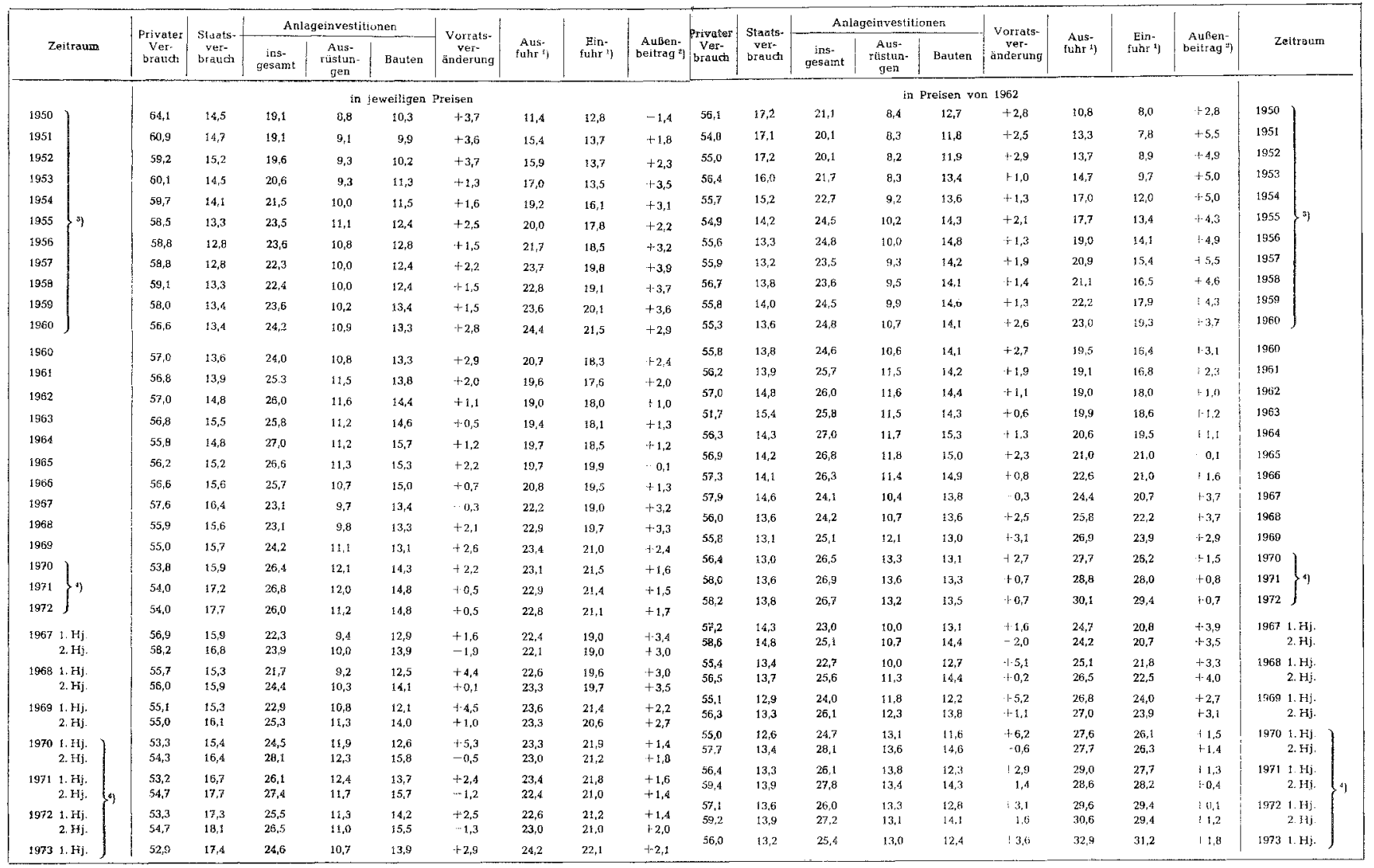

1) Waren-und Dienstleistungsverkehr mit der ïbrigen Wefti. 
Stellt man einen Vergleich zwischen dem Staatsverbrauch in der BRD zu jeweiligen Preisen und zu Preisen von 1962 an, so zeigt sich ein zunächst vielleicht überraschendes Moment: Während er nämlich zu jeweiligen Preisen allmählich angestiegen ist, hat er, auf Preise von 1962 umgerechnet, um einige Prozent abgenommen! Die Ursache hierfür ist darin zu sehen, daß die Preissteigerungen in den Bereichen, in denen der Staat nachfragt, besonders stark ausgefallen sind.

\begin{tabular}{|c|c|c|c|c|c|c|}
\hline Jahr & $\begin{array}{l}\text { Privar- } \\
\text { verbr. }\end{array}$ & $\begin{array}{l}\text { Staats- } \\
\text { verbr. }\end{array}$ & $\begin{array}{l}\text { Investition } \\
\text { Ausrüstig. }\end{array}$ & nan & $\begin{array}{l}\text { Export- } \\
\text { prsise }\end{array}$ & $\begin{array}{l}\text { Preisindex d. } \\
\text { "Brurosozial } \\
\text { produkis" }\end{array}$ \\
\hline 1950 & 100,0 & 100,0 & 900,0 & 100,0 & 100,0 & 100,0 \\
\hline 1951 & 107,8 & 112,8 & 196,0 & 115,2 & 122,3 & 110,8 \\
\hline 1952 & 109,6 & 121,4 & 126,4 & 123.4 & 127.9 & 116,1 \\
\hline 1953 & 108,0 & 124.8 & 123,7 & 120,2 & 126,4 & 115.2 \\
\hline 1954 & 108,5 & 126,7 & 420,6 & 120,4 & 123,9 & 715,0 \\
\hline 1955 & 110.2 & 131.2 & 121,9 & 126.5 & 126.2 & 118.9 \\
\hline 1956 & 112.6 & 133,8 & 125,0 & 129,8 & 131,7 & 121,6 \\
\hline 1957 & 115.5 & 143,6 & 128,5 & 134,6 & 135,1 & 125,8 \\
\hline 1958 & 118,3 & 148,8 & 130,3 & 160,2 & 132.9 & 129,7 \\
\hline 1959 & 119,5 & 199.6 & 129,2 & 147,8 & 1330 & 131.5 \\
\hline $1960^{\circ}$ & 120.7 & 157,6 & 130.8 & 156,5 & 135,7 & 134.7 \\
\hline $1960^{2}$ & 120.6 & 158,1 & 30.9 & 156,6 & 135,8 & 134,8 \\
\hline 1961 & 124,5 & 167.1 & 134,8 & 167.4 & 137,2 & 140,7 \\
\hline 1962 & 128.2 & 173,9 & 139,7 & 180,2 & 138,9 & 146,4 \\
\hline 1963 & 131,7 & 181,0 & 140,6 & 189,4 & 139,9 & 151.0 \\
\hline 1964 & 134,7 & 190.6 & 142,0 & 196,0 & 140.7 & 155.1 \\
\hline 1965 & 139,1 & 2045 & 946,9 & 200,7 & 943,2 & 160,0 \\
\hline 1966 & 144.0 & 218.8 & 150.0 & 201.3 & 146,0 & 168,5 \\
\hline 1967 & 146,2 & 224,3 & 150,4 & 198,6 & 945,4 & 168,2 \\
\hline 1968 & 149.1 & 233,9 & 489,7 & 206,3 & 1440 & 179.8 \\
\hline 1969 & 452,8 & 250,8 & 15.46 & 218.9 & 146.5 & 176,9 \\
\hline 1970 & 155,6 & 274.3 & 16,2 & 254,2 & $150_{s} .8$ & 138,8 \\
\hline 1971 & 167,6 & 305,6 & 172.2 & 278.3 & 153.9 & 204,6 \\
\hline 1972 & 977,3 & 329,7 & 173,8 & 292,3 & 857,8 & $21 \%$ \\
\hline
\end{tabular}

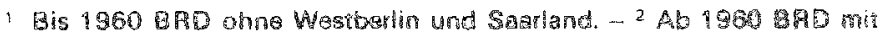
Westberlin und Saarland.

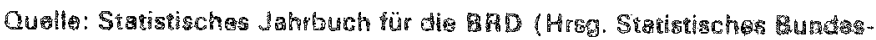

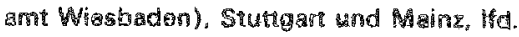


Tabelle II veranschaulicht die enorm unterschiedlichen Preissteigerungsraten in den wichtigsten Bereichen. Die Preise der Waren, die der Staat erwarb, stiegen etwa doppelt so schnell wie jene des Privatverbrauchs oder der Ausrüstungsgüter! Nur der Bausektor, auf dem wiederum der Staat als größter Nachfrager agiert, erreichte annähernd gleiche Preissteigerungen. Auffällig ist ferner, daß in sämtlichen Bereichen auch Jahre mit sinkendem Preisniveau zu verzeichnen sind: Privatverbrauch 1953, Ausrüstungen 1953, 1954, 1959, 1968, Bauten 1953, 1967, Exporte 1953, 1954, 1958, 1967, 1968. Ausgenommen ist dabei nur der staatliche Verbrauch in seiner Gesamtheit. Hier steigen die Preise also nicht nur weitaus am schnellsten, sondern auch ohne jede Unterbrechung. Dabei sollte doch gerade der Staat als außerordentlich potenter Nachfrager einen gewissen dämpfenden Einfluß auf das Preişniveau der von ihm nachgefragten Güter und Dienstleistungen haben.

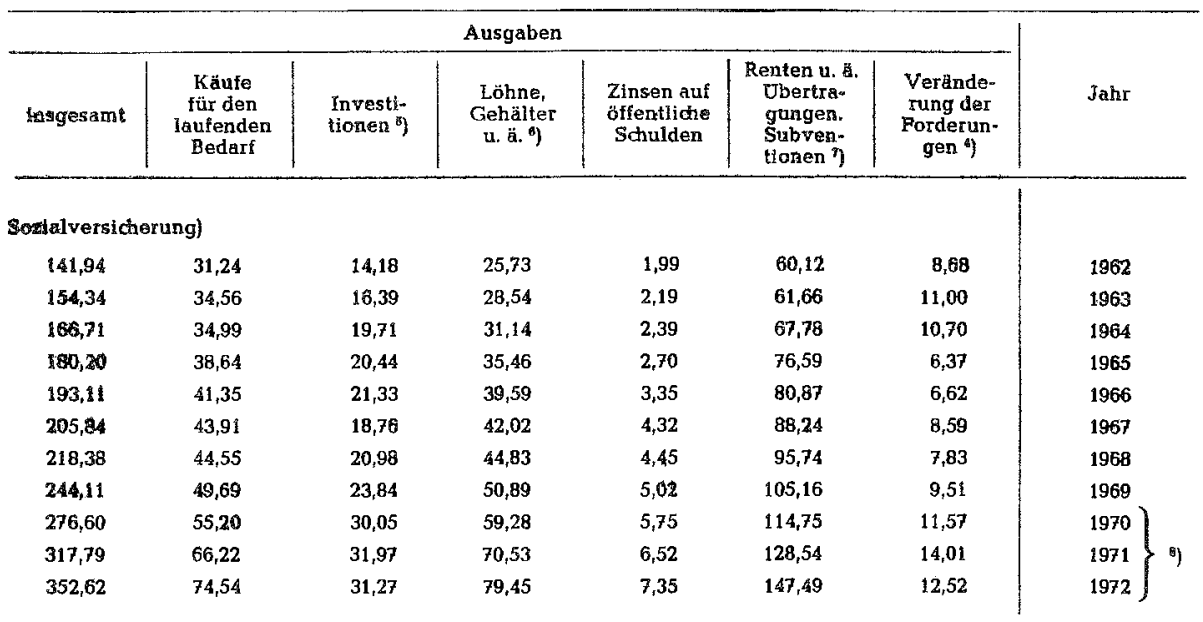


Eine grobe Aufschlïsselung der Staatsausgaben (Tabelle III) zeigt, daß der Posten der Zinslasten prozentual am stärksten gestiegen ist. Dieser Sachverhalt ist ein Symptom der zunehmenden Staatsverschuldung. Es folgt der Anstieg der Lohn- und Gehaltsaufwendungen. Hier macht sich bemerkbar, daß der Staat relativ viel Dienstleistungen, kauft, bei denen keine oder nur unterdurchschnittliche Produktivitätssteige rungen zu verzeichnen sind. Während zwischen 1952 und 1973 die Zahl der im öffentlichen Dienst Beschäftigten von 2,3 Mill. auf 3,3 Mill., also um 43,4\% stieg, kletterten die Personalkosten im gleichen Zeitraum von 9,3 Mrd. DM auf 95,6 Mrd. DM, also um etwa 928\%! (76) Es folgen Aufwendungen für den laufenden Bedarf. Da die Lieferanten des Staates häufig Monopolstellungen innehaben, (Rüstung !), geht man sicher nicht fehl in der Annahme, gerade hier überdurchschnittliche Preissteigerungen finden zu können. Am wenigsten zugenommen haben die Ausgaben für Anlageinvestitionen und Grundstückskäufe, was darauf schließen läßt, daß der Staat sich hier - in realen Größen betrachtet - sehr zurückgehalten hat.

In summa muß nach dem vorliegenden Material der Eindruck entstehen, daß der Staat, d. h. in diesem Falle natürlich der Steuerzahler, von seinen Lieferanten (un-)gehörig und erfolgreich ,zur Kasse gebeten" wird. Oder anders ausgedrückt: Es gelingt den großen Konzernen in zunehmendem Maße, die Ausbeutung der Arbeiterklasse relativ geräuschlos auch über staatliche Aufträge abzuwickeln.

Die Möglichkeit der Geldschöpfung innerhalb des Bankensystems sowie das gegenwärtige Währungssystem schaffen für die Kapitalisten erfahrungsgemäß ausreichend Möglichkeiten, mehr zu investieren, als gespart bzw. akkumuliert worden ist. Sie können dies innerhalb gewisser Grenzen nötigenfalls auch gegen der erklärten Willen der jeweiligen Regierungen. Dies gilt bekanntlich auch für die verschiedenen Gebietskörperschaften des Staates. Während sich die Verschuldung von inländischen Nichtbanken insgesamt innerhalb des deutschen Bankensystems von 1963 gleich 26,84 Mrd. DM auf 1972 gleich 86,41 Mrd. DM erhöht hatte (77), nicht berücksichtigt ist dabei die bedeutende Auslandsverschuldung deutscher Unternehmen), stieg die Kreditverschuldung der öffentlichen Haushalte von Ende März 1950 gleich 1,216 Mrd. DM auf Ende Dezember 1972 gleich 125,23 Mrd. DM (78). Die Staatsverschuldung hat sich hier innerhalb von nur 22 Jahren etwa verhundertfacht!

$\mathrm{Da}$ es den bürgerlichen Regierungen unter gegebenen Verhältnissen kaum möglich ist, die Summe der Investitionen auf ein preissniveau-neutrales Volumen zu begrenzen, wären umfangreiche Umgestaltungen des Banken- und Währungssystems erforderlich, wenn diese Quelle einer möglichen Übernachfrage tatsächlich wirksam gestopft werden sollte. Es muß jedoch angenommen werden, daß eine exakte Kredit-Steuerung von den herrschenden Kreisen keineswegs angestrebt wird. Denn interessant ist in diesem Zusammenhang, daß heute längst nicht mehr davon ge-

76 Siehe, „Der Volkswirt" Nr. $7 / 73$

77 Siehe Sachverständigenrat ,Jahresgutachten“" 1972/73, S. 228

78 Ebd., S. 227 
sprochen wird, daß ein Nachfrage-Sog daraus entstehen könnte, daß die Investitionen über die Ersparnis hinausgingen. Mittlerweile wird anders herum argumentiert: Der Nachfrage-Sog ergibt sich dann, wenn die Ersparnis nicht den Wert der Investitionen erreicht. Während es also zunächst die Investitionen waren, die sich der Höhe der Ersparnis anzupassen hätten, soll es heứe die Ersparnis sein, die sich den Investitionen anzupassen hätte.

Mit dem „,demand-pull ${ }^{\text {s }}$ können gewiß einige Preissteigerungen erklärt werden. Denn gewöhnlich sind die zyklischen Preisanhebungen, die im Zusammenhang mit einem Konjunkturaufschwung stehen und früher während des Abschwunges durch einen deflatorischen Prozeß auch wieder egalisiert wurden, auf entsprechende Konstellationen von Angebot und Nachfrage zurïckzuführen. Doch der Erklärungswert dieser Theorie sinkt rapide, wenn man sie anzuwenden versucht bei der Analyse der permanenten Inflation oder gar der Stagflation. Diese ist ja gerade dadurch gekennzeichnet, daß Nachfrage und Produktion stagnieren bzw. zurückgehen und die Preise dennoch steigen. Für derartige Phänomene hat die ,demand-pull'“-Theorie prima facie keinen Erklärungswert.

\subsubsection{Cost-push}

Der zweite wesentliche, von der Keynes'schen Theorie abgeleitete Ansatz zur Erklärung der Inflation ist der des , cost-push“.

Nach keynesianischer Ansicht ist der Preis der Waren im wesentlichen bestimmt durch bezahlte Arbeit. Entsprechend würden sich Lohnsteigerungen auf die Preise niederschlagen: „Das übliche Verfahren der Preisfestsetzung besteht darin, zu den Gestehungskosten eine prozentuelle Bruttospanne zu schlagen, die so kalkuliert ist, daß sie einen Nettogewinn liefert, den man vernünftigerweise und sicher anvisieren kann" (79) (Hervorhebung R.).

Es ist auffällig, daß der Preis hierbei völlig ohne Verbindung zum Markt, d. h. zum Verhältnis von Angebot und Nachfrage bestimmt wird: Dem Unternehmer sind die Gestehungskosten gegeben - und darauf schlägt er eine ,vernünftige, das soll heißen branchenübliche Spanne. Falls die Löhne und damit die Gestehungskosten (der Kostpreis) steigen, führt das häufig nicht nur zu Preiserhöhungen um den gleichen absoluten Betrag, wodurch die Profitmasse erhalten bliebe, oder um den gleichen Prozentsatz, um den die gesamten Gestehungskosten tatsächlich steigen, wodurch die Profitrate erhalten bliebe. Die Preise werden, wie J. Robinson schreibt, mitunter um den entsprechenden Prozentsatz erhöht, um den ein einzelner Kostenfaktor, nämlich die Löhne gestiegen sind, wodurch sowohl Profitmasse als auch Profitrate steigen. Folgende Zahlenbeispiele sollen den Sachverhalt veranschaulichen: 
Angenommen wird eine Ware, bei der $c=60, v=40, p=40$ ist ( $c=$ konstantes Kapital, $v=$ variables Kapital, $p=$ Profit). Der Preis beträgt demnach 140 .

I $60 \mathrm{c}+40 \mathrm{v}+40 \mathrm{p}=140$

Es handelt sich also um eine Profitmasse von 40 und eine Profitrate von $\frac{40 \times 100}{60+40}=40 \%$. Steigt nun der Lohn von 40 Einheiten auf 60 , also um $50 \%$ oder 20 Einheiten, und wird der Preis um eben diese 20 Einheiten erhöht, II $60 c+60 v+40 p=160$, so bleibt die Profitmasse von 40 erhalten, doch die Profitrate würde von $40 \%$ auf $\frac{100 \times 40}{120}=331 / 3 \%$ absinken.

Diese Profitratensenkung würde verhindert, wenn der Stück-Gewinn mit dem gleichen Prozentsatz stiege, mit dem auch die Stiick-Kosten angewachsen sind, also um $20 \%$, d. h. von 40 auf 48 . Eine Preissteigerung auf 168 wäre also profitratenneutral.

III $60 \mathrm{c}+60 \mathrm{v}+48 \mathrm{p}=168$

Die Profitrate beträgt hier wie in Fall I: $\frac{100 \times 48}{120}=40 \%$

Steigt aber der Preis um den gleichen Prozentsatz wie der Nominallohn, also um $50 \%$, d. h. um 70 i.c. auf 210, denn ergibt sich folgende Konstellation:

IV $60 \mathrm{c}+60 \mathrm{v}+90 \mathrm{p}=210$.

Wenn der Preis um 70 Einheiten steigt, wovon nur 20 durch Kostensteigerungen begründet sind, dann erhöht sich die Profitmasse um 50 auf insgesamt 90 , die Profitrate steigt von $40 \%$ auf $\frac{90}{120}=75 \%$.

Von einem ,Zwang ${ }^{6}$, die Preise annähernd proportional den Lohnsteigerungen zu erhöhen, kann daher nicht gesprochen werden. Wenn in der Praxis dennoch eine solche Preispolitik zu beobachten ist, dann muß daraus geschlossen werden, daß entweder die allgemeine Profitrate temporär steigt, oder daß es der entsprechenden Branche bzw. dem entsprechenden Betrieb gelingt, einen höheren Anteil des gesellschaftlichen Gesamtprofits an sich zu ziehen.

Anhand eines weiteren Zahlenbeispiels läßt sich nachvollziehen, warum gleiche Lohnsteigerungsraten bei Kapitalien unterschiedlicher organischer $\mathrm{Zu}$ sammensetzung in ungleichen Maße auf den Kostpreis (k) einwirken!

I $180 \mathrm{c}+20 \mathrm{v}=200 \mathrm{k}$

Unterstellt man eine Lohnerhöhung von $50 \%$, also von 20 auf 30, so erhöht sich ceteris paribus der Kostpreis auf:

II $180 \mathrm{c}+30 \mathrm{v}=210 \mathrm{k}$,

was eine Steigerungsrate von $\frac{10 \times 100}{200}=5 \%$ bedeutet. 
sei ein Kapital niedriger organischer Zusammensetzung:

I $80 \mathrm{c}+120 \mathrm{v}=200 \mathrm{k}$

Steigt der Lohn auch hier um $50 \%$, so bedeutet dies in absoluten Beträgen eine Steigerung von 120 auf 180 Einheiten.

II $80 \mathrm{c}+180 \mathrm{v}=260 \mathrm{k}$,

d. h. der Kostpreis erhöht sich um 60 oder $\frac{60 \times 100}{200}=30 \%$, anstelle von $5 \%$ im Fall A.

Daran ist zu ersehen, warum sich Lohnerhöhungen in Branchen mit relativ niedriger organischer Zusammensetzung, also mit hohem Lohnanteil (wie Bau, Textilien, Dienstleistungen) stärker auf den Kostpreis auswirken als in Branchen höherer organischer Zusammensetzung (wie Chemie und Elektrotechnik).

Derartige „short-run“-Analysen zeigen allerdings noch nicht die ganze Wahrheit. Der eben angestellte Vergleich der Wirkungen von Lohnerhöhungen bei Kapitalien unterschiedlicher organischer Zusammensetzung müßte berücksichtigen, daß normalerweise auch kostensenkende Produktivitätssteigerungen erzielt werden und zwar in den einzelnen Branchen unterschiedlich schnell - was u. a. bestimmt ist vom Stand der Kapitalakkumulation, vom jeweils erreichten Stand der Produktivität sowie von technischen und natürlichen Bedingungen. Es zeugt daher von einer totalen Befangenheit in der Welt der Erscheinungen, wenn das ,Handelsblatt" die Schuld an der Inflation den Branchen mit den höchsten Preissteigerungen anlastet:

„,Wer sind die Preistreiber in der Bundesrepublik? Die Industrie ist es nicht; ihre Preise stiegen seit 1962 um ein knappes Viertel. Bei der Fahndung nach den wirklichen Preistreibern stößt man sehr schnell auf die Sparten Dienstleistungen, Verkehr und Mieten. Auffallend ist auch, $\mathrm{da} ß$ vielfach jene Preise besonders kräftig anzogen, bei denen der Staat direkt oder indirekt die Finger im Spiel hat" (80).

Quelle: Condor

hier zitiert nach Handelsblatt vom 15.10.1973

Wer sind die Preistreiber?

Preisanstieg von 1962 bis Mitte 1973

Lebenshaltung insgesamt $48 \%$

darunter:

Einzelhandel insgesamt

Strom, Gas

Verzehr in Gaststätten

Kino, Theater, Sport

$91 \%$

Mieten

$94 \%$

Nahverkehr

$97 \%$

Kfz-Reparaturen 
Industrielle Erzeugnisse insgesamt

Chemie

Elektrotechnik

Eisen und Stahl

$\mathrm{Kfz}$

Ernährungsindustrie

Textilien

Allein mit der Feststellung der Tatsache, daß die großen Konzerne relativ geringe Preissteigerungen aufweisen, ist ihre Rolle in der permanenten Inflation sicherlich nicht korrekt beschrieben. Vielmehr muß gleichzeitig das Faktum berücksichtigt werden, daß in diesen Betrieben normalerweise auch die größten Produktivitätsfortschritte erzielt wurden. Wenn das allgemeine Preisniveau fallen oder zumindest stabil bleiben soll, dann müssen vor allem die Preise der Waren aus diesen Bereichen sinken. Weil die Großkonzerne jedoch die Preiskonkurrenz weitgehend zu eliminieren vermochten, richten sich ihre nominellen Preise weniger nach den augenblicklichen Marktbedingungen als nach der innerbetrieblichen Kalkulation. D. h. sie werden produktivitätssteigerungen nur selten in Preissenkungen weitergeben.

Sinken aber die Preise ihrer Waren nicht, obwohl sie relativ im Wert gefallen sind, so sind die Bereiche mit geringeren Produktivitätsfortschritten gezwungen, ihre Preise entsprechend zu erhöhen, sofern sie ihren relativen Anteil am Gesamtprofit nicht schmälern lassen wollen (81). Wenn diese Schlußfolgerung korrekt ist, dann kann der Ansicht des ,Handelsblattes“ entgegengehalten werden, daß gerade die „Industrie“ die Inflation dadurch verschulde, daß sich Produktivitätssteigerungen nicht in Preissenkungen niederschlagen. Der cost-push wird häufig als Symptom dafür angesehen, daß die Arbeiterklasse ihren Anteil am BSP erhöht und ist daher nach Wallich von einem demand-pull auf folgende Weise zu unterscheiden:

„In einfachen Fällen kann man den vorhandenen Typ der Inflation daran erkennen, wie sich die Anteile der Sozialpartner am Sozialprodukt verändern, bzw., was fast das gleiche ist, wie die Gewinnspannen der Unternehmer sich verhalten. Nachfrageinflation erhöht die Gewinnspannen und den Anteil der Unternehmer am Bruttosozialprodukt, Kostendruckinfaltion erhöht den Anteil der Arbeitnehmer und reduziert die Gewinnspanne" (82).

Kompliziert wird die Angelegenheit dadurch, daß z. B. hohe Lohnsteigerungen erst eine Reaktion auf erhöhte Preise darstellen können. Außerdem schließt Wallich nicht aus, daß beide Inflationstypen gleichzeitig wirksam sind. Dennoch glaubt er, bestimmte Phasen der Inflation in den USA exakt ettikettieren zu können, deshalb: „Kann man - wie heute in den USA - eine klare Kostendruckinflation beobachten, in der es den Unternehmern doch gelingt, die Preise schnell genug zu erhöhen, um

81 Zur Stiitzung unserer These müßte allerdings noch aufgezeigt werden, wie sich dieser „Zwang" an der Oberfläche der Erscheinungen konkret darstellt.

82 H. C. Wallich "Inflation und Wachstum" in: "Wirtschaftswachstum durch Geldwertschwund? ", Verlag Ges. Recht und Wirtschaft, Heidelberg 1971, S. 15 
die Gewinne zu schützen oder sogar zu steigern“(83). Wallich spricht also selbst dann von einem „Kostendruck", wenn es den Kapitalisten gelingt, ihre Gewinne „Sogar" noch zu steigern!

Nach Wallich's Auffassung ist normalerweise im Konjunkturverlauf ein Wechsel zwischen den Inflationstypen zu beobachten:

„Im Verlaufe eines Konjunkturzyklus ist der wahrscheinlichste Moment für den Beginn einer Nachfrageinflation das Erreichen der Vollbeschäftigung. Da die Preise im allgemeinen flexibler sind als Löhne, kann man in diesem Moment eine übermäßige Nachfrage, sei es infolge Kreditexpansion oder aus anderen Gründen, die Spanne zwischen Löhnen und Preisen erweitern. Die Gewinnzargen würden dann steigen. Mehrere Gründe jedoch lassen eine baldige Steigerung der jährlichen Lohnerhöhung erwarten. Seitens der Unternehmer erfordert die wachsende Knappheit an Arbeitskräften höhere Löhne und Gehälter, was durch erhöhte Gewinne auch möglich ist. Auf seiten der Arbeit wird ebenfalls die Vollbeschäftigung und außerdem die Erhöhung der Lebenshaltungskosten wirksam" (84).

Wallich selbst scheint Zweifel an dem Wert seiner Differenzierung gehabt zu haben, denn er schreibt weiter:

„Man kann natürlich behaupten, daß die Nachfrageinflation der ersten Periode die Kosteninflation der zweiten Periode, verschuldet hat. Man kann weiter behaupten, daß die gesamte Inflation als eine einzige Periode zu sehen ist, so daß die ,Schuld vermutlich diejenigen trifft, die die Nachfrageinflation auslösten" (85).

Logisch kann der Kostendruck von jeder Kosten-Art ausgehen - also auch von Rohstoffen, Vorprodukten oder Anlagen. Daher begründet eine Reihe von Ökonomen die Inflation mit der Preispolitik von Oligopolen und Monopolen. G. Haberler wehrt sich jedoch entscheiden gegen diesen Ansatz:

„Der Wunsch nach Unparteilichkeit in der Beurteilung verschiedener sozialer Gruppen trägt zweifellos zu der weit verbreiteten Gewohnheit bei, neben den Gewerkschaften auch den Unternehmer monopolen die Verantwortung für die Inflation zuzuschreiben.

Ich möchte jeden moralischen oder ethischen Unterton vermeiden, doch erscheint mir ein grundlegender Unterschied zwischen der Wirkung der industriellen Monopole und Oligepole einerseits und derjenigen der Gewerkschaften andererseits auf den Verlauf der Inflation zu bestehen" (86).

\section{Der angebliche Unterschied besteht nun in folgendem:}

${ }_{9}$ Ich gebe ohne weiteres zu, daß Unternehmungsmonopole (insoweit sie tatsächlich wirken und nicht erfolgreich beschränkt werden) die Preise auf einem höheren Niveau halten als dem, das unter freier Konkurrenz bestünde. Es besteht aber kein Grund zu der Annahme, daß derartige Monopolpreise immer höher hinaufgetrieben würden. Anders ausgedrückt würde die Einführung von zahlreichen Monopolen dort, wo früher Konkurrenz geherrscht hat, zu Preiserhöhungen

83 Ebd., S. 15

84 Ebd., S. 15

85 Ebd., S. 16

86 G. Haberler ,Geldinflation, Nachfrageinflation, Kosteninflation“", in: „Stabile Preise in wachsender Wirtschaft" ${ }^{\text {"s }}$, J. C. B. Mohr, Tübingen 1960, S. 90 
fïhren und zu einem dauernden Druck auf Preiserhöhung... Anderseits erscheint es als selbstverständlich, daßs starke Gewerkschaften jedes oder jedes zweite Jahr wesentliche Lohnerhöhungen durchzusetzen und dauernd das Niveau der allgemeinen Steigerung der Produktion per Arbeitsstunde zu überschreiten suchen, ganz besonders in Industrien, in denen die Produktivität schneller wächst als anderswo" (87).

G. Haberler verfällt offenbar dem Irrtum, die relative Preisstabilität in den monopolisierten Sektoren für einen Beitrag zur allgemeinen Preisniveau-Stabilität zu halten. Daß davon nicht die Rede sein kann, ist bereits gezeigt worden. Wenn Haberler anschließend die Gewerkschaften als preistreibendes Moment hinstellt, dann spricht er letztiich nur den politischen Charakter der cost-push-Theorie unumwunden aus: Jede Lohnerhöhung bedeutet eine temporäre Kostensteigerung. Die Unternehmer können daher stets argumentieren, daß sie Lohnerhöhungen auf ihre Preise abwälzen müßten, sofern sie ihre Profite nicht schmälern lassen wollten.

In seinem Jahresgutachten 1973 rechnete der Sachverständigenrat jedoch vor, daß die verfügbaren Reallohn-Erhöhungen mit $3 \%$ nicht einmal den durch Produktivitätssteigerungen vorgegebenen Spielraum von $6,8 \%$ auszuschöpfen vermochten (88). Dennoch war 1973 in der BRD eine Inflationsrate von $7 \%$ zu verzeich. nen!

\subsection{Der monetaristische Ansatz}

\subsubsection{Chicagoer Schule}

Die offensichtliche Ohnmacht der an Keynes orientierten Wirtschaftspolitik, das Inflationsproblem zu bewältigen, hat vor allem in den USA seit Beginn der Präsidentenschaft Nixon's zu einer erneuten Renaissance quantitätstheoretischer Ideen geführt.

Als geistiges Zentrum der Neo-Quantitätstheoretiker, neuerdings meist Monetaristen genannt, wird die Universität Chicago angesehen. Die „Chicagoer Schule“ weist bestimmte Analogien zur ORDO-Liberalen ,Freiburger Schule" auf; ihre Verfechter sind, wie die ORDO-Liberalen in der BRD, verbal ideologische Vertreter des Mittelstandes, wiewohl sie faktisch das Großkapital stützen.

\subsubsection{Stabilität des privaten Sektor}

Wie einst Say, so unterstellen die Monetaristen der kapitalistischen Wirtschaft auch heute noch, trotz Weltwirtschaftskrise und sich ständig wiederholenden Konjunkturzyklen in allen kapitalistischen Staaten, eine Tendenz zum natürlichen Gleichgewicht bei Vollbeschäftigung. Die große Depression wird noch als eklatanter Beweis

$87 \quad$ Ebd., S. 92

88 Siehe Sachverständigenrat ,Jahresgutachten“" 1973/74, S. 92, Ziffer 123 
für die Richtigkeit dieser These angesehen, da Friedman entdeckte, daß den Einkommens- und Beschäftigungs-Rückschlägen eine Reduktion der Geldmenge um $33 \%$ in der Zeit von Oktober 1929 bis April 1939 vorausgegangen war.

Der von Marx geführte Nachweis, daß die Eigendynamik des kapitalistischen Systems immer wieder zu Krisen führe, gilt bei den Monetaristen ebenso als überwunden wie die Keynes'sche Interpretation der Konjunkturzyklen. Karl Brunner schreibt,

„daß die Dynamik des privaten Sektors im Grunde sehr stabil ist. Im besonderen wird verneint, daß die Dynamik den Hauptteil der beobachteten Schwankungen erklären kann. Die monetaristische Position verneint somit die Behauptung, der vom privaten Sektor getragene dynamische Prozeß sei in wichtigen Bereichen instabil oder die Antizipationen der Geschäftswelt unterlägen unabhängig von großen politischen Ereignissen oder politischen Maßnahmen großen Schwankungen. Der Sektor absorbiert Schocks und formt sie in eine stabilisierende Bewegung $u^{\prime \prime}(89)$.

Als Voraussetzungen für die Selbstregulierung der kapitalistischen Wirtschaft werden genannt: Freie Konkurrenz - deshalb die vage erhobene Forderung der Auflösung bestehender und Verhinderung neuer Monopolpositionen - und eine gerechte Einkommens- und Vermögensverteilung - was immer darunter im einzelnen $\mathrm{zu}$ verstehen sein mag.

\subsubsection{Dominanz monetärer Impulse}

Nach Ansicht der Quantitätstheoretiker spielt das Geld im Wirtschaftsprozeß die dominierende Rolle. M. Friedman sieht sich in dieser Ansicht bestätigt durch seine gemeinsam mit Anna Schwartz durchgeführte Analyse der Geldgeschichte der USA von $1867-1960(90)$.

Darin war er zu der Erkenntnis gelangt, daß bedeutenden Änderungen des allgemeinen Preisniveaus fast immer entsprechende Variationen der Geldmenge vorausgegangen waren. Diese zeitliche Aufeinanderfolge wird als Beweis der Behauptung ausgelegt, daß die Geldmenge (M) tatsächlich die aktive Rolle spiele und das Preisniveau (P) sowie der Umfang der zirkulierenden Warenmasse (T) bei angeblich nahezu konstanter Umlaufgeschwindigkeit des Geldes (V) nur passiv reagiere.

Für J. Robinson besteht der Kern der Quantitätstheorie denn auch lediglich darin, daß sie die tautologische Quantitätsgleichung M.V = P.T , von links nach rechts statt von rechts nach links" liest (91). Inzwischen wird allerdings die Möglichkeit der Kausalität ,,von rechts nach links" nicht mehr völlig bestritten, wenngleich $\mathrm{K}$. Brunner ihre Bedeutung stark herunterspielt:

89 K. Brunner ,Die ,monetaristische Revolution" der Geldtheorie", in: „Der neue Monetarismus“, Hrsg. P. Kalmbach, Nymphenburger Verlagshandlung, München 1973, S. 75

90 M. Friedman, Anna Schwartz „A Monetary History of the United States, 1867-1960“, Princeton 1963

91 J. Robinson „Quantitätstheorien: Alt und Neu“, in: „Der neue Monetarismus“, S. 139 
„Immerhin, Wirkungen der umgekehrten Kausalität treten auf, und zwar meistens über den Termineinlagenquotienten und den Bargeldquotienten. Aber weit mehr als $50 \%$ der während der Nachkriegsperiode in den Vereinigten Staaten beobachteten Variationen der monatlichen Änderungen können durch die laufenden und die um einen Monat verzögerten Änderungen der Schatzamteinlagen bei Geschäftsbanken erklärt werden" (92).

Man erwartet volle Reagibilität der Preise und Löhne bei Nachfrage-Änderungen und eine exakte Steuerung der Kassehaitung nach ihrem realen Wert, mit anderen Worten, man unterstellt eine stabile reale Geldnachfragefunktion. Nach Friedman gibt es eine feste, wenn auch nicht präzise Beziehung zwischen der Wachstumsrate der Geldmenge und der Wachstumsrate des nominellen Einkommens: yn $=f(G)$. Die Beziehung sei deshalb nicht präzise, weil zum einen Anderungen in dèr Kassehaltung (es, wird angenommen, daß bei steigendem Realeinkommen die Kassehaitung zunimmt) und zum anderen Änderungen in der Präferenzstruktur geben kann daher ist nicht die absolute, sondern die Geldmenge pro Produkteinheit relevant.

\subsubsection{Transmissionsmechanismus}

Bezüglich der Frage nach der Transmission autonomer monetärer Impulse auf den realen Bereich sieht J. Robinson ein ,,mystisches Element ${ }^{\text {“6 }}$ in der Quantitätstheorie: „Das bloße Vorhandensein einer bestimmten Geldmenge fördert irgendwie die Ausgaben“ (93). Denn beispielsweise Friedman's Darstellung des Transmissionsmechanismus unterstellt, daß eine Erhohung der Geldmenge direkt und quasi automatisch zu einer Ausweitung der Nachfrage fuhre, indem die einzelnen Wirtschaftssubjekte versuchen, ihre überhöhte Kassehaltung durch zusätzliche Käufe auf ein gewünschtes Maß zu reduzieren:

„One individual can reduce or increase his cash balance only because another individual or several others are induced to increase or reduce theirs; that is, to do the opposite of waht he does. If individuals as a whole were to try to reduce the number of dollars they held, they could not all do so, they would simply be playing a game of musical chairs. In trying to do no, however, they would raise the flow of expenditures and of money income since each would be trying to spend more than he receives; in the process adding to someone else's receipts, and, reciprocally, finding his own higher than anticipated because of the attempt by still others to spend more than they receive. In the process, prices would tend to rise, which would reduce the real value of cash balances; that is, the quantity of goods and services that the cash balances will buy.

While individuals are thus frustrated in their attempt to reduce the number of dollars they hold, they succeed in achieving an equivalent change in their position, for the rise in money income and in prices reduces the ration of these balances to their income and also the real value of these balances. The process will continue until this ration and this real value in accord with their desires" (94).

K. Brunner, a. a. O., S. 90

93 J. Robinson, ebd., S. 138

94 M. Friedman „Monetary Theory and Policy“, in: „,Inflation“, Hrsg. R. J. Ball und Peter Doyle, Penguin Books Ltd, Harmondeworth, 1970, S. 141 
Friedman kann hierfür allerdings weder vermittelnde Schritte noch Motivationen angeben.

Dieser Mangel ist inzwischen formal, aber keineswegs überzeugend behoben. Man behauptet nun folgenden Ablauf:

,Gehen wir davon aus, daf die Geldmenge erhöht wird, indem die Zentralbank Offenmarktkäufe tätigt. Gleichgültig wie die institutionelle Ausgestaltung der Offenmarktoperation ist, wird das zu einer Erhöhung der Kurse bei den betroffenen Papieren führen; oder anders herum gesehen: nur eine Erhöhung der Kurse wird die Halter dieser Papiere veranlassen, sie zu verkaufen. Mit der Erhöhung der Kurse verbunden ist eine Senkung ihrer Rendite. (...) Der Kauf der Offenmarktpapiere ergibt kein neues Gleichgewicht. Zwar wird angesichts der Kurssteigerung der Verkauf dieser Papiere und insofern auch die damit verbundene höhere Kassenhaltung gewünscht, aber doch nur in einem vorläufigen Sinne. Was nun einsetzen wird ist das, was man als einen Substitutionseffekt bezeichnen kann: ein Umarrangement des Portefeuilles. Da die Renditen der nicht am offenen Markt gehandelten Papiere von den Offenmarktoperationen nicht beeinflußt werden, werden die Vermögensbesitzer versuchen, ihre jetzt zu umfangreichen Kassenbestände abzubauen, indem sie sich diesen Papieren zuwenden. Das wird wiederum deren Kurs in die Höhe treiben, denn der Bestand solcher Papiere ist in einem bestimmten Zeitpunkt begrenzt. Für die Anpassung der Vermögensstruktur ist jedoch auch damit noch kein Ende erreicht. Die Senkung der Wertpapiererträge - ein Vorgang, von dem angesichts der Substitutionsbeziehungen keine Art von Wertpapier ausgeschlossen ist - bleibt nicht ohne Einfluß auf die Preise des Realvermögens. Da sich die Nachfrage nach Realvermögen erhöht, ist hier mit einer Preiserhöhung zu rechnen. Das ist der Punkt, wo auf verschiedene Weise die Übertragung des monetären Impulses auf den realen Sektor einsetzt" (95).

Durch einen monetären Impuls verändern sich also zunächst die relativen Preise der verschiedenen Wertpapiere, des fiktiven Kapitals. Die Halter dieser Papiere reagieren angeblich sofort und vor allem uneingeschränkt $-\mathbf{u}$. a. auch durch Erwerb von realem Kapital. Hierdurch werde die Nachfrage und damit das Preisniveau in Sektor I steigen, was seinerseits den Konsum und damit die Produktion von Sektor II erhöhen werde. Am entscheidenen Punkt des Übergangs monetären Impulses auf das reale Kapital und den Konsum kommt auch dieser Erklärungsansatz über einen Versicherungs-Charakter nicht hinaus. M. Friedman und David Meiselman haben nun eine neuere Untersuchung vorgelegt, welche

„,anhand umfangreicher statistischer Tests amerikanischer Daten seit 1897 (zeigt), daß mit Ausnahme der dreißiger Jahre die Geldmenge stets ein besserer Indikator für den Konsum gewesen ist als die autonomen Ausgaben. Diese Ergebnisse werfen ein bedeutsames theoretisches Problem auf. Denn sie implizieren, daß jede Veränderung der Geldmenge, auch wenn sie keinen Vermögenseffekt hat, nichtsdestoweniger den Konsum beeinfluft. Die Schwierigkeit, diesen Zusammenhang zu verstehen, war der Hauptgrund für die Unzufriedenheit von Keynes, Wicksell und anderen Einkommenstheoretikern mit der Quantitätstheorie. Sie stellt auch heute noch den Kern des Widerstandes gegen die Quantitätstheorie dar" (96).

Es ist sehr fraglich, ob ein - erwartungsgemäß zeitlich begrenztes - Absinken der Wertpapiererträge genïgend Kapitalisten dazu veranlassen kann, Realkapital zu er-

H. G. Johnson, a. a. O., S. 51 
werben, zumal dessen zukünftiger individueller Ertrag gar nicht exakt vorherbestimmt werden kann.

Zudem bleibt in dieser Theorie sehr unbestimmt, ob eine Geldmengenausweitung hauptsächlich den Produktionsumfang ausdehnt oder vornehmlich das Preisniveau erhöht. „Auf kurze Sicht", so Friedman, ,die allerdings fünf oder gar zehn Jahre betragen mag, (!), beriihren monetäre Änderungen hauptsächlich den Output. In Jahrzehnten betrachtet, beeinflußt die monetäre Wachstumsrate vor allem die Preise" (97).

Im Gegensatz zu Keynesianern (P. Samuelson: „Eine milde Inflation schmiert die Räder der Industrie ${ }^{66}(98)$ ) erhoffen sich Monetaristen von permanenten Preissteigerungen also keine langfristige Stimulans für das BSP, es sei denn, es handele sich um einen sich laufend beschleunigenden Prozeß:

„Eine voraussehbare Inflation ist in keiner Weise dem Wachstum förderlich, weil sich jeder darauf einstellen kann. Wenn die Preise jährlich um 3 Prozent steigen und alle Leute wissen, daß sie um 3 Prozent steigen werden, dann ist auch der Zins entsprechend höher. Auch die Löhne, die dann einer Gleitklausel unterliegen werden, steigen mindestens um 3 Prozent - kurzum, man paßst sich an, und all das wird dem Wachstum in keiner Weise förderlich sein.

Deshalb ist die einzige Art von Inflation, die vielleicht zu einem Anschein von Wachstum beitragen könnte, eine Inflation, die schneller als erwartet abläuft. Dann kann man die Leute eine Zeitlang überlisten. Man kann die Arbeiter glauben machen, ihre Löhne seien höher als sie es in Wirklichkeit sind, und so kann man die Leute dazu bringen, mehr zu arbeiten, als sie eigentlich wollen. Aber das kann man auf die Dauer nur schaffen, wenn man von 2 Prozent Preissteigerung übergeht auf 5 Prozent, auf 8 Prozent, auf 15 Prozent. Aber das kann man nicht unbegrenzt tun“ (99).

Friedman ist insofern zuzustimmen, als vor allem lohnintensive Branchen an der Inflation wenig profitieren würden, falls es den Arbeitern tatsächlich gelänge, die zukünftige Preissteigerungsrate in den Lohnkämpfen voll zu antizipieren. Doch bei einem sich beschleunigenden Inflationsprozeß ist das in der Realität nicht immer möglich. Zudem gibt es eine Reihe von sozialen Gruppen mit fixierten Einkommen, denen keine Kampfmittel zur Durchsetzung der Antizipation von Verteuerungen der Lebenshaltung zur Verfügung stehen. Zumindest auf deren Schultern würde eine ansonsten von breiten Schichten antizipierte Inflation ausgetragen werden. Der Wert ihrer Einbußen an realen Einkommen würde in einem solchen Fall von anderen Gruppen angeeignet werden - was zwar eine partielle Umverteilung, aber keine Ausweitung des BSP bedeutete.

97 M. Friedman „Die Gegenrevolution in der Geldtheorie“, in: „Der neue Monetarismus“

98 P. A. Samuelson, a. a. O., Bd. I, S. 339

99 M. Friedman, in: ,Die Zeit“ vom 9.5.1969 
Auf Grund ihrer Aussage, daß die Geldmenge von entscheidender Bedeutung für den Wirtschaftsprozeß sei, wäre zu erwarten, daß Monetaristen die Geldpolitik als wichtigstes Instrument staatlicher Wirtschaftslenkung propagieren. Stattdessen erheben sie aber die Forderung, der Staat solle sich jeglicher Intervention enthalten, weil sie ,glauben, daß es Beweise dafür gibt, daß die Versuche von Regierungen, sich in die Wirtschaft einzumischen, weitgehend erfolglos blieben. Eine solche Einmischung hat eher Probleme geschaffen (...) Daß wir unstabile Verhältnisse hatten, liegt teilweise daran, daß die Regierungen Instabilität geschaffen hat" (100). Die ,bad King-John-Theorie" lautet also: nicht das kapitalistische Wirtschaftssystem ist in sich instabil, sondern all die Regierungen in sämtlichen kapitalistischen Staaten, die periodische Krisen des Systems erlebten und noch heute miterleben müssen, tragen in relativ gleichen Zeitabständen diese Instabilität erst durch eigene Unzulänglichkeit von außen in den Wirtschaftsprozeß hinein!

$\mathrm{Zu}$ Recht sehen die Monetaristen in der Wahl geeigneter Konjunkturindikatoren eines der ungelösten Probleme kapitalistischer Wirtschaftssteuerung. Ein solcher Indikator hätte nach ihrer Auffassung die Aufgabe, präzise und unverzüglich anzuzeigen, welcher Einfluß jeweils vom Geldsektor auf den realen Bereich ausgeht.

Die von Keynesianern bevorzugten Konjunkturindikatoren Zinsniveau und Bankenliquidität lehnen Monetaristen ab, nicht ohne Grund. Denn beispielsweise just in der Geburtsstunde der „vulgären“ Quantitätstheorie, als die amerikanischen Edelmetalle die Geldmenge in Europa aufblähten, stieg hier der Zinsfuß! Deshalb wird das Geldvolumen bzw. die sog. monetary base (Zentralbankgeld) als Indikator vorgeschlagen.

Damit ergeben sich jedoch zwei neue Probleme. Zum einen ist es nahezu unmöglich, eine vollkommen befriedigende Abgrenzung dessen zu finden, was unter Geld $\mathrm{zu}$ verstehen wäre. Die Tatsache, daß die Bundesbank bereits mehrmals ihre diesbezüglichen Definitionen geändert hat, ist ein Symptom dieser Schwierigkeit. H. G. Johnson unterscheidet vier Hauptrichtungen der Geld-Definition:

„Am einen Ende der Skala stehen dabei jene Theoretiker, die das Hauptunterscheidungskriterium des Geldes weiterhin in dessen Tauschmittelfunktion sehen und es als Währungsgeld zuzüglich der berichtigten Sichtdepositen definieren. (.) Ihnen am nächsten kommen die Quantitätstheoretiker der Chikago-Schule, die die Geldfunktion etwas allgemeiner als temporäre ,D Durchgangsstation" der Kaufkraft auffassen. Für ihre empirischen Untersuchungen zählen sie zum Geld das Währungsgeld sowie sämtliche Bankdepositen:. . Beiden Richtungen liegt die Ansicht zugrunde, daß es eine stabile Geldnachfrage - d. h. eine stabile Funktion der Umlaufgeschwindigkeit des Geldes - gibt, .. Eine dritte Richtung, .. umfaßt alle jene Theoretiker, die von der Ähnlichkeit zwischen Geld und anderen monetisierbaren Vermögensobjekten bzw. Methoden der Finanzierung von Güterkäufen derart überzeugt (sind), daß sie das herkömmliche Geldkonzept zugunsten eines wesentlich breiteren Finanzkonzepts .. ablehnen. ... Die eigentliche Auseinandersetzung der letzten Jahre ist jedoch ... von einer vierten Schule bestimmt gewesen.

Ebd. 
Diese Schule beschäftigte sich vor allem mit den Rückwirkungen des umfangreichen Bestands an liquiden Vermögensobjekten, die in enger Substitutionsbeziehung zum Geld stehen, auf die Umlaufgeschwindigkeit des Geldes ${ }^{66}(101)$.

Zum anderen ist die monetaristische Behauptung sehr umstritten, daß der Geldangebotsmultiplikator, d. h. die Umlaufgeschwindigkeit des Geldes, relativ konstant sei (dies wurde vor allem bis in die dreißiger Jahre angenommen) und eher der Bewegung des Geldvolumens folge denn sie konterkariere. So schreibt M. Friedman:

„Als die Geldmenge in den Vereinigten Staaten von 1929 bis 1933 um ein Drittel sank, ging auch die Umlaufgeschwindigkeit zurück. Wenn die Geldmenge schnell ansteigt, so nimmt auch die Umlaufgeschwindigkeit in fast jedem Land schnell zu“ (102).

J. Siebke und M. Willms führten eine entsprechende Untersuchung der Entwicklung des Geldangebotes in der BRD für den Zeitraum von 1958 bis 1968 durch. Sie kamen dabei zu folgendem, der monetaristischen Theorie widersprechenden Ergebnis:

\section{Das Geldangebot in der Bundesrepublik Deutschland}

Zeitliche Entwicklung von Geldmenge, Geldbasis und Multiplikator I958 I bis I968 II

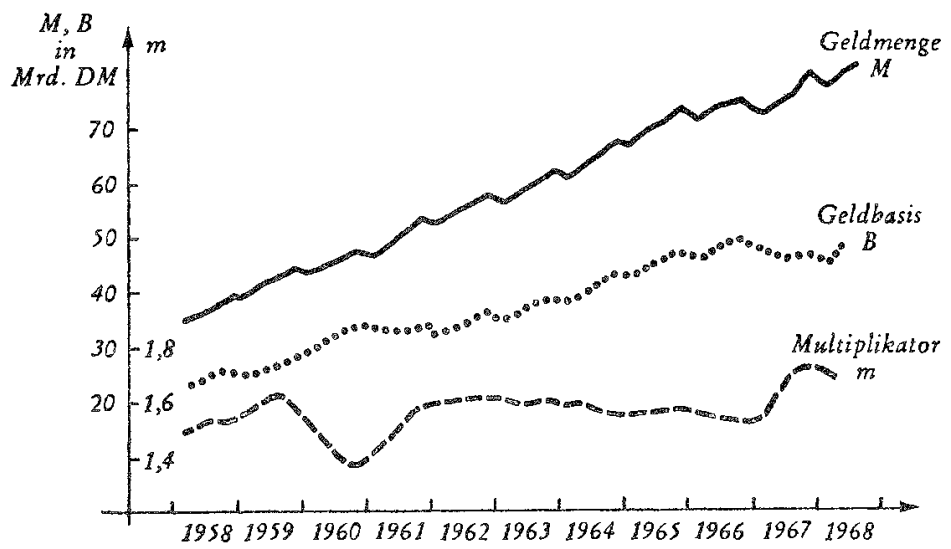

Figur 1

101 H. G. Johnson, a. a. O., S. 45

102 M. Fried man ${ }_{9}$ Der neue Monetarismus" ${ }^{6}$, S. 58 


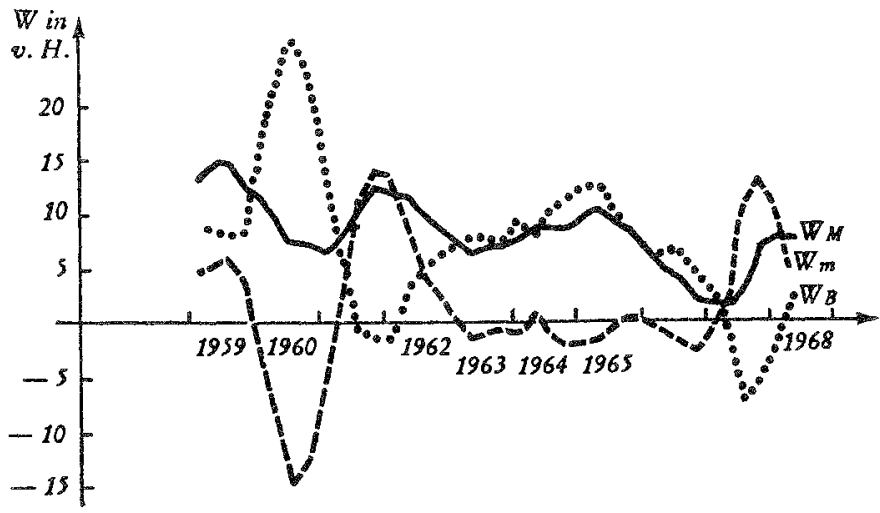

„Ein erster Blick auf diese Entwicklung scheint erkennen zu lassen, daß (1) über den gesamten Zeitraum die Ausdehnung der Geldmenge im wesentlichen von der Geldbasis getragen wurde, (2) der von Saisonschwankungen überlagerte Aufwärtstrend in der Geldmenge relativ stabil war, während Geldbasis und Multiplikator im kurzfristigen Ablauf in der Periode 1959 bis 1961 und seit 1967 - zwei ausgeprägte, jeweils zueinander entgegengesetzt verlaufende Schwankungen aufweisen, die sich damit zumindest zum Teil in ihrem Einfluß auf die Geldmenge kompensiert haben. Da jedoch solche Interpretationen nur allzusehr von dem Maßstab der graphischen Darstellung beeinfluß werden können, sind zusätzlich in Figur 2 die jährlichen Wachstumsraten der drei Größen dargelegt. Hierbei ist für jedes Quartal die Wachstumsrate gegenüber dem gleichen Quartal des Vorjahres berechnet. Dies hat den Vorteil, daß die Saisonschwankungen ausgeschaltet werden. Dabei zeigt sich, daß die Entwicklung der Geldmenge keineswegs gleichmäßig gewesen ist, sondern eindeutig zyklische Schwankungen aufweist, die bis 1962 und seit 1967 mit denen des Multiplikators und in den dazwischen liegenden Jahren mit denen der Geldbasis korrespondieren" (103).

Ein weiteres schwieriges Problem diskretionärer Konjunktursteuerung liegt nach Ansicht M. Friedman's darin, daß die Beziehung von Geldvolumen und Einkommensniveau nicht offen zutage treten,

,weil es Zeit braucht, bis Anderungen des monetären Wachstums das Einkommen beeinflussen, und diese Zeit selbst ist variabel (..) Eine Änderung der monetären Wachstumsrate führt im Durchschnitt etwa zwei bis drei Quartale später zu einer Änderung der Wachstumsrate des nominellen Einkommens" (104).

103 J. Siebke und M. Willms „Das Geldangebot in der Bundesrepublik Deutschland“, in: „Der neue Monetarismus", S. $278 \mathrm{ff}$.

104 M. Friedman, ebd., S. 63 
Friedman unterscheidet zwischen inside-lag und outside-lag. Der inside-lag bezeichnet die Zeit zwischen dem Auftreten und dem Erkennen konjunktureller Veränderungen, der zweite meint die Zeit zwischen Mitteleinsatz und Mittelwirkung kon* junktursteuernder Maßnahmen. Mehrere Autoren äußerten jedoch die Ansicht,

„daß Friedman's Vergleich zwischen den Wendepunkten in der Veränderungstate des Geldvolumens und den Wendepunkten im Niveau der wirtschaftlichen Aktivität methodisch nicht schlüssig sei. Bei ihrem Vergleich der Wendepunkte in der Veränderungsrate des Geldvolumens und der Veränderungsrate des Gesamtoutputs stellen sie nämlich fest, daßs sich Geldvolumen und Gesamtoutput im Zyklus in etwa simultan verändert haben" (105).

Auf Grund der Annahme, daß die Wirkungsverzögerungen monetärer Maßnahmen (outside-lags) von Zyklus zu Zyklus sehr unterschiedlich seien, besteht nach monetaristischer Ansicht permanent die Gefahr pro-zyklischer Steuerung. Deshalb seien die von Keynesianern präferierten fiskalpolitischen Maßnahmen der Konjunkturver * steuerung abzulehnen. Deren Wirkung beruhe qualitativ auf ihrem Einfluß auf die Geldmenge, der aber quantitativ nicht ausreichend exakt voherbestimmbar sei. Das daraus resultierende Dosierungsproblem wird in der Praxis als unlösbar angesehen. Um Fehlsteuerungen zu vermeiden, müßten Eingriffe in den Wirtschaftsprozeß abgelehnt werden. Die staatlichen Instanzen sollten sich vielmehr lediglich darauf beschränken, die Geldmenge jährlich um einen allen Wirtschaftssubjekten vorhersehbaren Prozentsatz auszuweiten. Wie groß dieser sein sollte, wird jedoch weder exakt bestimmt - die Angaben schwanken meist zwischen $2 \%$ und 5\%, (M. Friedman nennt $4 \%$ ) - noch ausreichend begründet. Diese Frage wäre aber von zentraler Bedeutung, zumal angenommen wird, daß der Zuwachs des Geldvolumens auch die Entwicklung des Outputs mitbestimmt.

\subsubsection{Steuerbarkeit der Geldmenge}

Die monetaristische Theorie behauptet eine tatsächliche Steuerbarkeit der Geldmenge durch den kapitalistischen Staat:

„Under present conditions in the United States, the Federal Reserve System essentially determines the total quantity of money; that is to say, the number of dollars of currency and deposits available for the public to hold. Within very wide limits, it can make this total anything it wants it to be" (106).

Der um dieses Problem schwelende Streit ist beinahe so alt wie die Quantitätstheorie überhaupt. Schon Thomas Tocke hatte in seiner Auseinandersetzung mit Ricardo's „currency-principle“ erklärt: „Die Bank hat keine Macht, nach eigenem Willen den Betrag der Noten (gemeint sind hier Banknoten, nicht Staatspapiere, O. E. D.) in der Hand des Publikums zu erweitern; sie hat die Macht, den Notenbe-

105 H. G. Johnson, a. a. O., S. 68

106 M. Friedman „Monetary Theory and Policy", S. 140 
trag in der Hand des Publikums zu vermindern, aber nur vermittelst einer gewaltsamen Operation" (107). Solche Operationen wurden dann in England 1847 und 1857 (s. o.) auch mit „Erfolg" durchgeführt! Marx stimmte mit der Ansicht Tocke's überein: „Die Menge der zirkulierenden Noten richtet sich nach den Bedürfnissen des Verkehrs, und jede überflüssige Note wandert sofort zurück zu ihrem Ausgeber" (108).

Auch unter den Bedingungen der moderen Geldsysteme ist es den kapitalistischen Staaten nicht möglich, die Geldmenge beliebig zu steuern, was von der Mehrheit der bürge rlichen Ökonomen auch anerkannt wird. So schreibt C. Köhler:

„Eine Veränderung der Geldmenge ist vom Willen der Nichtbanken und nicht vom Willen der Zentralbank abhängig. Wenn die Nichtbanken ihre Geldmenge erhöhen möchten, so ist das angesichts eines Vielfachen an Geldkapital, das auch noch zu einem Teil near money enthält, jederzeit möglich. Die Nichtbanken können auch, wenn sie es wünschen, ohne weiteres die Geldmenge verringern; sie brauchen Noten, Münzen oder Sichteinlagen nur im Bankensystem zu binden" (109).

C. Köhler geht sogar so weit, die Möglichkeit der Geldmengenreduzierung per Kreditrestriktionen in Frage zu stellen:

„Tatsächlich aber braucht ein solcher Eingriff die Geldmenge überhaupt nicht zu berühren. Wenn der Kreditbestand zurückgeht, dann entspricht dieser Schrumpfung eine Abnahme der Einlagen. Welche Teile der Einlagen davon tangiert werden, ob die Geldmenge oder das Geldkapital, kann a priori nicht gesagt werden. Das ist allein abhängig vom Verhalten der Nichtbanken" (110).

Im Zeichen multinationaler Konzerne und Bankverbindungen erscheint es ohnehin als Anachronismus, von einer nationalen Geldmengensteuerung Wesentliches erwarten zu wollen. Die jüngsten Ereignisse in der BRD haben erneut gezeigt, daß es den internationalen Konzernen in erheblichem Umfang gelingt, inländische Liquiditätsbeschränkungen zu umgehen. So bekennt denn auch ein Praktiker, der es eigentlich wissen müßte, nämlich das Direktoriumsmitglied der Deutschen Bundesbank, H. Irmler, seine Institution könne, ,sich weder darauf festlegen, noch könnte sie es mit auch nur einiger Sicherheit erreichen, das Geldvolumen kontinuierlich um eine bestimmte Zuwachsrate steigen zu lassen, so sehr sie das erstreben mag" (111). Er begruindet seine Ansicht mit „,den verschiedenen Durchkreuzungsmöglichkeiten der Geldpolitik: Ökonomisierung der Kassenhaltung im Publikum (Aktivierung von „,idle' money), Aktivtausch im Banksektor (Substitution der freien Liquiditätsreserven durch Zentralbankgeld), Auslandsverschuldung deutscher Unternehmer und Ausweitung des Lieferantenkredits, störende Devisenbewegungen im System fester

107 T. Tooke, hier zitiert nach K. Marx ,MEW“ 25, S. 540

108 K. Marx, ebd., S. 540

109 C. Köhler „,Geld wir tschaft“, Duncker und Humblot, Berlin 1970, S. 231

110 Ebd., S. 231

111 H. Irmler, in: ,Der Volkswirt“" Nr. 2/72 
Wechselkurse“"(112)。

Ein besonders markantes Beispiel aus der Geldgeschichte der BRD veranschaulicht die Berechtigung dieser Stellungnahme: 1955 hatte selbst die Stillegung außerordentlich umfangreicher Steuergelder zugunsten später vorgesehener Rüstungsausgaben keinerlei abkühlende Wirkung auf die zum fraglichen Zeitpunkt überhitzte Konjunktur ausüben können. Die Bank Deutscher Länder bemerkte dazu:

„Der Wirtschaftsorganismus verstand es offenbar, den ,Blutentzug ${ }^{6}$, den er durch die hohen nicht wieder verausgabten Steuern erlitt, auszugleichen. Teilweise geschah das durch einen erhöhten Auslandsabsatz, der seinen Niederschlag im Zahlungsbilanzüberschuß und der damit verbundenen Vergrößerung des Geldvolumens aufgrund von Devisenzugängen fand. Entscheidend aber war die fortdauernde Zuflucht zum Kredit. Mancherlei Anzeichen sprechen dafür, daß die anhaltend starke Tendenz zur Kreditexpansion in ursächlichem Zusammenhang mit den Überschüssen des öffentlichen Haushalte steht: Die Wirtschaft holte gewissermaßen ais Kredit wieder herein, was ihr der Staat in Form von Steuern nimmt und nicht wieder in Gestalt von entsprechenden Ausgaben zuleitet" (113).

Auf derartige Einwände reagieren die Monetaristen mit dem Hinweis, daß diese Probleme durch eine zweckmäßige Umgestaltung der gegenwärtigen Geldsysteme behoben werden könnten.

Sie schlagen vor, den Geschäftsbanken eine $100 \%$ ige Reserveverpflichtung aufzuerlegen. Damit soll sichergestellt werden, daß der Staat bzw. die Notenbanken oder besser noch speziell hierfür einzurichtende ,,brokerage firms" per Offenmarkt-Politik die jeweils erforderliche Geldmengenpolitik präzise durchführen können. Darüberhinaus müßten vor allem die Wechselkurse freigegeben werden, um stoßartige internationale Geldbewegungen auszuschließen.

\subsubsection{Dichotomie}

In seiner Auseinandersetzung mit der neoklassischen Preistheorie hatte Keynes den Widerspruch in der ,klassischen Dichotomie" aufgegriffen, wonach die relativen Preise durch Angebot und Nachfrage, das absolute Preisniveau aber von der Geldmenge und deren Umlaufgeschwindigkeit bestimmt werde. Keynes schreibt:

"Solange sich Ökonomen mit dem beschäftigen, was die Preistheorie genannt wird, waren sie gewohnt zu lehren, daß die Preise durch die Bedingungen des Angebotes und der Nachfrage beherrscht werden... Wenn sie aber ... zur Theorie des Geldes und der Preise übergehen, hören wir nichts mehr von diesen schlichten, aber verständlichen Begriffen und gehen über in eine Welt, in der die Preise durch die Menge des Geldes, durch ihre Einkommenumlaufsgeschwindigkeit, durch die Umlaufsgeschwindigkeit im Verhältnis zur Menge der Transaktionen,

112 Ebd.

113 Bank deutscher Länder, hier zitiert nach: H. Röper ,Geschichte der D-Mark“, FischerVerlag Frankfurt a. M. 1968, S. 78 
durch Hortung, durch erzwungenes Sparen, durch Inflation und Deflation et hoc genus omne beherrscht werden ..." (114). (Hervorh. K)

Uber diesen Aspekt ist auch nach Keynes noch heftig diskutiert worden, wobei sich besonders Don Patinkin engagiert hatte. Seiner Auffassung nach besteht das wesentliche Argument gegen die Dichotomie darin,

,daß zwischen der klassischen Werttheorie, nach der Konsumgüternachfrage und -angebot allein von den relativen Preisen und nicht auch vom Realwert der Kassenhaltung der Wirtschaftssubjekte abhängen, und der Quantitätstheorie des Geldes, nach der die Abhängigkeit der Ausgaben vom Realwert der Kassenhaltung jenen Mechanismus herstellt, durch den die Geldmenge das stabile Gleichgewichtspreisniveau bestimmt, ein logischer Widerspruch vorläge ... Seiner Meinung nach ist eine Überwindung dieses Widerspruchs und damit eine Rettung der klassischen Theorie allein dadurch möglich, daß die Nachfrage- und Angebotsfunktionen nicht nur von den relativen Preisen, sondern auch von der realen Kassenhaltung abhängig gemacht werden" (115).

Eine Begründung der relativen Preise durch das Verhältnis von Angebot und Nachfrage unterstellt, daß die Waren ohne Preis in die Zirkulation treten. Wie Marx jedoch nachzuweisen vermochte, werden durch das Marktgeschehen zwar permanent Schwankungen der wirklichen Marktpreise um eine Basisgröße, den durch Arbeit bestimmten Wert, hervorgerufen. Der Wert aber wird in der Produktion, nicht jedoch in der Zirkulation bestimmt.

Bei der Begründung des absoluten Preisniveaus unterstellt die Neoklassik wiederum, daß das Geld ohne Wert in den Kreislauf eintrete, denn nach ihrer Darstellung steht einer gegebenen Menge an Waren (und Dienstleistungen) eine autonom bestimmte Geldmenge gegenüber. In der Zirkulation werde das quantitative Verhältnis beider Größen ermittelt und damit das absolute Preisniveau bestimmt. In realite kann der Staat die nominelle Geldmenge zwar innerhalb gewisser Grenzen, jedoch keinesfalls beliebig steuern.

Wie Marx im Zusammenhang mit dem Geldumlauf darstellt, erscheinen die Gesetze der Geldzirkulation beim Wertzeichen umgekehrt und auf den Kopf gestellt: „Während die Quantität des zirkulierenden Goldes steigt oder fällt mit dem Steigen oder Fallen der Warenpreise, scheinen die Warenpreise zu steigen oder zu fallen mit dem Wechsel in der Quantität des zirkulierenden Papiers" (116). Es ist nun nachzuvollziehen, warum Marx in diesem Zusammenhang von scheinbaren Preissteigerungen spricht: Gold war Maßstab der Preise geworden als fixiertes Quantum seiner selbst. Weil es als Zirkulationsmittel selbst nur Repräsentant von Wert ist, kann es in dieser Funktion durch andere Wertzeichen ersetzt werden. Zirkuliert Papiergeld in dem Umfang, in dem Gold zirkulieren würde, dann repräsentiert es tatsächlich seinen Nennwert. Übersteigt jedoch seine nominelle Quantität die des potentiell erforderlichen Goldes, wo wird das Repräsentationsverhältnis Papiergeld/Gold gestört. Ein bestimmtes Wertzeichen vertritt dann faktisch eine geringere Goldmenge und damit weniger Wert als vorher.

\footnotetext{
114 J. M. Keynes, a. a. O., S. 247

115 H. G. Johnson, a. a. O., S. $26 \mathrm{f}$ 。

116 K. Marx, MEW 13, S. 100
} 
Der gesunkene Tauschwert des Wertzeichens gegenüber dem Gold spiegelt sich aber auch im gleichen Maße gegenüber allen anderen Waren wider. Während also die nominellen (absoluten) Preise der gesamten Warenwelt steigen, ändert sich am Tausch-Verhältnis des Goldes mit den anderen Waren nichts, d. h. die relativen Preise bleiben auch bei überhöhter Papiergeld-Zirkulation unverändert.

Abstrahiert man zunächst von den konkreten Bedingungen der Preisniveau-Transformation, dann bleibt als Resultat einer übermäßigen Ausdehnung der Wertzeichen-Zirkulation lediglich eine nominelle Preisänderung sämtlicher Waren, einschließlich des Goldes. Eine bestimmte Menge Gold, die vorher von sage $1 \mathrm{DM}$ repräsentiert wurde, wird nun beispielsweise von $2 \mathrm{DM}$ repräsentiert - und eine bestimmte Ware, deren Preis ursprünglich 1 DM war, kostet nun 2 DM. Die relativen Wertverhältnisse der Waren bleiben unverändert. Was sich ändert ist deren nomineller Ausdruck.

Die „klassische Dichotomie“" ist also insofern berechtigt, als eine Manipulation der zirkulierenden Geldmenge sehr wohl das absolute Preisniveau beeinflussen kann, ohne - zumindest theoretisch - gleichzeitig die relativen Preise verändern zu müssen. Gelingt es gewissen Wirtschaftssubjekten bzw. dem Staatsapparat, die nominelle Geldmenge relativ zu erhöhen, so können sich daraus unter bestimmten Voraussetzungen Übernachfrage und damit inflationistische Tendenzen ergeben. Die Beseitigung des Geldschöpfungsmechanismus innerhalb des Bankensystems und eine verbesserte Kontrolle von Devisenströmen sind daher sicher brauchbare Schritte zur Beseitigung der Inflation. Sie wären.jedoch keineswegs hinreichend - schon deshalb nicht, weil nicht alle Preissteigerungen auf einen „demand-pull“ zurückzuführen sind (Stagflation!).

Offene Fragen bleiben in diesem Zusammenhang der Transmissionsmechanismus solcher monetärer Impulse auf den realen Bereich sowie der Grad der von den Monetaristen behaupteten „Neutralität des Geldes“. Denn in der Realität verläuft die Transformation der Preise nicht synchron. Gerade dieser Umstand macht die Inflation einerseits zu einer Quelle von Extraprofiten und andererseits zu einer ökonomischen und politischen Gefahr. Das Nichterkennen des Sachverhaltes, daß Wertzeichen nur als Zirkulationsmittel dienen können, sofern sie Gold, d. h. Wert repräsentieren, führt darüber hinaus zu der Fehleinschätzung, das Gold total und ersatzlos entmonetisieren zu können.

Solange in einem Staat die Inflationsrate unterhalb eines gewissen Limits bleibt, können die Wertzeichen sowohl die Zirkulationsmittel- als auch die Schatzfunktion erfuillen. In Perioden politischer und ökonomischer Stabilität wird das Gold daher kaum in Erscheinung treten. Das macht es verständlich, daß in solchen Phasen stets eine größere Anzahl von Ökonomen zu der Anschauung gelangt, daß der Moment gekommen sei, das Gold als Währungsmetall endgültig zu eliminieren. Die gegenwärtige faktische Aktivierung des Goldes zeigt jedoch erneut, daß davon nicht die Rede sein kann (117).

117 Man erinnere sich etwa der Neubewertung der italienischen Währungsgold-Reserven zu "freien“" Marktpreisen bei der Absicherung eines BRD-Kredits! 
Schließlich ist zu bemerken, daß für Monetaristen ein gewisser intellektueller Reiz darin zu liegen scheint, alle Inflationen der Vergangenheit und Gegenwart auf eine gemeinsame Ursache zurückführen zu wollen. Wird dann eine Fehlsteuerung der Geldmenge als Ursache ,erkannt “", so erscheinen allgemeine Preissteigerungen quasi als Produkt einer technischen Panne; die permanente Inflation ist dann nicht länger Ausdruck sozialer Kämpfe. Indem die Geldmengenvariation ,zur alleinigen Ursache der Preisniveauveränderungen erklärt wird, ist der ökonom aus der Verpflichtung entlassen, sich um andere Ursachen der Preisniveauerhöhung zu kümmern und auch davon, die Ursachen der Geldmengenvariation zu berücksichtigen. $\mathrm{Ob}$ Kriegsfinanzierung durch Bedienen der Notenpresse oder Offenmarktkäufe seitens der Zentralbank vorliegen, scheint ohne Belang" ${ }^{66}(118)$.

\section{Isolierte Inflationstheorien}

\subsection{Importierte Inflation}

Neben den oben abgehandelten Inflationstheorien existiert eine Reihe weiterer Erklärungsansätze des permanenten Preissteigerungsprozesses, die jed och einen geldtheoretischen background vermissen läßt. Häufig wird die Inflation in Beziehung mit einem der wirtschaftlichen Ziele: Außenhandelsgleichgewicht, Vollbeschäftigung oder wirtschaftliches Wachstum gesetzt, also mit jenen Elementen, die ursprünglich gemeinsam als ,,magischer" Problemkreis interpretiert worden waren.

Die Theorie der ,,importierten Inflation“ zielt auf Einflüsse ab, welche internationale Handelsverflechtungen auf das inländische Preisniveau ausüben:

1. Einkommenseffekt

Steigt bei den Handelskonkurrenten eines Landes A das Preisniveau, bzw. steigt es dort schneller als in A, so ergibt sich bei festen Wechselkursen für dessen Außenhandel folgende Situation. Die Waren des Auslandes werden relativ teuer, was einerseits den Export aus A erleichtert, da verbilligt, und andererseits den Import aus den Konkurrenzländern erschwert, da verteuert. Somit ,verbessert" sich die Handelsbilanz von A. In diesem Land erhöht sich infolgedessen die Summe der wirtschaftlichen Aktivitäten und das inländische Einkommensniveau steigt. Die Nachfrage expandiert nun auch vom Inland her. Bei hoher Kapazitätsauslastung ruft diese zweiseitige Nachfragesteigerung schließlich Nachfrageüberschüsse und damit allgemeine Preissteigerungen hervor.

2. Liquiditätseffekt

Erwirtschaftet ein Land Überschüsse in der Leistungsbilanz, so führt das in entsprechendem Umfang zu Devisen-, d. h. zu Geldmengenzuflüssen.

Keynesianer argumentieren, daß die Erhöhung der Geldmenge, also die Erhöhung des Angebots an Kredit, den Zins herabdrückt. Sind ausreichend Absatz-

P. Kalmbach, a。 a。 O., S. 44 
chancen gegeben, wird die Nachfrage nach Investitionsgütern und damit tendenziell auch das Preisniveau steigen.

Quantitätstheoretiker dagegen argumentieren, daß durch die Erhöhung der Geldmenge die tatsächliche Kassehaltung die geplante Kassehaltung übersteigt. Das „überschüssige" Geld werde so lange als vermehrte Nachfrage in die Zirkulation zurückfließen, bis die zusätzliche Geldmenge durch Preissteigerungen neutralisiert sei. Da diese Theorie nur auf Überschüsse in der Summe der gesamten Geldströme abzielt, kann sich nach Auffassung seiner Verfechter der Liquiditätseffekt selbst dann ergeben, wenn die Leistungsbilanz ausgeglichen oder sogar negativ ist, die Kapitalbilanz dieses Manko aber mehr als ausgleicht. Relevant sei letztlich der Saldo der Zahlungsbilanz. Die Ursache des Überschusses ist dabei ohne Belang, d. h. es ist gleichguiltig, ob er z. B. aus unterschiedlichen nationalen Inflationsraten, wie oben angenommen, oder aus konjunkturell bedingten Nachfragesteigerungen des Auslandes resultiert.

\section{Preisverflechtung}

Von diesen an den „,demand pull“6 angelehnten Hypothesen hebt sich eine weitere insofern ab, als hier auf den ,, cost-push ${ }^{6}$ hingewiesen wird, der bereits durch bloße Verquickung des inländischen Marktes mit ausländischen Waren und daher mit deren Preisniveau entstehen kann. Herrscht in den Konkurrenzländern Inflation, so verteuern sich für das Land A sämtliche Importwaren. Das inländische Preisniveau wird durch Import-Preise unmittelbar erhöht.

Der Einfluß der Import-Preise sei um so größer, je stärker der Anteil der Importwaren am BSP ist. In der BRD beträgt er z. B. z. Zt. etwa $21 \%$. In dem Maße, in dem das Inland die erhöhten Importpreise nicht akezptiere, würden ausländische Waren von Markt des Landes A abgelenkt. Das Warenangebot kontrahiere, weshalb ein ,demand-pull" entstehe. Derselbe Effekt ergebe sich daraus, daß inländische Produkte im Ausland höhere Preise erzielen könnten und dadurch verstärkt in das Ausland abflössen. Analysiert man nun die relevanten Fakten für die BRD, so stellt sich heraus, daß die Zusammenhänge zwischen den angesprochenen Salden und der Inflationsrate keineswegs eindeutig sind, wenngleich sie nicht völlig bestritten werden sollen.

Die folgende Tabelle IV stellt die Leistungs- bzw. Devisenbilanzsalden den jeweiligen Inflationsraten in der BRD von 1950 bis 1972 gegenüber.

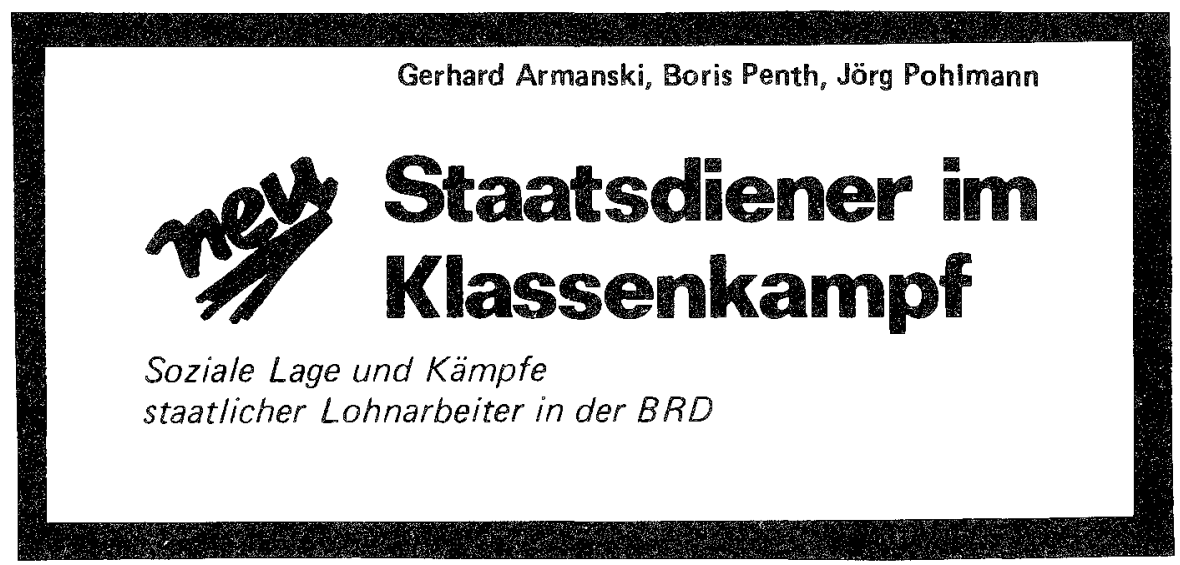


Erzeugerpreise für landwirtschaftlicha Produkte und Einkzufspreise für landwirtschaftlich Betriebsmittel in der BAD $1950 / 51=100$

\begin{tabular}{lll}
\hline Wirtschaftsjahr & $\begin{array}{l}\text { Landw. Erzeuger- } \\
\text { preise }\end{array}$ & $\begin{array}{l}\text { Einkaufspreise pür } \\
\text { landw. Betriebsmittel }\end{array}$ \\
\hline $1951 / 52$ & 115,5 & 112,8 \\
$1952 / 53$ & 113,4 & 113,8 \\
$1953 / 54$ & 111,7 & 114,6 \\
$1954 / 55$ & 116,2 & 115,4 \\
$1955 / 56$ & 122,7 & 116,8 \\
$1956 / 57$ & 127,5 & 120,3 \\
$1957 / 58$ & 129,1 & 121,5 \\
$1958 / 59$ & 130,2 & 125,2 \\
$1959 / 60$ & 133,4 & 127,7 \\
$1960 / 61$ & 127,2 & 129,9 \\
$1961 / 62$ & 132,4 & 133,4 \\
$1962 / 63$ & 134,6 & 137,9 \\
$1963 / 64$ & 138,2 & 141,8 \\
$1964 / 65$ & 143,1 & 144,0 \\
$1965 / 66$ & 152,0 & 148,6 \\
$1966 / 67$ & 145,9 & 151,6 \\
$1967 / 68$ & 136,0 & 151,9 \\
$1968 / 69$ & 143,3 & 153,8 \\
$1969 / 70$ & 150,9 & 159,0 \\
$1970 / 71$ & 141,5 & 166,6 \\
$1971 / 72$ & 153,7 & 175,1
\end{tabular}

Quelle: Statistisches Jahrbuch für die BRD (Hrsg. Statistisches Bundesamt Wiesbaden), Stuttgari und Mainz, lfd.

Mit Hinblick auf die Hypothese des Einkommenseffektes von Leistungsbilanzüberschüssen ist der Tabelle zu entnehmen: Im Jahre 1968 ergab sich für die BRD mit $10904 \mathrm{Mrd}$. DM der weitaus größte positive Saldo im betrachteten Zeitraum; die Inflationsrate blieb mit $1,5 \%$ jedoch unter dem Durchschnitt. Ein Jahr später schmolz der Bilanzüberschuß auf beinahe die Hälfte zusammen, nämlich auf 6,228 Mrd. DM, doch die Inflationsrate entwickelte sich entgegengesetzt; mit 3,5\% hatte sie sich gegenüber dem Vorjahr mehr als verdoppelt. Im Jahre 1964, als die Leistungsbilanz mit -0,016 Mrd. DM nahezu ausgeglichen war, herrschte in der BRD eine Preissteigerungsrate von 2,2\%. Im folgenden $\mathbf{J}$ ahr erhöhte sich das Defizit gewaltig, nämlich auf $-6,723 \mathrm{Mrd}$. DM; die Inflationsrate aber sank nicht nur nicht, sondern stieg auf $3,3 \%$ an.

Mit Ausnahme der Jahre 1953 und 1954 gab es Preissteigerungen von 1,2\% und mehr. Die Leistungsbilanz aber war 1962, 1964 und 1965 ,negativ" gewesen, hätte also zumindest Preisstabilität erwarten lassen sollen. Die Jahre 1970-1972 brachten einen erheblich beschleunigten Anstieg der Inflationsrate und waren doch 
Jahre mit (im Vergleich zu den Vorjahren) niedrigen Überschüssen in der Leistungsbilanz.

Erwartet man bei einem ansteigenden Leistungsbilanz-Saldo ein steigendes Preisniveau, so sieht man seine Prognose in der betrachteten Periode sechsmal erfüllt. In den Jahren 1959, 1962, 1964 gingen die Werte darüber hinaus gemeinsam, also „erwartungsgemäß" nach unten. Doch neben dieser neunfachen Bestätigung der Prognose offenbart die Tabelle zwölf ,unerwartete" Bewegungen: Trotz steigenden Bilanz-Salden sank die Inflationsrate fünfmal, Andererseits stiegen die Preise im Betrachtungszeitraum selbst bei sinkenđen Leistungsbilanz-Ưberschüssen, im Verlaufe von sieben Jahren.

Eine Korrelation zwischen Überschüssen in der Leistung sbilanz und der Inflationsrate, wie sie die Hypothese des Einkommenseffektes behauptet, kann aus diesem Material nicht konstatiert werden. Gegen die Existenz eines erkennbar engen Zusammenhangs zwischen der Bewegung des Preisniveaus und dem Handels- bzw. Leistungsbilanzsaldo spricht eine weitere Tatsache: Inflation herrscht in allen kapitalistischen Staaten, unabhängig davon, ob sie in ihren entsprechenden Bilanzen Überschüsse aufzuweisen haben (BRD, Japan) oder nicht (USA, England).

Mit Hinblick auf die Hypothese des Liquiditätseffektes ist der Tabelle zu entnehmen: In den beiden einzigen Jahren des Betrachtungszeitraumes, in denen das allgemeine Preisniveau sank, nämlich 1953 und 1954, hatte sich der Saldo der Zahlungsbilanz gegenüber den Vorjahren z. T. kräftig erhöht.

Andererseits stieg die Inflationsrate in den Jahren 1961 und 1962 gegenüber den Vorjahren erheblich an, obgleich der Saldo von +8,109 Mrd. DM auf $-0,822$ Mrd. DM bzw. -0,877 Mrd. DM abgesunken war. Sehr deutlich ist der Widerspruch zur Hypothese in den Jahren 1968/69, in denen sich die Inflationsrate von $1,5 \%$ auf $3,5 \%$ erhöhte, obwohl die Zahlungsbilanz vom bis dahin zweithöchsten Stand +7,009 Mrd. DM auf die Minus-Rekordmarke von -10,263 Mrd. DM umgekehrt worden war. Nicht in einem einzigen Jahr mit ,passiver ${ }^{66}$ Devisenbilanz hat sich auch nur ein stabiles geschweige denn ein sinkendes Preisniveau ergeben. Faßt man die von der Hypothese des Liquiditätseffektes nahegelegte Prognose etwas weiter und rechnet auf ein Ansteigen der Preiskurve bei einer ,Verbesserung“ der Zahlungsbilanz, so sieht man dies sechsmal bestätigt. Auch eine gleichzeitige Umkehrung der Trends findet in fün Jahren gleichzeitig statt. Doch neben diesen elf „theoriegerechten“ Bilanz- und Preisbewegungen gibt es fast ebensoviel, nämlich zehn, widersprechende Beispiele. Die Inflationsrate beschleunigte sich selbst bei absinkenden Zahlungsbilanz-Überschüssen (siebenmal) und sank andererseits auch bei steigendem Bilanzüberschuß (dreimal). Folglich ist die permanente Inflation in der BRD durch den Liquiditätseffekt der nahezu permanenten Exportüberschüsse nicht zu erklären.

Die Hypothesen des Einkommens- und des Liquiditätseffektes gehen global von allgemeinen Nachfragesteigerung aus, die zu ,,bottle-necks“ führen sollen. Daher müßte man Preissteigerungen finden, die in Abhängigkeit zum Auslastungsgrad der jeweiligen Branchen stehen. In der Realität finden wir auch von Branche zu Branche stark divergierende Preissteigerungen. Die unterschiedlichen Preissteige- 
rungsraten sind jedoch, wie der Sachverständigenrat für die Exportgüter feststellte, kein Reflex des jeweiligen Auslastungsgrades der Produktionskapazitäten: „Die Unterschiede in der Auslastung der Produktionsanlagen haben sich in den Ausfuhrpreisen kaum niedergeschlagen “ (119). Zur Überprïfung der Relevanz der Preisverflechtungstheorie bietet sich ein Blick auf den Index der Importwaren in Tabelle V an. Das Preisniveau hat sich im Betrachtungszeitraum 1958-1972 nur wenig verändert, wobei der Stand von 1958 noch nicht einmal wieder erreicht worden ist. Die Lebenshaltungskosten dagegen stiegen in diesem Zeitraum von 75,9 auf 110,7 Punkte - bei Berechnung mit dem Basisjahr 1970 = 100. Die Preise der importierten Waren sind somit eher ein stabilisierendes denn ein preisniveau-treibendes Moment gewesen! Das Importpreis-Niveau und die Lebenshaltungskosten wiesen in insgesamt sieben Jahren einen gemeinsamen Trend auf. Doch in ebensovielen Fällen bewegten sie sich in einander entgegengesetzten Richtungen. Demnach hat auch die Theorie der Preisverflechtung kaum Erklärungswert für den permanenten Preisanstieg in der BRD.

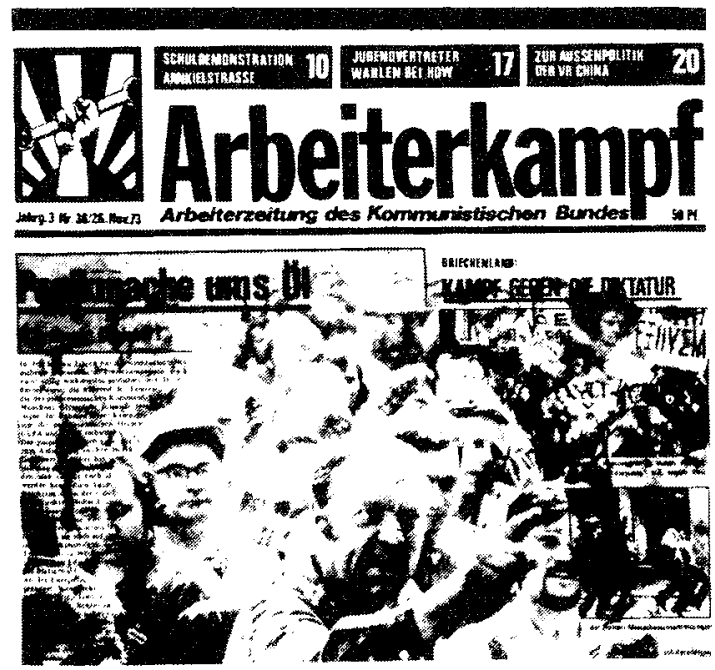

VERL.AG ARBEITERKAMPPF

J. Reents, 2000 Hamburg 13, Rutschbahn 35

Ein Abonnement für 6 Ausgaben kortet DM 4,80 inkl. Porto Ein Abonmement für 12 Ausgaben kostet DM 9,60 inkI. Porio Förderabonnement für 6 Auggaben ab DM 6 ,

Förderabonnement für 12 Ausgaben ab DM 12,

Der ARBEITERKAMPF erschoint dreiwöchentlich. 
Index der Binkaufspreise fur Auslandsgiter

$1962=100$

\begin{tabular}{|c|c|c|c|c|c|c|c|c|}
\hline \multirow{4}{*}{ Zeítraum } & \multirow{4}{*}{ Insgesamt } & \multirow{4}{*}{$\begin{array}{l}\text { Güter der } \\
\text { Ernäh- } \\
\text { rungs- } \\
\text { wirtschaft }\end{array}$} & \multicolumn{6}{|c|}{ Guiter der gewerblichen Whrtschaft } \\
\hline & & & \multirow{3}{*}{ zusammen } & \multirow{3}{*}{ Rohstoffe } & \multirow{3}{*}{ Halbwaren } & \multicolumn{3}{|c|}{ Fertigwaren } \\
\hline & & & & & & \multirow[b]{2}{*}{ zusammen } & \multicolumn{2}{|c|}{ darunter } \\
\hline & & & & & & & $\begin{array}{l}\text { Investi- } \\
\text { tions - } \\
\text { güter }\end{array}$ & $\begin{array}{c}\text { Ver- } \\
\text { brauchs- } \\
\left.\text { güter }{ }^{1}\right)\end{array}$ \\
\hline 1958 & $\log _{,} 5$ & 109,5 & 109,5 & 116,3 & 106,7 & 107,1 & 101,8 & 114,5 \\
\hline 1959 & 105,4 & 103,8 & 106,0 & $110_{i}^{2}$ & 104,9 & 104,3 & 101,9 & 105,2 \\
\hline 1960 & 105,0 & 101,9 & 106,3 & 109,3 & 107,1 & 104,3 & 101.9 & 102,9 \\
\hline 1961 & 100,8 & 97,8 & 102,1 & 103,7 & 102,2 & 101,2 & 99,6 & 99,5 \\
\hline 1962 & 100 & 100 & 100 & 100 & 100 & 100 & 100 & 100 \\
\hline 1963 & 102,0 & 104,4 & 101,0 & 100,5 & 100,9 & 101,3 & 102,5 & 102,1 \\
\hline 1964 & 103,7 & 105,9 & 102,8 & 101,4 & 104,5 & 102,8 & 104,0 & 98,7 \\
\hline 1965 & 106,3 & 110,8 & 104,3 & 100,9 & 109,2 & 103,8 & 106,0 & 97,0 \\
\hline 1966 & 108,2 & 110,8 & 107,0 & 102,5 & 113,9 & 106,0 & 109,0 & 99,0 \\
\hline 1967 & 105,9 & 107,1 & 105,4 & 99,7 & 112,2 & 105,0 & 107,7 & 101,9 \\
\hline 1968 & 105,4 & 104,2 & 105,9 & 100,2 & 115,2 & $104_{8} 3$ & 108,1 & 102,6 \\
\hline 1969 & 108,0 & 108,0 & 108,0 & 98,8 & 121,2 & 106,3 & 108,6 & 100,5 \\
\hline 1970 & 107,2 & 107,1 & 107,3 & 97,2 & 121,2 & 105,7 & 105,5 & 101,8 \\
\hline 1971 & 106,7 & 105,5 & 107,2 & 102,8 & 111,9 & 107,3 & 107,5 & 106,8 \\
\hline 1972 & 106,6 & 107,0 & 106,5 & 102,1 & 107.4 & 108,4 & 105,5 & 106,6 \\
\hline
\end{tabular}


Die Theorie der importierten Inflation soll offenbar dazu dienen, die jeweiligen Regierungen aus der Verantwortung für den Geldwert zu entbinden. Denn nicht die Bedingungen im Inland, sondern unkontrollierbare - und vor allem nicht zur Verantwortung ziehbare - fremde Mächte werden für die Preissteigerungen verantwortlich gemacht. Ist die Verantwortung für die Inflation in das Ausland verlagert, so läßt sich leicht argumentieren, daß sie nicht im Inland bekämpft werden kann. Mangelnder Wille oder mangelnder Erfolg bei der Bekämpfung der Inflation lassen sich auf diese Weise leicht rechtfertigen.

Im Jahresgutachten 1972/73 argumentiert der Sachverständigenrat entsprechend. In Ziffer 18 spielt er auf Preisverflechtungen an und geht auf Hindernisse ein, durch zusätzliche Importe Druck auf die Preise auszuüben: „So hat ein einzelnes Mitgliedsland nicht mehr die Möglichkeit, etwas für die Geldwertstabilität durch den Abbau von Einfuhrschranken zu tun. Besonders ausgeprägt ist ... die Bindung an ein Gemeinschaftsrecht in der Agrarpolitik .. "(120). In Ziffer 20 behandelt er die Schwierigkeiten der Geld- und Kreditpolitik, die Liquidität unter Kontrolle zu halten:

„,De facto gibt es aber, selbst wenn man die bestehenden Kapitalverkehrskontrollen in Rechnung stellt, keine Möglichkeit für ein einzelnes Land, durch Einsatz der Geld- und Kreditpolitik auf längere Sicht ein großes Maß an Stabilität zu erreichen als die Partnerländer, sofern man Wechselkursänderungen nicht in Betracht zieht" (121).

Auch für das „klassische“ keynesianische Instrument der Inflationsbekämpfung, der Drosselung der verfügbaren Einkommen, sieht der Rat in Ziffer 22 wenig Chancen:

„Will man etwa die Inflation oder einen Konjunkturaufschwung in der Gemeinschaft zu Hause dadurch bremsen, daß man die Ausgaben drosselt oder die Einnahmen erhöht, so muß man, je stärker die Mächte der Gemeinschaftsländer miteinander verflochten sind, desto mehr rechnen, daß der Nachfrageausfall des Staates oder der Privaten durch Nachfrage aus den Partnerländern ersetzt wird. Widerum überspitzt formuliert: Bei vollständiger Integration müßte ein einzelnes Land gleichsam den privaten Verbrauch aller EWG-Länder zurückdrängen, um eine Dämpfung der Konjunktur oder des Preisanstieges im eigenen Land zu erreichen" (122).

Wenn die Überprüfung der drei Hypothesen gezeigt hat, daß sie nicht in der Lage sind, den Inflationsprozeß in der BRD zu erklären, dann bleibt zu fragen, ob es etwa andere Mechanismen und Zwänge gibt, die einen jeden kapitalistischen Staat von ökonomischer Bedeutung dazu bewegen könnten, in etwa angepaßte Inflationsraten zuzulassen. Nach W. Hofmann ist dies der Fall:

„In unseren Tagen schließlich ist - man spricht hiermit kein Geheimnis mehr aus - die Pflicht zur Inflation zu einem praktischen Postulat der weltwirtschaftlichen Solidarität geworden. Wollte eine Handelsnation inmitten einer inflationären Umwelt auf eigene Faust Politik des stabilen Geidwerts betreiben, so würde dies von den Partnern als eine Weise empfunden werden,

120 Ders. „Jahresgutachten“ $1972 / 73$, S. 4, Ziffer 18

121 Ebd., S. 5, Ziffer 20

122 Ebd., S. 5, Ziffer 22 
mit den Mitteln der Währungspolitik jenen alten Krieg um Märkte fortzusetzen, von dem man in der Hendelspolitik sich losgesagt hat" (123). (Hervorhebungen W. H.)

Hier bleibt allerdings die Frage offen, worin die ,inflationierte Umwelt" begründet ist. Wenn es für die Unternehmer einiger kapitalistischer Staaten nützlich ist, einen permanenten Preissteigerungsprozeß in Gang zu halten - trifft das dann nicht in allen kapitalistischen Staaten zu? Eine spezifische Analyse müßte hier aufzeigen, inwiefern aus nationalen Bedingungen, etwa dem Stand der Kapitalakkumulation oder der Struktur des Außenhandels, fundamental unterschiedliche Positionen gegenüber der schleichenden Inflation bestehen.

\subsection{Phillips-Kurve}

Der Engländer Arthur W. Phillips veröffentlichte 1958 seine Untersuchung über: „The relationship between unemployment and the rate of change of money wage rates in the United Kingdom, 1861-1957" (124). Wie H. G. Johnson feststellte, versuchte Phillips ,gar nicht erst, eine Hypothese über die Ursache der Inflation zu formulieren, er konzentrierte sich stattdessen auf die dynamischen Aspekte des Arbeitsmarktes " (125). Phillips ist der Ansicht, die aus der keynesianischen Literatur bekannte These, wonach Lohneinkommen und Beschäftigungsgrad in einem kausalen Zusammenhang stünden, empirisch belegen zu können:

„The statistical evidence.. seams in general to support the hypothesis..., that the rate of change of money wage rates can be explained by the level fo unemployment and the rate of change of unemployment, except in or immediately after those years in which there is a suffisiently rapid rise in import prices to of fset the tendency for increasing productivity to reduce the cost of living ${ }^{6 /}(126)$.

Phillips versuchte, die Arbeitslosenrate exakt zu bestimmen, die notwendig sei, um Lohnkosten-Stabilität sicherzustellen: „If, as is sometimes recommended, demand were kept at a value which would maintain stable wage rates the associated level of unemployment would be about $51 / 2$ per cent ${ }^{66}(127)$.

123 W. Hofmann, a. a. O., S. 68

124 A. W. Phillips, ,Unemployment and wage rates", in: ,,Inflation“"

125 H. G. Johnson, $a_{\circ}$ a. O., S. 143

126 A. W. Phillips, a. a. O., S. 296

127 Ebd., S. 297 


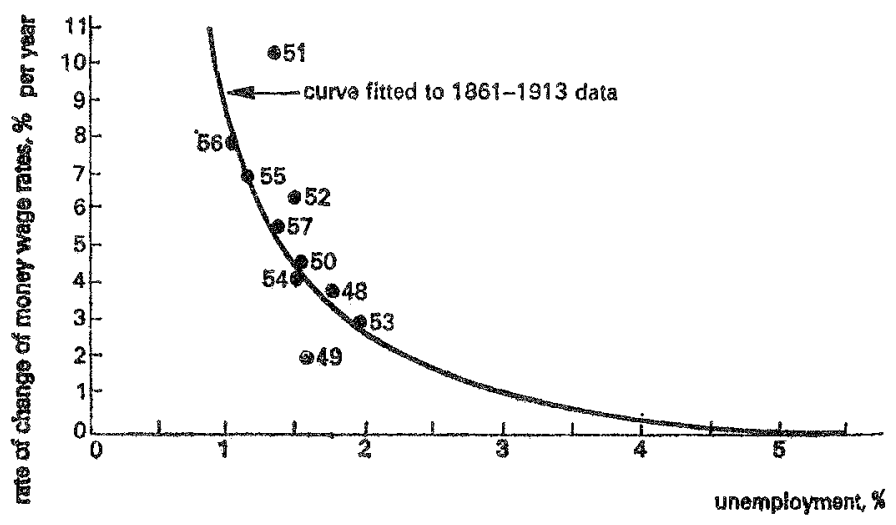

Die graphische Darstellung des Untersuchungsergebnisses wurde bekannt als einfache oder ursprüngliche Phillips-Kurve.

Zwischen Keynesianern und Neoklassikern entwickelte sich daraufhin eine heftige Diskussion, in deren Verlauf anstelle der Lohnsteigerungsrate die Preissteigerungsrate in Beziehung zur Arbeitslosenquote gesetzt wurde. Diese Abwandlung der ursprünglichen Kurve wird mit der Annahme einer konstanten Relation zwischen Preis und Stücklohnkosten erklärt.

Die Hypothese, daß die Arbeitslosenquote für die gesamte Marktsituation bestimmend sei, wird damit begründet, daß die Arbeitslosenquote zum einen die Lohnentwicklung bestimme. Zum andern sei sie symptomatisch für die Auslastung des Gütermarktes, weil die Arbeitsnachfrage in engem Zusammenhang mit der gesamtwirtschaftlichen Güternachfrage stehe. Daher sei die Arbeitslosenquote nicht nur für die Lohnentwicklung, sondern auch für die allgemeine Preisentwicklung von Bedeutung.

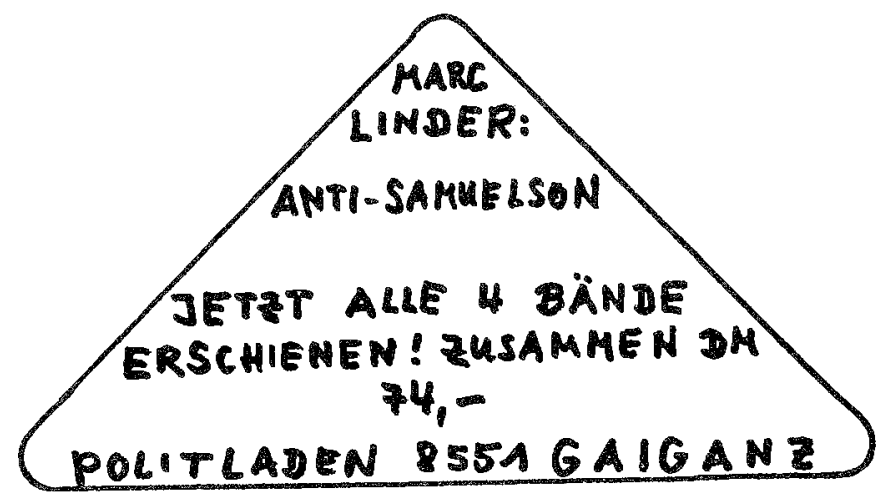




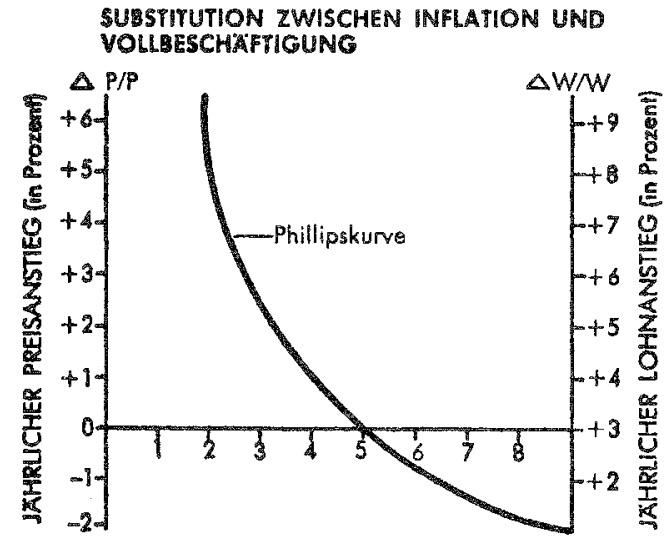

Die in diesem Sinne transformierte Kurve ist der Ausdruck des ,grausamen Dilemmas" dem sich die kapitalistische Wirtschaftsordnung nach Ansicht etwa von P. Samuelson ausgesetzt sieht. Angeblich muß sich die Gesellschaft zwischen Arbeitslosigkeit und Inflation entscheiden: „Das moderne ökonomische Mischsystem scheint an einer neuartigen Krankheit zu leiden -- eine Tendenz zur Annäherung an Vollbeschäftigung führt zur, schleichenden Inflation" “(128). Die keynesianische Interpretation des ,trade-off" lautet wie folgt: Eine Steigerung der Nachfrage führt über „bottle-necks" zu Preissteigerungen und sinkenden Reallöhnen. Weil die Arbeiter vorwiegend am Nominallohn interessiert sind, ist es jetzt möglich, die Beschäftigung zu erhöhen, also die Arbeitslosenquote zu senken.

Gegen diese Interpretation der Phillips-Kurve wandten die Neoklassiker berechtigterweise ein, daß der ,,trade-off ${ }^{\text {" }}$ nur kurzfristig bestehen könne, nämlich so lange, wie die Arbeiter tatsächlich der Geld-Illusion unterliegen. So lange werden sie für einen niedrigeren Reallohn arbeiten. Erkennen sie aber, daß sie effektiv schlechter entlohnt sind, so werden sie den Ausgleich des erlittenen Verlustes plus einem Zuschlag für erwartete weitere Preissteigerungen verlangen. Der , positive ${ }^{6 \text { Effekt }}$ der Preissteigerungen auf Beschäftigung und Wirtschaftswachstum bleibe daher dann und nur dann langfristig erhalten, wenn die tatsächlichen Preissteigerungen über denen der von den Arbeitern antizipierten liegen.

In den letzten Jahren wurden die aus der Phillips-Kurve abgeleiteten Prognosen von der Praxis mehrmals widerlegt. R. Nixon betrieb 1969 eine nach diesem Modell ausgerichtete Stabilitätspolitik. Doch, obwohl die Arbeitslosigkeit kräftiger als erwartet stieg, konnte die Inflation nicht gestoppt werden. Im Gegenteil, sie

P. A. Samuelson, a. a. O., Bd. I, S. 189 
beschleunigte sich weiter! Das Phänomen rigider Arbeitslosenquoten bei steigender Inflationsrate erklären Neoklassiker damit, daß es eine von monetären Faktoren unabhängige, bisher allerdings noch nicht exakt bestimmbare „natürliche“" Arbeitslosigkeit gäbe. Würde durch eine expansive Beschäftigungspolitik die Arbeitslosigkeit unter diese ,natürliche" Quote gesenkt, so gerate das gesamte System in Ungleichgewicht - ein Inflation sei die notwendige Folge.

1971 entwickelte James Tobin aus den gegensätzlichen Ansichten von Monetaristen und Keynesianern einen Kompromiß-Vorschlag. Danach soll die Kurve bei hoher Arbeitslosigkeit sehr flach und bei niedriger Arbeitslosigkeit sehr steil verlaufen.

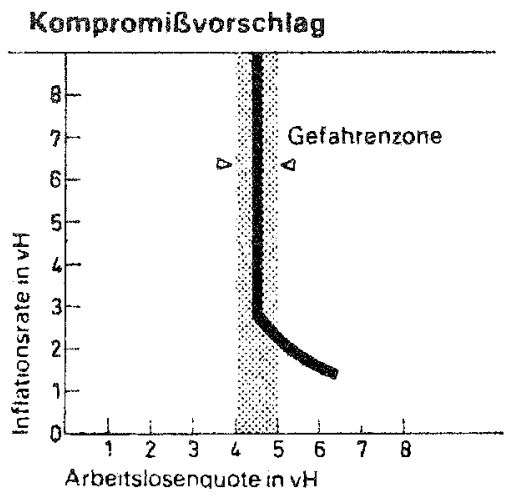

Die Kurve erhält also einen Knick, der im Bereich der „,natürlichen“ Arbeitslosigkeit liegt. In diesem Bereich bzw. darüber hinaus, so die Monetaristen, kann Beschäftigungspolitik nur zur „Explosion“" der Preise führen.

Neo-Keynesianer bestätigen zwar, daß Beschäftigungspolitik in der Nähe von Vollbeschäftigung inflationär sei. Als Begründung dafür werden zwei Versionen angeboten: Erstens: Im Aufschwung treiben die Unternehmerauf ihrer Jagd nach Arbeitskräften die Löhne hoch. Im Abschwung verhindern die Arbeiter bzw. ihre Gewerkschaften eine Senkung der Nominallöhne. - Dem ist zumindest für die BRD entgegenzuhalten, daß die Effektivlöhne häufig erheblich über den Tariflöhnen liegen und daher im Abschwung auch ein nomineller Lohnabbau sehr wohl praktiziert werden kann.

Zweitens: Die Löhne werden bestimmt durch die jeweilige Stärke der Tarifparteien im Konjunkturverlauf. Die relative Stärke der Arbeiter nimmt im Aufschwung zu und führt zu Lohnsteigerungen. 
Der monetaristischen Ansicht, daß dies zur permanenten Fortsetzung des Inflationsprozesses führen müsse, widersetzten sich Neo-Keynesianer jedoch, da sie nach wie vor unterstellen, daß die Arbeiterklasse der Geldillusion unterliege. So schreibt Albert Rees: „Ich kann Milton Friedman's Argument nicht akzeptieren, daß unorganisierte Arbeiter tatsächlich um ihren Reallohn kämpfen" (129). Der politische Charakter der Phillips-Kurve wird durch den Versuch des Sachverständigenrates offenbar, die Arbeiterschaft vermittelst Androhung von Arbeitslosigkei zu disziplinieren:

„Würde man ihr (der Wirtschaftspolitik, O: E. D.) jedoch aufgeben, jegliches Beschäftigungsrisiko von den Bürgern zu nehmen, könnte dies allzuoft nur auf Kosten der Geldwertstabilität erreicht werden. Nicht steigende Inflationsraten, die alle gleich treffen, (!) sondern Gewinnrückgänge und Beschäftigungseinbußen können die Haftung ausmachen für diejenigen, die, indem sie ihre gesamtwirtschaftliche Macht nutzen, den Zielkonflikt zwischen Preisniveaustabilität und Vollbeschäftigung erst entstehen lassen“"(130).

Auch von den Politikern wird der Öffentlichkeit immer wieder suggeriert, man habe zwischen etwas mehr Arbeitslosigkeit und weniger Inflation, bzw. zwischen etwas mehr Inflation und weniger Arbeitslosigkeit zu wählen. Daß dem keineswegs so ist, wird nicht nur durch das Scheitern der Stabilitätspolitik Nixon's bewiesen.

Länder wie England, Irland und Italien haben sowohl hohe Inflations- als auch hohe Arbeitslosigkeitsraten zu verzeichnen. Von den Ländern der ,dritten Welt" ganz zu schweigen. Dagegen ist die Inflationsrate etwa in der BRD und in Belgien relativ zu anderen Staaten niedrig, und doch haben diese beiden Staaten einen hohen Grad der Beschäftigung aufzuweisen.

Es wäre allerdings auch nicht zu begreifen, wenn die Inflation dadurch zu stoppen wäre, daß $5 \%-6 \%$ der Arbeiter statt Lohn, für den sie schließlich Waren produzieren würden, Arbeitslosenunterstützung erhalten. Zwar liegt die Unterstützung unterhalb des Lohnniveaus, weshalb die Nachfrage nach Konsumgiitern zurückginge, diesem Effekt müßte jedoch entgegenwirken, daß in einem solchen Falle auch weniger Waren produziert werden.

Die in der Analyse von Phillips ermittelte Korrelation stimmt wahrscheinlich allein für England und dort auch nur im untersuchten Zeitraum. Eine generelle und exakt quantifizierbare Relation zwischen Arbeitslosigkeit und Inflationsrate existiert nicht und kann daher auch nicht ermittelt werden.

Sicher ist unumstritten, daß im Verlauf eines Konjunkturaufschwunges die Beschäftigung zu-, d. h. die Arbeitslosigkeit abnimmt und daß die Preise besonders in dieser Phase des Zyklusses steigen. Das Versagen der Phillips-Kurve als Ausgangspunkt von Prognosen und als Grundlage für eine Stabilitätspolitik liegt darin begrïndet, daß sie diese beiden Erscheinungen, weil sie gleichzeitig auftreten, auch schon in einen kausalen Zusammenhang stellt, was absolut unzulässig ist. Mit gleichem Erfolg könnte man sicher eine annähernd ebenso gute Korrelation suchen zwischen

129 A. Rees in: „,Der Volkswirt“6 Nr. 21/73

130 Sachverständigenrat ,Jahresgutachten ${ }^{\circ} 1973 / 74$, S。122, Ziffer 332 
der Inflationsrate und anderen Größen, die sich im Konjunkturverlauf zyklisch verändern, etwa der Profitrate, dem Zins oder gar der Lagerhaltung. Eine einigermaßen plausibel klingende Begründung eines Kausalzusammenhanges ließe sich dann vermutlich auch noch konstruieren.

\subsection{Lohn-Preis-Spirale}

Insbesondere im Zusammenhang mit lohnpolitischen Auseinandersetzungen wird die permanente Inflation häufig nach dem Modell der sog. Lohn-Preis-Spirale erklärt. Nach dieser Hypothese drücken sich Löhne und Preise gegenseitig in einer endlosen Spirale in die Höhe. Auffälligerweise gehen die Erläuterungen fast ausschließlich von einer Situation aus, in der von den Löhnen ein Druck auf die Kosten und damit auf die Preise ausgeübt wird. Auch wenn Galbraith versichert, daß dem Ansatzpunkt keinerlei inhaltliche Bedeutung beizumessen sei, so bleibt doch seine Begründung für eine derartige Verfahrensweise, die in der gegebenen Häufigkeit als tendenziös erscheinen muß, recht unbefriedigend: „Für die Untersuchung dieser Spirale ist es am einfachsten, wenn man an der Stelle einen Schnitt vornimmt, wo die Löhne auf die Preise einwirken“(131). Es ist keinesfalls einsichtig, daß die Erläuterung der Spirale didaktisch schwieriger sein sollte, wenn man den Schnitt bei den Preiserhöhungen vornimmt - es könnte allerḋings politisch unbequemer sein.

Folgt man aber der gängigen Praxis, dann stellt sich der Prozeß nach Galbraith so dar:

„Wenn die Arbeitslosenrate klein ist, dann haben die Gewerkschaften im allgemeinen eine günstige Verhandlungsposition. Ihre Mitglieder können einen Streik in der Gewißheit riskieren, daß sie unersetzlich sind. Vom praktischen Standpunkt aus gesehen wissen sie, daß sie dem Unternehmer schwere geschäftliche Verluste zufügen und sofort wieder eingestellt werden, wenn der Streik vorüber ist. Die Arbeitgeber werden es unter diesen Voraussetzungen für klüger halten, einer Lohnerhöhung zuzustimmen. Die starke Nachfrage garantiert die Möglichkeit, die Kosten der Lohnerhöhungen auf Verbraucher und andere Käufer'abzuwälzen. Wenn sich das Reservoir der Arbeitslosen erst einmal bis auf den harten Kern der Unbrauchbaren verringert hat, dann tritt für gewöhnlich an bestimmten Punkten der Produktion ein Mangel an einfachen Arbeitern auf. Höhere Löhne erscheinen dann als ein Mittel, Arbeitskräfte anzulocken und die vorhandenen zu halten. Tarifabkommen umfassen für gewöhnlich einen wesentlichen Teil der Industrie. Das bedeutet, daß alle oder doch die meisten Firmen gleichzeitig von Lohnerhöhungen betroffen werden. Dadurch werden auch alle gleichzeitig zu Preissteigerungen veranlaßt.... Preiserhöhungen bedeuten Kostensteigerungen für die Kunden - entweder andere Industriezweige oder Endverbraucher. In jedem Falle steigern sie mittelbar oder unmittelbar die Lebenshaltungskosten und verwandeln sich so zum Anreiz für eine neue Runde von Lohnverhandlungen. Wenn eine Bedarfssteuerung mit dem Ziel der Vollbeschäftigung vorhanden ist und wenn keine anderen Maßnahmen ergriffen werden, dann ist die Lohn-Preis-Spirałe ein natürliches (!) Merkmal des Industriesystems" (132).

131 J. K. Galbraith „Die moderne Gesellschaft“, Management Buchclub, München/Zürich 1968, S. 278

132 Ebd., S. $279 \mathrm{f}$. 
Galbraith gebraucht hier gleich beide Varianten der oben erwähnten Thesen über das Entstehen eines Lohnkosten-Drucks und deutet grundsätzlich jede Lohnerhöhung als Kostendruck. Damit unterläßt er sogar noch die sonst übliche Bewertung des Ausmaßes von Lohnsteigerungen. Entsprechen diese dem Produktivitätszuwachs, so spricht man von verteilungsneutralen Lohnerhöhungen. Gewöhnlich werden diese dem Proletariat von bürgerlichen Ökonomen als oberste Grenze zugestanden, zumal sie die offenbar als gerechtfertigt angesehenen herrschenden Besitzverhältnisse nicht gefährden. Völlige Einigkeit besteht darüber jedoch nicht. Einerseits hält W. Röpke selbst eine Stabilisierung des Lohnanteils am BSP - trotz prozentualen Anwachsens der unselbständig Beschäftigten an der Gesamtbevölkerung - noch für unbegründet:

„Es hat sich mehr und mehr herausgestellt, daß eine Parallelität von Lohnsteigerung und Produktivitätssteigerung, sosehr sie uns vor den schlimmsten Übertreibungen der Lohnpolitik (!) bewahren kann, keineswegs die Sicherheit gibt, die wir suchen, wenn wir eine inflatorische Wirkung von Lohnsteigerungen verhüten wollen. Ist es wirtschaftlich vernünftig und in Übereinstimmung mit dem Wesen der Marktwirtschaft (!), jede Steigerung der Produktivität, die doch vor allem dem technischen Fortschritt, der Verbesserung der Produktionsmethoden und dem steigenden Einsatz von Kapital zu verdanken ist, durch eine Lohnsteigerung ausschöpfen zu lassen? " (133)

Andererseits vertritt G. Bombach die Ansicht, daß auch Lohnerhöhungen über den Produktivitätsfortschritt hinaus nicht unbedingt zu Preissteigerungen führen müssen und daß die Wirkung der Lohnerhöhungen im einzelnen gar nicht eindeutig feststellbar sei:

„Bindung der Reallöhne an die Arbeitsproduktivität ist weder eine notwendige noch hinlängliche Vorbedingung für Preisstabilität, und ein im Vergleich zur Arbeitsproduktivität schnelleres Wachstum der Reallöhne - nehmen wir jetzt an bei steigenden Preisen - kann sowohl ein Zeichen von Kosten- als auch von Nachfrageinflation sein. Der statistische Reflex ist bei beiden Inflationstypen der gleiche" (134).

In letzter Zeit tritt der Begriff der kostenneutralen Lohnpolitik stärker in den Vordergrund. Vermutlich ist das im Zusammenhang mit den enormen Preiserhöhungen bei den Rohstoffen zu sehen.

Die folgende Tabelle VI zeigt, daß die Rohstoffpreise allein in den ersten 9 Monaten des Jahres 1973 mit 6,6\% beinache ebenso schnell gestiegen sind wie vorher in den letzten 10 Jahren zusammengenommen, nämlich 8,1\%. Eine derartige rapide Erhöhung der Rohstoffpreise muß sich natürlich erheblich auf das Kostengefüge auswirken. Die Mehrbelastung soll mit Hilfe des Konzepts der kostenneutralen Lohnpolitik offenbar auf die Arbeiterklasse abgewälzt werden. Denn eine Erhöhung des Kostenfaktors Rohstoffe müßte den Spielraum einengen für eine Erhöhung des Kostenfaktors Lohn.

133 W. Röpke, a. a. O., S. 291

134 G. Bombach „Ursachen der Nachkriegsinflation und Probleme der Inflationsbekämpfung", in: „Stabile Preise in wachsender Wirtschaft", S. $198 \mathrm{f}$. 
Im Endeffekt hieße das, daß die Arbeiterklasse sich die Preisstabilität durch Verzicht auf einen gewissen Teil des Zuwachses an realen Einkommen „erkaufen" müßte, der unter dem alleinigen Gesichtspunkt der Verteilungsneutralität durchaus vertretbar wäre.

Inder der Grumdstoftpretse

$1962=100$

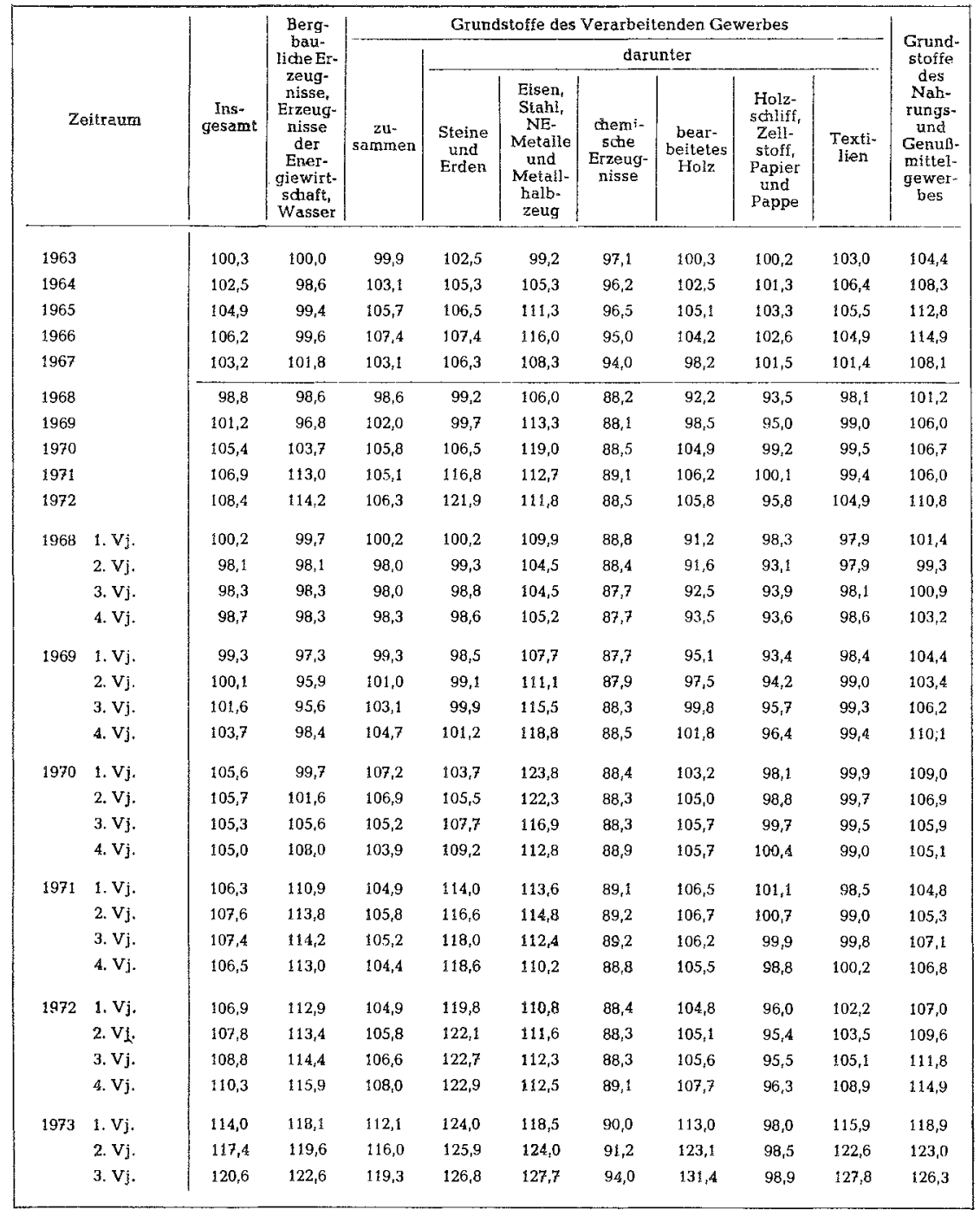

1) Gruadstoffe industrieller Herkunft; big 1967 einschließlich, ab 1968 ohne Umsatzstener. 
Beide Konzept gehen von der Vorstellung aus, daß die Arbeiterklasse in der Weise am Produktivitätsfortschritt partizipieren solle, daß die Löhne allmählich steigen und das Preisniveau konstant bleibt. Die Konstanz des Preisniveaus werde dadurch zustande kommen, daß Branchen mit überdurchschnittlichen Produktivitätssteigerungen ihre Preise senken, solche mit mittleren Fortschritten ihre Preise stabil halten und nur Bereiche mit unterdurchschnittlichen Kostensenkungen ihre Preise erhöhen. Mit J. Robinson ist gegen eine so konstruierte Stabilität des Preisniveaus einzuwenden, daßs sie ,vom Standpunkt der Gewerkschaften betrachtet, keineswegs befriedigen. Für die Arbeiter sind die Preise jener Produkte interessant, die sie kaufen, und nicht jener, die sie herstellen" (135). Es ist nämlich verstellbar, daß ein Großteil derjenigen Waren, die in den Konsum der Arbeiterfamilien eingehen, ausgerechnet aus solchen Branchen stammen, die z. Zt. nur unterdurchschnittliche Produktivitätssteigerungen aufweisen (Wohnungsbau, Dienstleistungen). C. Föhl leitet aus diesem Umstand sogar die praktische Unvermeidbarkeit des inflatorischen Prozesses ab:

„,Lohnerhöhungen werden zunächst einmal in jenen Branchen durchgesetzt, in denen erhebliche Produktivitätsfortschritte erzielt werden konnten. Infolge der dadurch wachsenden Arbeitseinkommen und der aus diesen getätigten Verbrauchsausgaben steigen mit großer Wahrscheinlichkeit die Preise jener Güter, bei deren Herstellung die Produktivität nicht gestiegen ist, wie dies in der Regel bej den landwirtschaftlichen Erzeugnissen der Fall sein wird. Das ist dann Grund genug, um auch in den Branchen mit schwacher Produktivitätssteigerung Lohnerhöhungen zu fordern, selbst wenn dort nicht schon ohnehin die Tendenz bestehen sollte, mit den Kollegen in den begünstigten Branchen gleichzuziehen. Zum Schluß kommt in der Praxis auf diese Weise eben doch eine das Produktivitätswachstum übersteigende Vergrößerung des gesamten Lohnvolumens und damit ein Anstieg des Preisniveaus heraus, mögen die Gewerkschaften sich auch noch so sehr bemühen, im Interesse der Geldwertstabilität eine gemäßigte Lohnpolitik zu betreiben $^{\text {"6 }}(136)$.

Die Behauptung, daß Tarifauseinandersetzungen ,zunächst einmal“ ihren Anfang bei Branchen mit überdurchschnittlichen Produktivitätsfortschritten nehmen würden, ist jedoch ebenso unhaltbar wie die Annahme, daß ihr Ergebnis allein vom Zuwachs der Produk tivität bestimmt sei. Kampfbereitschaft der Arbeiter einerseits und momentane Marktsituation andererseits sind nicht zu unterschätzende weitere Bestimmungsfaktoren.

Es ist sicher kein Zufall, daß in der keynesianischen Theorie, aus der das Modell der Lohn-Preis-Spirale ja entlehnt ist, die Frage offenbleibt, wie die Preisniveau-Stabilität praktisch hergestellt werden sollte, d. h. wie diejenigen Branchen und Betriebe, welche überdurchschnittliche Produktivitätsfortschritte aufweisen, konkret dazu veranlaßt werden könnten, die Preise ihrer Güter zu senken? Hier schließt sich die Frage an, warum diese Preise nicht heute schon sinken - oder vielmehr, warum sie heute bei Konjunkturabschwüngen nicht mehr sinken? Nach C. Föhl wird das durch Lohnrigidität verhindert: ,Dieser Effekt kommt bekannt-

135 J. Robinson ,Die fatale politische ökonomie ${ }^{6}$, S. 19

136 C. Föhl "Geldwertstabilisierung bei Vollbeschäftigung", in: „Stabile Preise in wachsender Wirtschaft", S. 152 
lich infolge der nach unten starren Lohntarife nicht zur Auswirkung“ (137).

Von Bedeutung scheint ihm dabei die Zeitspanne, die zwischen der Erhöhung der Produktivität und den daraus potentiell resultierenden Preissenkungen liegt:

„Der Vorgang der Preisanpassung nach unten, der nach unserer Vermutung mit großer Wahrscheinlichkeit (!) und in einem für die Erhaltung der Lohnquote ausreichenden Maße eintreten würde, erfordert eine gewisse Zeit. Erhöht man die Löhne, ohne diese Zeit abzuwarten, so tritt die Preissenkung selbstverständlich nicht ein“ (138).

Die permanente Inflation läge demnach letztlich darin begründet, daß die Arbeiter, seit etlichen Jahren kein Vertrauen mehr in die ,Vermutung einer großen Wahrscheinlichkeit" haben (woher der Umschwung?) und vorschnell Lohnerhöhungen verlangen.

Die Annahme, daß die Preise ohne Lohnrigidität tatsächlich selbständig und ausreichend tief sinken würden, stützt $C$. Föhl auf die Vermutung, „daß die Leiter von Unternehmen in mark tbeherrschender Stellung sich bemühen, einen Gewinn zu erwirtschaften, dessen absolute Höhe sie mit Rücksicht auf die auszuschüttende Dividende und die Selbstfinanzierung geplanter Rationalisierungs- und Erweiterungsvorhaben wählen. Wenn das zutreffend ist, dann werden sie auch bei einer durch Produktivitätsfortschritte gewachsenen Kapazität ihrer Anlagen die Preise so stellen, daß eben diese ihre Gewinnwünsche wieder realisiert werden. Das würde aber bedeuten, daß in allen diesen Fällen die Produktivitätsfortschritte auch ohne Lohnerhöhung in voller Höhe dem Verbraucher zugute kommen" (139). Wenn diese Hypothese zutreffend wäre, dann hätte es wohl niemals Absatzmangel und relative Überproduktion gegeben; dann hätte es auch staatlicher Nachfragestimulierung nicht bedurft. Die Argumentation C. Föhl's ist insofern besonders unverständlich, als er selbst Momente angibt, die den von ihm prognostizierten Preisverfall verzögern oder völlig verhindern können:

„Das tritt beispielsweise dann ein, wenn die Unternehmer für den Zuwachs ihrer Produktion lohnenden Absatz durch eine Steigerung des Exportgeschäftes finden können, wie dies ja in den vergangenen Jahren in der Bundesrepublik in der Tat der Fall war. Desgleichen wird aber auch der Zwang zur Preissenkung dann ausgeschaltet, wenn durch eine verstärkte Investitionstätigkeit zusätzliche Einkommen geschaffen werden, ... " (140).

Galbraith erklärt die Umkehrung des Preistrends aus der Wandlung der Unternehmensformen und den angeblich daraus resultierenden Veränderungen der Unternehmensziele und Verhaltensweisen:

„Das Auftauchen des ausgereiften Betriebs hat wesentlich zur Wahrscheinlichkeit einer solchen Spirale beigetragen. Vom Unternehmerbetrieb erwartete man ohnehin, daßs er je nach dem augenblicklichen Stand der Nachfrage den höchstmöglichen Gewinn anstreben würde... Wenn

137 Ebd., S. 148

138 Ebd., S 153

139 Ebd., S. 153

$140 \quad$ Ebd., S. $153^{2}$ 
die Gewinne schon einen Höchststand hatten und die Preise so gestaltet waren, daß sie derartige Profite erlaubten, dann konnte man Lohnerhöhungen nicht mehr in Form von Preiserhöhungen weitergeben. Das Maximum kann man nicht weiter steigern. Wenn sich Lohnerhöhungen aber nicht abwälzen ließen, dann mußte man sie aus den Gewinnen bezahlen. Es lag in der Natur des Unternehmer-Betriebs, daß solche Gewinne zum Großteil dem Unternehmer zufielen. Das Bezahlen fällt dann besonders schwer, wenn man aus der eigenen Tasche bezahlen muß. Der Unternehmer hatte also allen Grund zum Widerstand. . . Im ausgereiften Betrieb kalkuliert die Technostruktur die Preise nicht nach dem Gesichtspunkt des höchsterreichbaren Gewinns,... Das bedeutet ... daß die Technostruktur doch einen gewissen Spielraum zur Steigerung der Einkünfte durch Preiserhöhungen besitzt. Deshalb kann sie Lohnerhöhungen abwälzen ... Und schließlich hat die Technostruktur, bei der die Entscheidung über höhère Löhne liegt, nicht aus eigener Tasche zu bezahlen" (141).

Auf die Frage nach Veränderungen in den Unternehmenszielen soll hier nicht eingegangen werden. Festzustellen bleibt jedoch folgendes: Wenn es sich bei Galbraith's Ausführungen um die Darstellung der Realität handeln würde, dann bliebe unerfindlich, warum die Arbeiter trotz relativer ,Spendierfreudigkeit ${ }^{6 /}$ der Technostruktur nach wie vor. mit Streiks und anderen Druckmitteln um ihren Anteil am BSP kämpfen müssen.

Es wäre unbegreiflich, warum nach Feststellung des Sachverständigenrates die Reallohnposition der Arbeitnehmer in den elf Jahren von 1963 bis 1973 sich insgesamt sechsmal verschlechtert hat! (Tabelle VII)

Znr Entwidslung der Reallohnpostion ${ }^{1}$ )

Veränderung gegenüber dem Vorjabr in vH

\begin{tabular}{|c|c|c|c|c|c|c|c|c|}
\hline \multirow{3}{*}{ Jahr } & \multicolumn{4}{|c|}{ Realer Verteilungsspielraum } & \multicolumn{3}{|c|}{ Reale Verteizung } & \multirow[b]{2}{*}{$\begin{array}{c}\text { Realiohn- } \\
\text { position } \\
\text { der } \\
\text { Arbeit- } \\
\text { nehmer } \\
(7)-(4)\end{array}$} \\
\hline & $\begin{array}{c}\text { Brutto- } \\
\text { inlands- } \\
\text { produkt } \\
\text { je } \\
\text { Erwerbs- } \\
\text { tätigen }\end{array}$ & $\begin{array}{c}\text { Terms- } \\
\text { of-Trade- } \\
\text { Effekt } 5\end{array}$ & $\begin{array}{l}\text { Lohn- } \\
\text { kosten- } \\
\text { effekt der } \\
\text { Arbeit- } \\
\text { geberbei- } \\
\text { träge }{ }^{3}\end{array}$ & $\begin{array}{l}\text { ins. } \\
\text { gesamt } \\
(1)+(2) \\
-(3)\end{array}$ & $\begin{array}{l}\text { Brutto- } \\
\text { lohn- } \\
\text { und } \\
\text {-gehalts- } \\
\text { summe je } \\
\text { Arbeit- } \\
\text { nehmer }\end{array}$ & $\begin{array}{l}\text { Preis- } \\
\text { index für } \\
\text { die } \\
\text { Lebens- } \\
\text { hal- } \\
\text { tung }{ }^{4} \text { ) }\end{array}$ & $\begin{array}{c}\text { Reale } \\
\text { Brutto- } \\
\text { lohr-und } \\
\text {-gehalts- } \\
\text { summe je } \\
\text { Arbeit- } \\
\text { nehmer } \\
\text { (5) - (6) }\end{array}$ & \\
\hline & (1) & (2) & (3) & (4) & (5) & (6) & (7) & (8) \\
\hline 1963 & $+3,5$ & $+0,1$ & $-0,0$ & $+3,6$ & $+6,0$ & $+2,9$ & $+3,0$ & $-0,6$ \\
\hline 1964 & $+7,4$ & $\pm 0,0$ & $-0,7$ & $+8,2$ & +96 & $+2,3$ & $+7,1$ & $-1,0$ \\
\hline 1965 & $+5,5$ & $-0,2$ & $-0,2$ & $+5,5$ & +89 & $+3,3$ & $+5,4$ & $-0,1$ \\
\hline 1966 & $+3,4$ & $-0,1$ & +0.4 & $+2,9$ & $+7,0$ & $+3,5$ & $+3,4$ & $+0,5$ \\
\hline 1967 & $+3,6$ & $-0,0$ & $+0,2$ & +3.4 & $+3,1$ & $+1,5$ & $+1,6$ & $-1,7$ \\
\hline 1968 & $+7,4$ & $+0,2$ & $+0,6$ & $+7,0$ & $+6,5$ & $+1,2$ & $+5,2$ & $-1,7$ \\
\hline 1969 & $+7,0$ & $-0,2$ & $+0,5$ & $+6,3$ & $+8,9$ & $+1,5$ & $+7,3$ & $+0,9$ \\
\hline 1970 & $+5,0$ & $+0,7$ & $+0,3$ & +5.4 & $+15,4$ & $+3,4$ & $+11,6$ & $+5,9$ \\
\hline 1971 & $+2,9$ & $+0,6$ & +0.7 & $+2, \boldsymbol{B}$ & $+11,2$ & $+5,3$ & $+5,6$ & $+2,7$ \\
\hline 1972 & $+4,2$ & $+0,9$ & +0.7 & $+4,4$ & $+9,5$ & +52 & $+4,1$ & $-0,3$ \\
\hline$\left[973^{5}\right)$ & $+6,8$ & $-0,6$ & $+0,7$ & $+5,4$ & $+12,6$ & +6.6 & $+5,6$ & $+0,2$ \\
\hline
\end{tabular}

1) Gesamtwirtscoaft ohne Staat. Berectinung der Spatten (4), (7) und (B) durch multiplikative Verknüpfung.

a) Gesamtwirtschaft.

9) Arbeitgeberbeiträge zur Soziniversicherung einschliellich zusätziicher Sozialaufwendungen der Arbeitgeber.

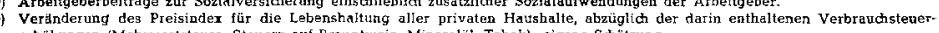
orhöhungen (Mebrwertsteuer; Steuern auf Brânntwein, Mineralöl, Tabak); eigene Schätzung.

G) Eigene Schätzurg.

141 J. K. Galbraith, a. a. O., S. 279 f. 
Das Modell der Lohn-Preis-Spirale setzt stets voraus, daß die durch Lohnerhöhungen entstehenden Kostensteigerungen ohne weiteres auf die Preise überwälzt werden können. Mit anderen Worten, es wird gleichzeitig ein Nachfragesog, also eine Hochkonjunktur unterstellt. Das Modell kann den Tatbestand nicht würdigen, daß die Preise nicht nur im Aufschwung steigen - was ja schon seit Bestehen des Kapitalismus immer der Fall gewesen ist - sondern seit einigen Jahren selbst im Abschwung noch erhöht werden können. „Fest steht, daß die Erhöhung einer Kostenposition im Rechengefüge der Unternehmungen nach Möglichkeit weitergegeben wird. Aber daß sie weitergegeben werđen $k a n n$, daß der Markt den höheren Preis zahlt, ist das, was eigentlich nach Erklärung verlangt ${ }^{6 /}$ (142). (Hervorhebungen $W . H$.)

Nach H. G. Paulssen

,besteht hier folgender Zusammenhang: steigen die Löhne einer Volkswirtschaft im Durchschnitt schneller als die Produktivität, so erhöhen sich zunächst die Lohnkosten je Produkteinheit. Dadurch entsteht von der Kostenseite her ein Aufwärtsdruck auf die Preise. Ob hieraus jedoch tatsächlich Preissteigerungen entstehen, hängt in einer Marktwirtschaft nicht nur von der Entwicklung der Kosten, sondern vor allem von der Entwicklung von Angebôt und Nachfrage auf den Märkten ab.

An dieser Stelle kommt nun die Kaufkraftwirkung des Lohnes zum Zuge: In der Vollbeschäftigung pflegt sich eine Lohnerhöhung sehr schnell und ohne Abschwächung durch Beschäftigungsrückschläge in Konsumkaufkraft der Lohnempfänger umzuwandeln. Sie tritt dann - vor allem, wenn man nicht mit einer erhöhten Sparquote rechnen kann - in vollem Umfange als zusätzliche Konsumkaufkraft auf den Gütermärkten in Erscheinung“ (143).

Makroökonomisch betrachtet bedeuten Lohnerhöhungen zunächst eine temporäre Umverteilung des BSP und führen nur dann zur Erhöhung der gesamtgesellschaft. lichen Nachfrage, wenn sie auf der Unternehmensseite trotz momentaner Verringerung deren Anteil am BSP keinerlei Ausgabenbeschränkungen hervorgerufen - was durch das moderne Bankensystem erleichtert wird. Somit erweist sich das gegenwärtige Geld- und Kreditsystem als eine Voraussetzung dafür, daß sich ,die Kostenwirkung und die Kaufkraftwirkung des Lohnes in eigenartiger Weise gegenseitig verstärken" (144). Eine mikroökonomische Betrachtung läßt erkennen: Lohnsteigerungen erhöhen zunächst nur die Kosten der betroffenen Branche und weiten die Nachfrage nach Konsumgütern aus. Es hängt aber ganz von der Struktur des Warenangebotes der jeweiligen Branchen ab, ob sich ein Teil dieser zusätzlichen Nachfrage auf ihre Produk te richten kann. D. h. daß die von H. G. Paulssen unterstellte Nachfrageerhöhung, wenn überhaupt, dann nur in erheblich abgeschwächten Umfang als Nachfragesteigerung für die betreffende Branche relevant werden kann. Wenn die Preise dennoch, wie häufig beobachtet werden kann, unmittelbar nach Lohnerhöhungen heraufgesetzt werden, dann muß daraus geschlossen werden, daß die hierzu "erforderliche" kaufkräftige Nachfrage auch vorher schon bestanden haben

142 W. Hofmann, a. a. O., S. 42

143 H. C. Paulssen ,Löhne und Preise in der Vollbeschäftigung", S. 8 f.

144 Ebd., S. 8 
muß. Die Preise hätten also auch vor den Lohnverhandlungen erhöht werden können. Daß dies nicht geschehen ist, entlarvt sich so als Taktik der Unternehmer, den "Schwarzen Peter" bezüglich der Lohn-Preis-Spirale den Arbeitern und ihren Gewerkschaften zuzuschieben.

\section{Resümee}

Als Facit dieser Arbeit ist festzuhalten, daß alle bürgerlichen Inflationstheorien auf einen ungenügenden Verständnis des Wesens und der Funktionen des Geldes beruhen und daß keiner der hier untersuchten Erklärungsansätze in der Lage ist, die Inflation tatsächlich zu begründen.

Weder die demand-pull-Theorie, die alle Preise allein durch das Verhältnis von Angebot und Nachfrage bestimmt wähnt und folglich eine permanente Übernachfrage behaupten muß, noch die cost-push-Theore, die alle Preise als von bezahlter Arbeit bestimmt wähnt und deshalb einen permanenten Lohnkosten-Druckbehauptet, halten einer empirischen Überprüfung stand. Das Phänomen der Stagflation führt sie vollends ad absurdum. Die Keynes'sche Kritik an der „Klassischen Dichotomie" erweist sich als unberechtigt - was allerdings nicht etwa heißen soll, daß die Quantitätstheorie akzeptabel wäre.

Die Monetaristen irren erstens, wenn sie - ebenso wie die Keynesianer - der Ansicht sind, daß die relativen Preise durch Angebot und Nachfrage bestimmt würden. Veränderungen in diesem Verhältnis können in Wirklichkeit lediglich gewissse Schwankungen, nicht aber die Basis der Preisausschläge erklären. Sie irren zweitens in dem Glauben, das Geldvolumen beliebig regulieren zu können. Umlaufgeschwindigkeit des Geldes, private Kreditgewährung und internationale Devisenströme sind unter gegebenen Umständen keine steuerbaren Größen. Obendrein vermögen weder Keynesianer noch Monetaristen die Transmission monetärer Impulse auf den realen Bereich befriedigend zu erklären.

Der dritte Irrtum schließlich liegt in dem Glauben, das Geld vollständig entmonetarisieren zu können. Würde die Quantitätstheorie stattdessen anerkennen, daß Papiergeld nur als Repräsentant von Gold, also Wert, zirkulieren kann, so käme sie der Erklärung der Inflation sehr nahe. Die Preissteigerungen in Papiergeld-Größen erweisen sich dann nämlich als lediglich nominelle Preiserhöhungen. Denn sofern tatsächlich überschüssiges Papiergeld in die Zirkulationskanäle gepreßt werden kann, wird automatisch das Repräsentationsverhältnis von Papiergeld zu Gold gestört. Die realen Preise jedoch, d. h. die auf Goldeinheiten bezogenen Preise, können durch überschüssige Ausgabe von Papiergeld nicht beeinflußt werden, wenn man von ,Reibungen" bei der Transformation des Preisniveaus einmal absieht.

Im Währungssystem von Bretton Woods war der „Goldpreis“, d. h. das Repräsentationsverhältnis von Papiergeld zu Währungsgeld fixiert worden, ohne daß gleichzeitig alle anderen Preise fixiert und damit am Steigen gehindert worden wären. Als dann die Marktkräfte an einem bestimmten Höhepunkt des Mißverhältnisses von nominellen und realen Goldwert die Bindung des "Goldpreises ${ }^{\text {"6 }}$ aufbrachen und diesen in die Höhe trieben, erschien dies den meisten bürgerlichen, 
aber auch vielen sich auf Marx berufenden Theoretikern als wilde Machenschaft des internationalen Spekulantentums. Ohne einen solchen Einfluß vollkommen ausschließen zu wollen, muß aber doch festgestellt werden, daß es sich dabei hauptsächlich um die Durchsetzung eines durch juristische Eingriffe zeitweilig verletzten ökonomischen Gesetzes handelt. Die „Goldpreis“-Erhöhungen der letzten Zeit stellen im Prinzip nur wie der her, was lange gestört war, nämlich die durch gesellschaftlich notwendige Arbeit bestimmten Tauschrelationen zwischen Gold und den anderen Waren.

Das durch verschiedene Einflüsse manipulierte Repräsentationsverhältnis von Papiergeld zu Gold führte und führt zu Veränderungen der nominellen, im Prinzip aber nicht zu Veränderungen der relativen Preise.

Diese Ansicht wird dadurch gestützt, daß sich auch unter den Bedingungen der permanenten Inflation das Wertgesetz durchsetzt - wenngleich in veränderter Form. Relative Wertveränderungen drücken sich heute normalerweise nicht mehr in absoluten Preissenkungen, sondern in unterschiedlich starken Preissteigerungen aus. Die Ursachen der Umkehrung des Preistrends konnten auch in diesem Beitrag nicht festgemacht werden. Folgende Momente dürften jedoch von wesentlicher Bedeutung sind:

1) Solange es Konjunkturzyklen gibt, solange gibt es auch Phasen allgemeiner Preissteigerungen, nämlich im Konjunkturaufschwung. Bisher wurden diese Preiserhöhungen stets durch Preissenkungen im Konjunkturabschwung mehr als egalisiert. Durch die Politik des deficit-spending und andere staatliche Maßnahmen zur Konjunktursteuerung sind diese depressiven Phasen abgeschwächt worden.

2) Die Ausgestaltung des Bankensektors mit ihrem Geldschöpfungsmechanismus hat zusätzliche Möglichkeiten der Realisierung von Übernachfrage geschaffen.

3) Wenn das allgemeine Preisniveau sinken soll, dann müssen Preissenkungen vornehmlich von den Branchen und Betrieben ausgehen, welche die höchsten Produktivitätssteigerungen zu verzeichnen haben. Da dies aber meist für die großen Konzerne zutrifft, die ihrerseits ihre nominellen Preise immer weniger vom Markt denn von ihren Kalkulationen abhängig machen, ist der normale Weg der Durchsetzung des Wertgesetzes nahezu versperrt.

Die Untauglichkeit der bürgerlichen Inflationstheorien erweist sich in der Praxis darin, daß sie nicht in der Lage sind, wirkungsvolle Instrumente zur Eindämmung des Preissteigerungsprozesses zur Verfügung zu stellen. Als Konsequenz darauf folgt für die bürgerliche Wirtschaftswissenschaft ihre Hinwendung zur Erarbeitung einer Einkommenstheorie und für die Wirtschaftspolitik das Liebäugeln mit ganz und gar nicht marktwirtschafts-gerechten Lohn- und Preis-Stopps.

Sofern die Einkommenspolitik darauf abzielen sollte, die Aufteilung des BSP zu ungunsten der Arbeiterklasse bzw. der Verbraucher zu beeinflussen (gewöhnlich spricht man nicht von einem Dividenden-Stopp) - und je ,erfolgreicher" sie dabei wäre, desto sicherer ist zu erwarten, daß die Wirtschaftskrisen lediglich in einer anderen Form erscheinen würden. Denn wenn die Marx'sche Krisentheorie begründet ist, dann wird eine relative Zurückdrängung der Endnachfrage sehr bald zu einer Unterkonsumtions- bzw. Überproduktions-Krise auf Grund zu großer Kapitalakkumulation führen. 